\title{
WestVirginiaUniversity
}

THE RESEARCH REPOSITORY @ WVU

Graduate Theses, Dissertations, and Problem Reports

2019

\section{A Study of Gastrointestinal Pathophysiology}

Emily Minor

West Virginia University, eaminor@mix.wvu.edu

Follow this and additional works at: https://researchrepository.wvu.edu/etd

Part of the Translational Medical Research Commons

\section{Recommended Citation}

Minor, Emily, "A Study of Gastrointestinal Pathophysiology" (2019). Graduate Theses, Dissertations, and Problem Reports. 4115.

https://researchrepository.wvu.edu/etd/4115

This Dissertation is protected by copyright and/or related rights. It has been brought to you by the The Research Repository @ WVU with permission from the rights-holder(s). You are free to use this Dissertation in any way that is permitted by the copyright and related rights legislation that applies to your use. For other uses you must obtain permission from the rights-holder(s) directly, unless additional rights are indicated by a Creative Commons license in the record and/ or on the work itself. This Dissertation has been accepted for inclusion in WVU Graduate Theses, Dissertations, and Problem Reports collection by an authorized administrator of The Research Repository @ WVU.

For more information, please contact researchrepository@mail.wvu.edu. 
A Study of Gastrointestinal Pathophysiology

\title{
Emily A. Minor
}

\author{
Dissertation submitted \\ to the School of Medicine at West Virginia University \\ in partial fulfillment of the requirements for the degree of \\ Doctor of Philosophy in Cellular and Integrative Physiology
}

\author{
Robert Brock, PhD, Chair \\ Eric Kelley, PhD \\ Justin Kupec, MD \\ Vazhaikkurichi Rajendran, PhD, PI \\ David Siderovski, PhD \\ Department of Physiology and Pharmacology
}

Morgantown, West Virginia, USA 2019

Keywords: iron, ulcerative colitis, colon, divalent metal transporter 1 (DMT1), ferroportin 1 (FPN1), dextran sulfate sodium (DSS) 


\section{ABSTRACT \\ "A Study of Gastrointestinal Pathophysiology"}

Emily A. Minor

Though the duodenum is the primary site of iron absorption, the colon also contains iron transporters and participates in iron absorption. The purpose of this study was to characterize colonic iron absorption in control patients and those with ulcerative colitis (UC), a disease that frequently results in iron deficiency. Using RT-qPCR and western blot analysis, we found that colonic expression of the apical iron importer, divalent metal transporter 1 (DMT1), is equal to duodenal expression. However, colonic expression of ferroportin 1 (FPN1), an iron exporter, is only about one-quarter that of the duodenum. Patients with active ulcerative colitis were found to have increased DMT1 $(2 \mathrm{x})$ and FPN1 $(5 \mathrm{X})$ in the colon. Immunostaining demonstrated that the transporters were localized to membrane (DMT1-apical, FPN1-basolateral) and ${ }^{59} \mathrm{Fe}$ uptake studies revealed that the transporters contributed to increased colonic iron uptake in UC tissue, which may help alleviate the iron deficiency that is a frequent complication of UC.

Once we identified the colon as an ideal site to target for iron absorption in ulcerative colitis, we next wanted to determine whether it is safe to prescribe oral iron supplementation to patients with UC. Using an animal model of colitis, we found that oral iron supplementation led to increased disease activity. However, we cannot make any definitive conclusions without conducing a human clinical trial. If we find that colonic iron absorption is not a suitable treatment in UC then we can pursue it for other causes of iron deficiency, such as Celiac disease or gastric bypass. 


\section{ACKNOWLEDGEMENTS}

I first want to thank my parents for their endless support and encouragement. They instilled in me the value of an education and made it possible for me pursue my dreams. I want to especially thank my mom for everything she did to make my life easier during the grueling medical school years. She delivered Dunkin to the library, cleaned my apartment, and basically just kept my life together. It was the kind of support that only a mom can give. Thank you will never be enough.

My sister, Megan. Thanks for always cheering me on. You are the one who originally inspired my interest in research in hopes that I could someday help you.

Jackie, my favorite cousin. Thanks for all the fun boat weekends, cocktails, $5 \mathrm{Ks}$, and girl time. My favorite place in the world is with you on Borrowed Time.

Auntie Dear, thanks for all the home-cooked meals and for always leaving your door open to me. Charleston is my home away from home.

Thanks to my favorite (crazy) Uncle Dean for always showing up for me.

Dear family friends, Becky and Pod. Pod, thanks for recruiting me to WVU and showing me around Morgantown. I wouldn't be here if it wasn't for you. Becky, thanks for the endless margaritas and the many perfect pool days.

Thank you Lauryn for being a great mentor/ role model and even better friend. Your advice over the years was much appreciated.

Amanda, thank you for helping me make the microbiome project a reality. I couldn't have done it without you.

Mackey, thanks for being my partner-in-crime and for all your help with editing papers and posters. You made lab a lot more fun. 
Thank you to my committee for always supporting and believing in me. Raj, thank you for being my mentor and for introducing me to the field of digestive physiology. Dr. Kupec, thank you for being a great clinical role model and for collecting endless patient biopsies. You deserve a PhD for all of the work that you put into this project. Dr. Brock, thank you for serving as the chair of my committee and for being my go to person whenever I had a question. Dr. Siderovski, thank you for your endless guidance throughout the years. You encouraged me to pursue my clinical interests and helped me find a happy home in the CIP program. And finally, Dr. Kelley, thank you for answering all of my iron-related questions.

Thank you to my labmates, Drew, Trey, and Karthi. I couldn't have done it without you guys. Thanks to Karthi for performing the immunofluorescence studies. Special thanks to Drew for all his help with editing papers, sacking animals, answering many dumb questions, and for (kind of) teaching me how to play pool in-between experiments.

And finally, a special thanks to all my friends and family for their support and love along the way: Cousin Sheila, Jen, Stevers, Shane, Nina, Divine, Haley, Tristan, Abby, and Gina. You guys kept me sane. Cheers to you all. 


\section{ABBREVIATIONS}

\begin{tabular}{|c|c|}
\hline 5-ASA & 5-aminosalicylic acid \\
\hline $\mathrm{BPB}$ & Butyrate-producing bacteria \\
\hline $\mathrm{CRC}$ & Colorectal cancer \\
\hline DAI & Disease activity index \\
\hline DMT1 & Divalent metal transporter 1 \\
\hline DSS & Dextran sulfate sodium \\
\hline $\mathrm{Fe}$ & Iron \\
\hline FPN1 & Ferroportin 1 \\
\hline GI & Gastrointestinal \\
\hline $\mathrm{Hb}$ & Hemoglobin \\
\hline Hct & Hematocrit \\
\hline IBD & Inflammatory bowel disease \\
\hline IDA & Iron deficiency anemia \\
\hline IV & Intravenous \\
\hline $\mathrm{MCV}$ & Mean corpuscular volume \\
\hline PCR & Polymerase chain reaction \\
\hline $\mathrm{RBC}$ & Red blood cells \\
\hline $\mathrm{SE}$ & Standard error \\
\hline Th2 & T helper 2 \\
\hline $\mathrm{TNF} \alpha$ & Tumor necrosis factor alpha \\
\hline TRFLP & Terminal restriction fragment length polymorphism \\
\hline UC & Ulcerative colitis \\
\hline
\end{tabular}




\section{A STUDY OF GASTROINTESINAL PATHOPHYSIOLOGY}

TITLE PAGE.............................................................. i

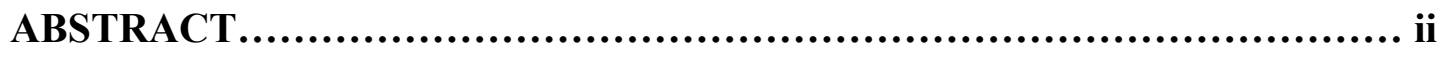

ACKNOWLEDGEMENTS...................................................... iii

ABBREVIATIONS........................................................ v

TABLE OF CONTENTS.............................................................. vi

I. Translational Research Studies................................................... 1

A. Introduction

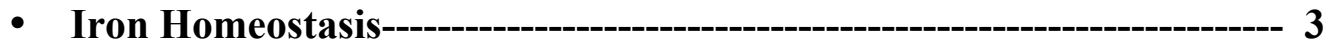

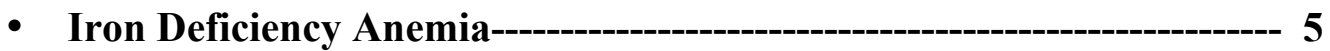

- Inflammatory Bowel Disease--------------------------------------------------- 6

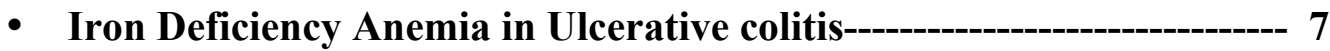

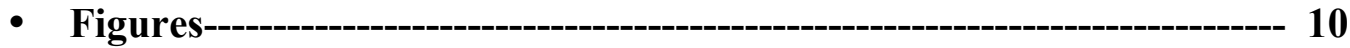

- References-------------------------------------------------------------------------- 12

B. Increased apical and basolateral iron transporter expression with enhanced iron uptake in ulcerative colitis human colon

- Specific Aims----------------------------------------------------------------------- 21

- Paper

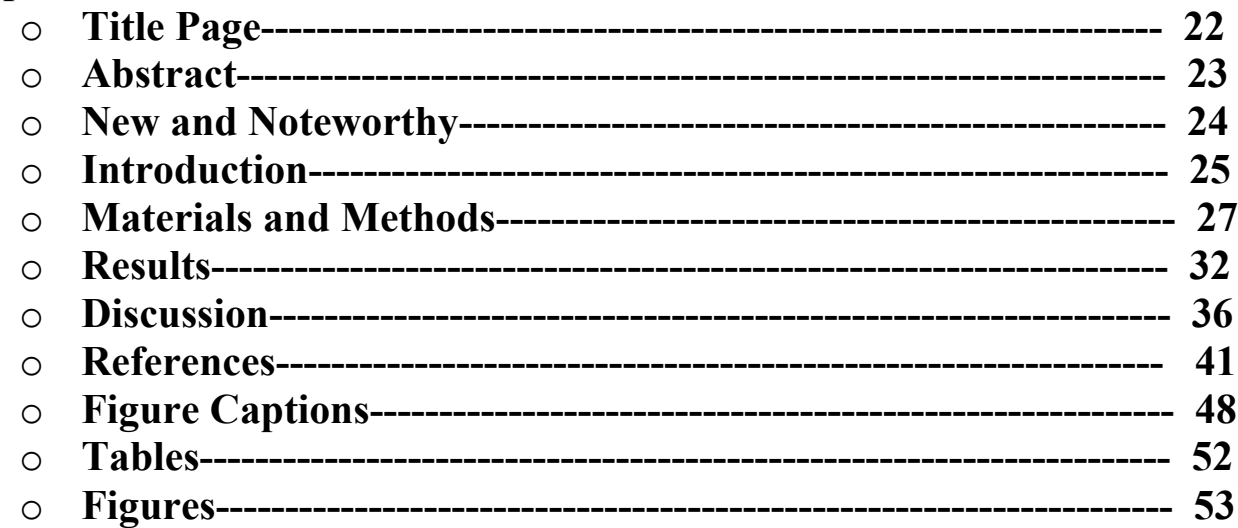

C. Oral iron supplementation exacerbates dextran sulfate sodium (DSS)induced colitis and leads to pathogenic changes in the microbiome

- Background

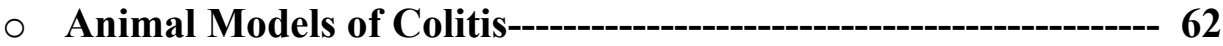

- Oral Iron Supplementation in Ulcerative Colitis------------------ 63

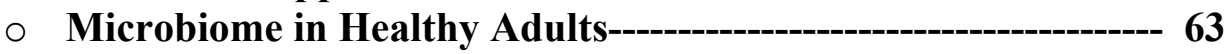

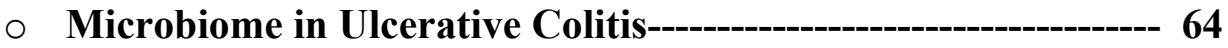

$\bigcirc \quad$ Effect of Iron Supplementation on the Microbiome--------------- 64

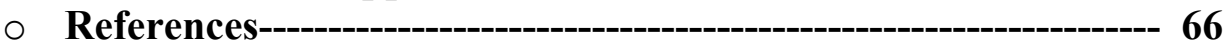

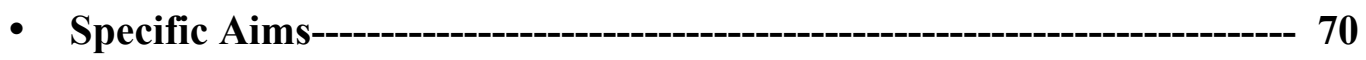

- Paper 


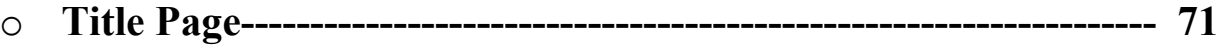

○ Abstract--- 72

○ Introduction-- 73

○ Materials and Methods---_-_- 76

○ Results------ 82

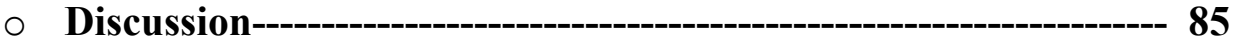

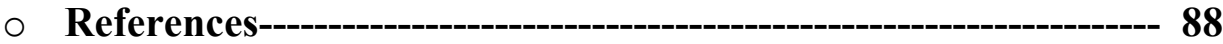

○ Figure Captions---o 96

○ Tables-- 99

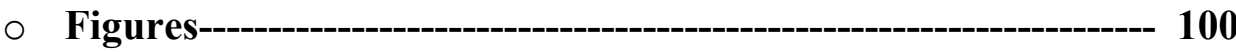

D. Conclusions and Future Directions--_-_- 106

○ Conclusions---o- 107

O Future Directions---o- 110

○ References-- 116

II. Case Reports............................................................... 119

A. Chronic, recreational chloroform-induced liver injury

- Paper

$\circ$ Title Page---_- 121

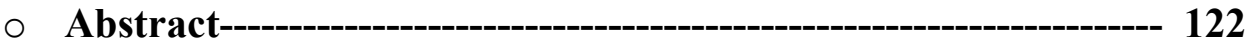

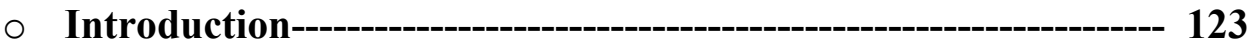

○ Case Presentation--- 124

0 Discussion-- 126

○ Tables-- 129

○ References--- 130

B. Successful Treatment of Coin Ingestion Using Esophageal Bougienage

- Paper

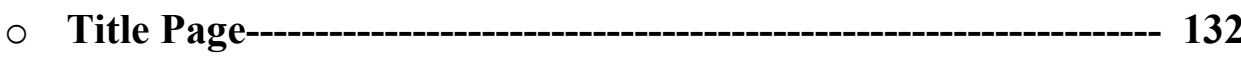

○ Abstract----on 133

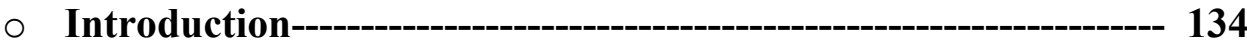

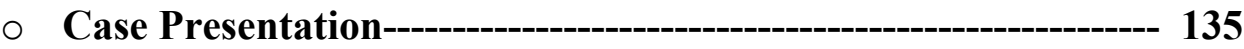

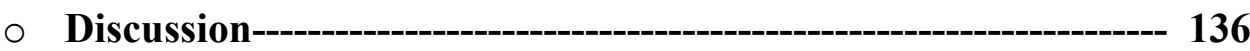

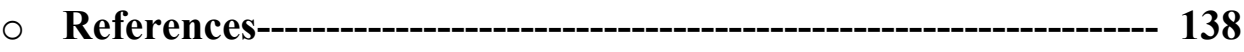

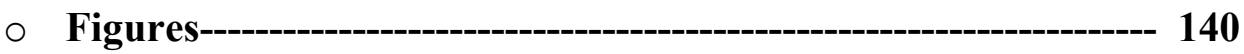




\section{Chapter I}

Translational Research Studies 
Section A

Introduction 


\section{Iron Homeostasis}

Iron is an essential nutrient that is required for many important physiological processes including redox reactions of the electron transport chain, oxygen transport, and DNA synthesis $(1,2)$. Whole body and cellular iron concentration are tightly regulated because iron imbalance in either direction is detrimental to normal functioning (3). Iron overload results in the formation of damaging free radicals, while too little iron can lead to iron deficiency with subsequent anemia $(4,5)$. The body lacks a coordinated excretory mechanism for iron, so homeostasis is therefore maintained at the level of absorption, which varies based on iron type $(6,7)$.

Dietary iron exists in two forms: inorganic non-heme iron ( $\sim 90 \%)$ and organic heme iron $(\sim 10 \%)(8)$. Heme iron comes from hemoglobin and myoglobin animal food sources (9). It represents only a small fraction of the total iron in ones diet, but it is more readily absorbed than non-heme iron and therefore makes up about $40 \%$ of the total iron absorbed (10). The majority of iron absorption occurs in the duodenum, the first part of the small intestine (11). Absorption of heme iron is not entirely understood, but there are two prevailing hypotheses: 1) receptor mediated endocytosis or 2) heme carrier protein 1 (HCP1)-mediated transport across the apical membrane followed by liberation of iron via heme oxygenase 1 (HO-1) $(12,13)$.

Non-heme iron absorption has been much more extensively studied and is the focus of my research. Inorganic non-heme iron is found in both animal and plant sources where it predominantly exists in the ferric $\left(\mathrm{Fe}^{3+}\right)$ form. Ferric iron is reduced to ferrous $\left(\mathrm{Fe}^{2+}\right)$ iron by duodenal cytochrome b (Dcytb) and then transported across the apical membrane via divalent metal transporter 1 (DMT1) $(14,15)$. DMT1 is a proton-coupled 
transporter consisting of 12 transmembrane domains (16). There are four mRNA transcript variants: differing 5' promoters that transcribe either DMT1 1A or 1B and alternate splicing of the 3' UTR, leading to transcripts with or without the iron response element (IRE), (+IRE or -IRE) (17). Once inside the cell, iron can either be stored as ferritin or transported across the basolateral membrane by ferroportin 1 (FPN1), the only known iron exporter (16). See Figure 1 for a depiction of non-heme iron absorption.

The daily iron absorption requirement is approximately one to two milligrams, which compensates for the iron lost due to sloughing of skin/mucosa and menstruation (18). Iron homeostasis is very tightly regulated, so the daily loss is quite small compared to the three to four grams of iron contained within the body, mostly present in circulating erythrocytes (hemoglobin), muscle myoglobin, and liver hepatocytes (19). The recommended daily allowance (RDA) for iron is eight milligrams per day for men and postmenopausal women and $18 \mathrm{mg}$ per day for premenopausal women (20). This accounts for the fact that only about $10-15 \%$ of the iron in ones diet is actually absorbed in the duodenum (21).

The absorption of iron is one critical mediator of whole body iron homeostasis, however, it is not the only one. Hepcidin, a 25 amino acid liver-derived hormone, is also an important negative regulator of iron status that is released in times of iron loading and inflammation (22). High iron levels are sensed by hepatocytes, while inflammationinduced hepcidin production is signaled via IL-6 (23). Hepcidin leads to the internalization and ubiquitin-mediated degradation of FPN1 and can also directly occlude the channel $(24,25)$. Inadequate hepcidin fails to limit iron absorption, resulting in iron 
overload, as seen in hereditary hemochromatosis, commonly called bronze diabetes (26). Symptoms include arthritis, liver disease, diabetes mellitus, and skin discoloration (27).

\section{Iron Deficiency Anemia}

On the other end of the spectrum is iron deficiency, the most common nutrient deficiency worldwide, affecting approximately two billion people (4). Iron deficiency is the number one cause of anemia, defined as a reduction in the amount of circulating red bloods cells (28). The main burden of the disease falls on developing countries due to the increased incidence of poverty, famine, and a cereal-based diet in those areas (29). Children are particularly susceptible because of the increased demand for iron during periods of growth (30).

Iron deficiency anemia (IDA) in the adult population is largely due to insufficient intake, impaired absorption, or blood loss (31). It is classified as a hypochromic, microcytic anemia with insufficient iron available for hemoglobin $(\mathrm{Hb})$ production resulting in pale RBCs with reduced mean corpuscular volume (MCV). Symptoms include fatigue, weakness, cold intolerance, and difficulty concentrating (32). IDA can greatly reduce quality of life, as evidenced by several well-validated instruments used to document patient outcomes showing reduced quality of life (QOL) in patients with anemia (33). The broad detrimental impact of iron deficiency anemia (IDA) can be attributed to the critical role of iron in many biological processes, as described above $(1,34)$.

Diagnosis of anemia is typically achieved via blood draw and laboratory analysis of various $\mathrm{RBC}$ parameters (35). IDA is defined as $\mathrm{Hb}<13.0 \mathrm{~g} / \mathrm{dL}$ in adult males and $\mathrm{Hb}$ 
$<12.0 \mathrm{~g} / \mathrm{dL}$ in non-pregnant females (36). The reduction in $\mathrm{Hb}$ is accompanied by low serum iron, hematocrit (Hct), MCV, and transferrin saturation with an increase in total iron-binding capacity (TIBC). These particular laboratory findings help distinguish iron deficiency as the cause of anemia.

\section{Inflammatory Bowel Disease}

Inflammatory bowel disease (IBD) is an umbrella term that encompasses both Crohn's disease and ulcerative colitis (UC), two chronic, relapsing inflammatory diseases of the intestines (37). The exact etiology is unknown, but IBD is thought to be an autoimmune condition that results from aberrant host-microbiome interactions in a genetically susceptible individual (38). IBD affects more than three million people in the United States ( $>1 \%$ of the population) (38). Direct and indirect healthcare costs are estimated to be between $\$ 14.6$ and $\$ 31.6$ billion annually, making it one of the top five most expensive gastrointestinal (GI) disorders $(39,40)$.

Though IBD has some unifying features, Crohn's disease and UC are very much different diseases. Crohn's can occur anywhere in the digestive tract and typically involves transmural inflammation that is discontinuous (41). UC, on the other hand, only involves the colon with mucosal inflammation beginning in the rectum and extending proximally in a continuous manner to involve a variable length of the large intestine (42). UC is equally common in both sexes, while Crohn's affects more females than males (43). Symptoms of both include diarrhea, bloating, and abdominal pain. Patients with Crohn's present with more diffuse pain indicating both small bowel and colonic disease, whereas UC patients often present with bloody, mucous-laden diarrhea and pain more 
localized to the area of affected colon (44). Characteristics of UC and Crohn's disease are summarized in Figure 2.

My research focuses specifically on ulcerative colitis, which has a higher incidence than Crohn's disease, but is not as well studied (45). Diagnosis of UC is achieved first by obtaining a relevant history focusing on stool frequency, consistency, blood, and mucous content. Colonoscopy with biopsy is performed for a definitive diagnosis (42). Treatment depends on the severity and localization of the disease. For mild disease, a topical 5-aminosalicylic acid (5-ASA) is preferred. More extensive disease warrants oral and local 5-ASA administration plus corticosteroids, and in severe cases, immunomodulators (such as 6-mercaptopurine, a purine analog that inhibits nucleotide synthesis) and/ or biologics (such as humira, a TNF $\alpha$ inhibitor) may be necessary (46).

In addition to the symptoms described above, $\mathrm{UC}$ is also associated with various other manifestations. Because it is an autoimmune condition, patients are at an increased risk of developing other autoimmune diseases (47). UC patients also have a higher risk of developing colorectal cancer (CRC): $2 \%$ risk at 10 years, $8 \%$ at 20 years, and $18 \%$ at 30 years (48). Peripheral arthritis, oral apthous ulcers, erythema nodosum, uveitis, ankylosing spondylitis, and primary sclerosing cholangitis also occur.

\section{Iron Deficiency Anemia in Ulcerative Colitis}

Iron deficiency anemia (IDA) is the most common extraintestinal manifestation of UC (49). Approximately 70\% of patients newly diagnosed with UC will develop IDA in the first 10 years after diagnosis, largely due to blood loss in areas ulceration and 
impaired absorption as a result of inflammation and faster intestinal transit time $(50,51)$. Female sex and extent of disease activity are the biggest risk factors for development of anemia (52). IDA has a large detrimental impact on quality of life in UC patients, can lead to hospitalization and delayed discharge, and results in an overall increase in the healthcare burden (53).

Oral iron supplementation is the first line therapy for IDA (18). It is simple, cheap, and cost effective. Various formulations exist including ferrous fumarate and ferrous gluconate, however, ferrous sulfate is the best tolerated and most commonly used clinically (54). Whether or not symptoms are present, all patients with IDA and most with iron deficiency should be treated because there is a clear benefit to treating iron deficiency-associated fatigue without anemia $(55,56)$. Therapeutic Guidelines recommend a dose of 325-650 $\mathrm{mg}$ daily of ferrous sulfate, which is equivalent to $105-210$ mg of elemental iron (57). A one gram per deciliter increase in hemoglobin after one month of treatment indicates an adequate response to treatment (58). However, therapy should be continued for three months after the anemia is corrected in order for iron stores to replenish (59).

The biggest issue with oral iron supplementation is its tolerability. Some studies have shown that oral iron increases gastrointestinal side effects such as bloating, constipation, flatulence, tarry stools, and abdominal pain (60). This can lead to poor compliance with medication and failure to resolve the iron deficiency. One group found that as many as $40 \%$ of patients did not use their medication regularly, largely due to gastrointestinal issues and weight gain (61). There is still a debate in the literature about 
the prevalence of side effects following oral iron administration with some groups finding minimal associated symptoms and others observing a large negative effect (62).

In cases of severe iron deficiency or failed response to oral iron, intravenous (IV) iron supplementation is required. IV iron leads to faster and greater increases in hemoglobin levels, but has the potential for some serious adverse effects, including anaphylactic shock (63). Older formulations, especially iron dextran, had an unacceptably high rate of adverse events. However, some of the newer preparations with a carbohydrate shell have proven to be much safer because they bind elemental iron more tightly, allowing for slower release (64). Though IV iron supplementation was touted as the more efficacious treatment for IDA with a lower side effect profile, recent studies have begun to dispute this finding. One group found no difference in side effects or hemoglobin levels following oral iron administration compared to IV iron (65). Some say that there is no evidence IV iron raises hemoglobin at a faster pace, nor that oral iron activates or exacerbates clinical symptoms (66). 
Figure 1- Non-heme iron absorption

\section{Lumen Duodenal enterocyte Interstitium}

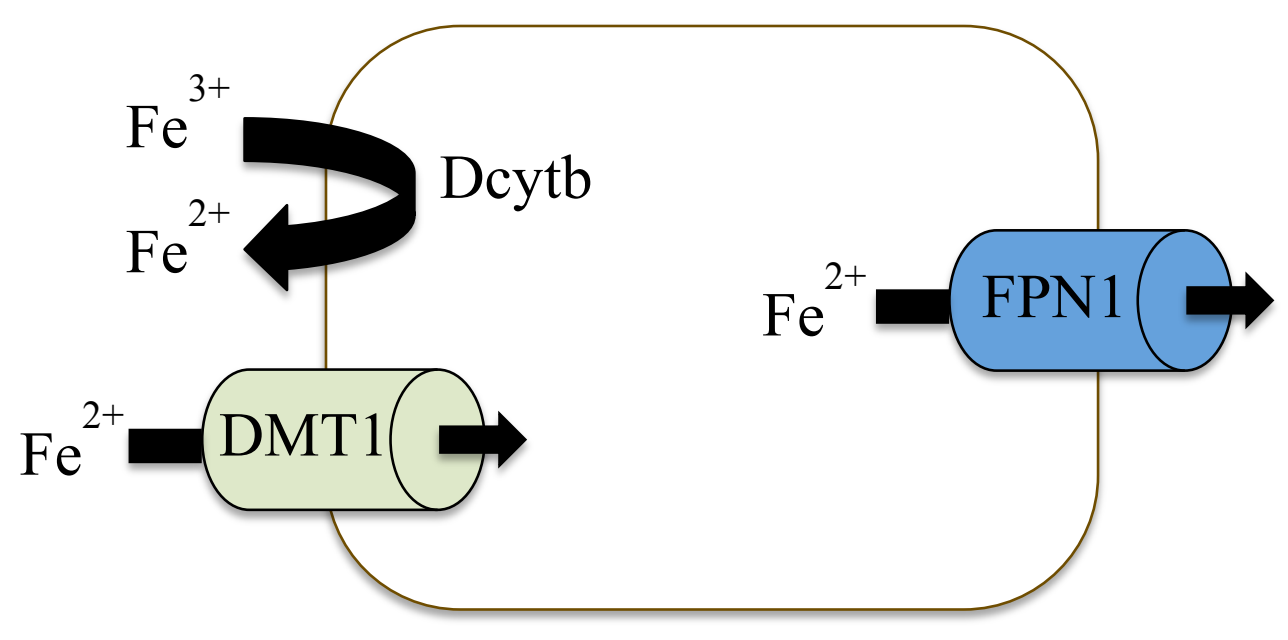

A simplified schematic of non-heme iron absorption in the duodenum. Dietary ferric iron $\left(\mathrm{Fe}^{3+}\right)$ is converted to ferrous iron $\left(\mathrm{Fe}^{2+}\right)$ by duodenal cytochrome $\mathrm{b}$ (Dcytb). Ferrous iron is then transported across the apical membrane via divalent metal transporter 1 (DMT1).

Once inside the cell, iron can either be stored as ferritin or exported across the basolateral membrane by ferroportin 1 (FPN1), the only known iron exporter. 
Figure 2- Hallmark characteristics of crohn's disease and ulcerative colitis.

\section{Chron's Disease}

- Anywhere in the digestive tract

- Transmural inflammation

- Skip lesions

- Crampy abdominal pain

\section{Ulcerative colitis}

- Colon only

- Mucosal inflammation

- Continuous disease activity

- Bloody diarrhea 


\section{References}

1. Lieu PT, Heiskala M, Peterson PA, Yang Y. The roles of iron in health and disease. Mol Aspects Med. 22(1-2):1-87.

2. Abbaspour N, Hurrell R, Kelishadi R. Review on iron and its importance for human health. J Res Med Sci. 2014 Feb;19(2):164-74.

3. Wang J, Pantopoulos K. Regulation of cellular iron metabolism. Biochem J. 2011 Mar 15;434(3):365-81.

4. Miller JL. Iron deficiency anemia: a common and curable disease. Cold Spring Harb Perspect Med. 2013 Jul 1;3(7).

5. Emerit J, Beaumont C, Trivin F. Iron metabolism, free radicals, and oxidative injury. Biomed Pharmacother. 2001 Jul;55(6):333-9.

6. Silva B, Faustino P. An overview of molecular basis of iron metabolism regulation and the associated pathologies. Biochim Biophys Acta - Mol Basis Dis. 2015 Jul;1852(7):1347-59.

7. Wallace DF. The Regulation of Iron Absorption and Homeostasis. Clin Biochem Rev. 2016 May;37(2):51-62.

8. Muñoz M, Villar I, García-Erce JA. An update on iron physiology. World J Gastroenterol. 2009 Oct 7;15(37):4617-26.

9. Hooda J, Shah A, Zhang L. Heme, an essential nutrient from dietary proteins, critically impacts diverse physiological and pathological processes. Nutrients. 2014 Mar 13;6(3):1080-102.

10. Hurrell R, Egli I. Iron bioavailability and dietary reference values. Am J Clin Nutr. 2010 May 1;91(5):1461S-1467S. 
11. Gulec S, Anderson GJ, Collins JF. Mechanistic and regulatory aspects of intestinal iron absorption. Am J Physiol Gastrointest Liver Physiol. 2014 Aug 15;307(4):G397-409.

12. Gräsbeck R, Kouvonen I, Lundberg M, Tenhunen R. An intestinal receptor for heme. Scand J Haematol. 1979 Jul;23(1):5-9.

13. Le Blanc S, Garrick MD, Arredondo M. Heme carrier protein 1 transports heme and is involved in heme-Fe metabolism. Am J Physiol Cell Physiol. 2012 Jun 15;302(12):C1780-5.

14. Lane DJR, Bae D-H, Merlot AM, Sahni S, Richardson DR. Duodenal cytochrome b (DCYTB) in iron metabolism: an update on function and regulation. Nutrients. 2015 Mar 31;7(4):2274-96.

15. Andrews NC. The iron transporter DMT1. Int J Biochem Cell Biol. 1999 Oct;31(10):991-4.

16. Ganz T. Cellular iron: Ferroportin is the only way out. Cell Metab. 2005 Mar;1(3):155-7.

17. Andolfo I, De Falco L, Asci R, Russo R, Colucci S, Gorrese M, et al. Regulation of divalent metal transporter 1 (DMT1) non-IRE isoform by the microRNA Let-7d in erythroid cells. Haematologica. 2010 Aug 1;95(8):1244-52.

18. Johnson-Wimbley TD, Graham DY. Diagnosis and management of iron deficiency anemia in the 21st century. Therap Adv Gastroenterol. 2011 May;4(3):177-84.

19. Abbaspour N, Hurrell R, Kelishadi R. Review on iron and its importance for human health. J Res Med Sci. 2014 Feb;19(2):164-74.

20. Intakes DR, Vanadium U, Levels ZR, Intakes DR, Committee S, Evaluation S, et 
al. Institute of Medicine 2001 - Dietary Reference Intakes for Vitamin A. 2000.

21. Waldvogel-Abramowski S, Waeber G, Gassner C, Buser A, Frey BM, Favrat B, et al. Physiology of iron metabolism. Transfus Med Hemother. 2014 Jun;41(3):21321.

22. Nemeth E, Tuttle MS, Powelson J, Vaughn MB, Donovan A, Ward DM, et al. Hepcidin regulates cellular iron efflux by binding to ferroportin and inducing its internalization. Science. 2004 Dec 17;306(5704):2090-3.

23. Nemeth E, Rivera S, Gabayan V, Keller C, Taudorf S, Pedersen BK, et al. IL-6 mediates hypoferremia of inflammation by inducing the synthesis of the iron regulatory hormone hepcidin. J Clin Invest. 2004 May;113(9):1271-6.

24. Aschemeyer S, Qiao B, Stefanova D, Valore E V., Sek AC, Ruwe TA, et al. Structure-function analysis of ferroportin defines the binding site and an alternative mechanism of action of hepcidin. Blood. 2018 Feb 22;131(8):899-910.

25. De Domenico I, Ward DM, Kaplan J. Hepcidin and ferroportin: the new players in iron metabolism. Semin Liver Dis. 2011 Aug;31(3):272-9.

26. Papanikolaou G, Tzilianos M, Christakis JI, Bogdanos D, Tsimirika K, MacFarlane J, et al. Hepcidin in iron overload disorders. Blood. 2005 May 15;105(10):4103-5.

27. Clark P, Britton LJ, Powell LW. The diagnosis and management of hereditary haemochromatosis. Clin Biochem Rev. 2010 Feb;31(1):3-8.

28. Polin V, Coriat R, Perkins G, Dhooge M, Abitbol V, Leblanc S, et al. Iron deficiency: From diagnosis to treatment. Dig Liver Dis. 2013 Oct;45(10):803-9.

29. Camaschella C. Iron-Deficiency Anemia. Longo DL, editor. N Engl J Med. 2015 
May 7;372(19):1832-43.

30. Cusick SE, Georgieff MK, Rao R. Approaches for Reducing the Risk of Early-Life Iron Deficiency-Induced Brain Dysfunction in Children. Nutrients. 2018 Feb $17 ; 10(2)$

31. Warner MJ, Kamran MT. Anemia, Iron Deficiency. StatPearls. 2018.

32. Brunner C, Wuillemin WA. [Iron deficiency and iron deficiency anemia symptoms and therapy]. Ther Umsch. 2010 May;67(5):219-23.

33. Strauss WE, Auerbach M. Health-related quality of life in patients with iron deficiency anemia: impact of treatment with intravenous iron. Patient Relat Outcome Meas. 2018;9:285-98.

34. Abbaspour N, Hurrell R, Kelishadi R. Review on iron and its importance for human health. J Res Med Sci. 2014 Feb;19(2):164-74.

35. Zhu A, Kaneshiro M, Kaunitz JD. Evaluation and treatment of iron deficiency anemia: a gastroenterological perspective. Dig Dis Sci. 2010 Mar;55(3):548-59.

36. Jimenez K, Kulnigg-Dabsch S, Gasche C. Management of Iron Deficiency Anemia. Gastroenterol Hepatol (N Y). 2015 Apr;11(4):241-50.

37. Fakhoury M, Negrulj R, Mooranian A, Al-Salami H. Inflammatory bowel disease: clinical aspects and treatments. J Inflamm Res. 2014;7:113-20.

38. Zhang Y-Z, Li Y-Y. Inflammatory bowel disease: pathogenesis. World J Gastroenterol. 2014 Jan 7;20(1):91-9.

39. Dulai PS, Singh S, Ohno-Machado L, Sandborn WJ. Population Health Management for Inflammatory Bowel Disease. Gastroenterology. 2018 Jan;154(1):37-45. 
40. Mehta F. Report: economic implications of inflammatory bowel disease and its management. Am J Manag Care. 2016;22(3 Suppl):s51-60.

41. Gohil K, Carramusa B. Ulcerative colitis and Crohn's disease. P T. 2014 Aug;39(8):576-7.

42. Collins P, Rhodes J. Ulcerative colitis: diagnosis and management. BMJ. 2006 Aug 12;333(7563):340-3.

43. Baumgart DC. The diagnosis and treatment of Crohn's disease and ulcerative colitis. Dtsch Arztebl Int. 2009 Feb;106(8):123-33.

44. Waugh N, Cummins E, Royle P, Kandala N-B, Shyangdan D, Arasaradnam R, et al. Faecal calprotectin testing for differentiating amongst inflammatory and noninflammatory bowel diseases: systematic review and economic evaluation. Health Technol Assess (Rockv). 2013 Nov;17(55).

45. M'Koma AE. Inflammatory bowel disease: an expanding global health problem. Clin Med Insights Gastroenterol. 2013;6:33-47.

46. Meier J, Sturm A. Current treatment of ulcerative colitis. World J Gastroenterol. $2011 \mathrm{Jul} 21 ; 17(27): 3204-12$.

47. Wilson JC, Furlano RI, Jick SS, Meier CR. Inflammatory Bowel Disease and the Risk of Autoimmune Diseases. J Crohn's Colitis. 2016 Feb;10(2):186-93.

48. Lakatos P-L, Lakatos L. Risk for colorectal cancer in ulcerative colitis: changes, causes and management strategies. World J Gastroenterol. 2008 Jul $7 ; 14(25): 3937-47$.

49. Tulewicz-Marti E, Moniuszko A, Rydzewska G. Management of anemia in inflammatory bowel disease: a challenge in everyday clinical practice. Prz 
Gastroenterol. 2017;12(4):239-43.

50. Khan N, Patel D, Shah Y, Yang Y-X. Factors Predicting Testing and Treatment of Iron Deficiency in a Nationwide Cohort of Anemic UC Patients. Inflamm Bowel Dis. 2016;22(12):2894-901.

51. Kaitha S, Bashir M, Ali T. Iron deficiency anemia in inflammatory bowel disease. World J Gastrointest Pathophysiol. 2015 Aug 15;6(3):62-72.

52. Lucendo AJ, Arias Á, Roncero Ó, Hervías D, Verdejo C, Naveas-Polo C, et al. Anemia at the time of diagnosis of inflammatory bowel disease: Prevalence and associated factors in adolescent and adult patients. Dig Liver Dis. 2017 Apr;49(4):405-11.

53. Patel D, Trivedi C, Khan N. Management of Anemia in Patients with Inflammatory Bowel Disease (IBD). Curr Treat Options Gastroenterol. 2018 Mar;16(1):112-28.

54. Cancelo-Hidalgo MJ, Castelo-Branco C, Palacios S, Haya-Palazuelos J, CiriaRecasens M, Manasanch J, et al. Tolerability of different oral iron supplements: a systematic review. Curr Med Res Opin. 2013 Apr;29(4):291-303.

55. Patterson AJ, Brown WJ, Roberts DC. Dietary and supplement treatment of iron deficiency results in improvements in general health and fatigue in Australian women of childbearing age. J Am Coll Nutr. 2001 Aug;20(4):337-42.

56. Krayenbuehl P-A, Battegay E, Breymann C, Furrer J, Schulthess G. Intravenous iron for the treatment of fatigue in nonanemic, premenopausal women with low serum ferritin concentration. Blood. 2011 Sep 22;118(12):3222-7.

57. Baird-Gunning J, Bromley J. Correcting iron deficiency. Aust Prescr. 2016 
Dec;39(6):193-9.

58. Short MW, Domagalski JE. Iron deficiency anemia: evaluation and management. Am Fam Physician. 2013 Jan 15;87(2):98-104.

59. Goddard AF, James MW, McIntyre AS, Scott BB. Guidelines for the management of iron deficiency anaemia. Gut. 2011 Oct 1;60(10):1309-16.

60. Tolkien Z, Stecher L, Mander AP, Pereira DIA, Powell JJ. Ferrous sulfate supplementation causes significant gastrointestinal side-effects in adults: a systematic review and meta-analysis. PLoS One. 2015;10(2):e0117383.

61. Gereklioglu C, Asma S, Korur A, Erdogan F, Kut A. Medication adherence to oral iron therapy in patients with iron deficiency anemia. Pakistan J Med Sci. 32(3):604-7.

62. Köpcke W, Sauerland MC. Meta-analysis of efficacy and tolerability data on iron proteinsuccinylate in patients with iron deficiency anemia of different severity. Arzneimittelforschung. 1995 Nov;45(11):1211-6.

63. Cançado RD, Muñoz M. Intravenous iron therapy: how far have we come? Rev Bras Hematol Hemoter. 2011;33(6):461-9.

64. Auerbach M, Macdougall IC. Safety of intravenous iron formulations: facts and folklore. Blood Transfus. 2014 Jul;12(3):296-300.

65. Lee T, Clavel T, Smirnov K, Schmidt A, Lagkouvardos I, Walker A, et al. Oral versus intravenous iron replacement therapy distinctly alters the gut microbiota and metabolome in patients with IBD. Gut. 2017;66(5):863-71.

66. Rizvi S, Schoen RE. Supplementation With Oral vs. Intravenous Iron for Anemia With IBD or Gastrointestinal Bleeding: Is Oral Iron Getting a Bad Rap? Am J 
Gastroenterol. 2011 Nov 7;106(11):1872-9. 
Section B

Increased apical and basolateral iron transporter expression with enhanced iron uptake in ulcerative colitis human colon 


\section{Specific Aims}

(1) Localize non-heme iron transporters divalent metal transporter 1 (DMT1) and ferroportin 1 (FPN1) throughout normal human colon compared to duodenum.

(2) Determine whether expression of DMT1 and FPN1 is altered in the distal colonic epithelium of patients with active ulcerative colitis (UC) compared to controls and measure in vitro ${ }^{59} \mathrm{Fe}$ uptake. 
Increased apical and basolateral iron transporter expression with enhanced iron uptake in ulcerative colitis human colon

Running title: Increased iron transporters in UC colon

Emily A. Minor ${ }^{1,2}$, Justin T. Kupec ${ }^{3}$, Andrew J. Nickerson ${ }^{1,2}$, Vazhaikkurichi M. Rajendran $^{2,3}$

${ }^{1}$ Department of Physiology and Pharmacology, ${ }^{2}$ Department of Biochemistry, and

${ }^{3}$ Department of Medicine, Section of Digestive Diseases, West Virginia University School of Medicine, Morgantown, West Virginia, USA

Keywords: Divalent metal transporter 1 (DMT1), ferroportin 1 (FPN1), iron deficiency anemia (IDA), inflammatory bowel disease (IBD), 59Fe uptake 


\begin{abstract}
Iron deficiency anemia is a common complication of ulcerative colitis (UC) that can profoundly impact quality of life. Most iron absorption occurs in the duodenum via divalent metal transporter 1 (DMT1)-mediated uptake and ferroportin 1 (FPN1)-mediated export across the apical and basolateral membranes, respectively. However, the colon also contains iron transporters and can participate in iron absorption. Studies have shown increased duodenal DMT1 and FPN1 in patients with UC, but there is conflicting evidence about whether expression is altered in UC colon. We hypothesize that expression of colonic DMT1 and FPN1 are also increased to compensate for iron deficiency. RT-qPCR and western blot analyses were performed on duodenal and segmental colonic (right, transverse, left colon, and rectum) biopsies obtained during colonoscopy. Colonic DMT1 mRNA and protein abundance were approximately equal to duodenal levels, while colonic FPN1 abundance was about one-quarter that of the duodenum. In patients with UC, DMT1 mRNA and protein abundance in the colon were increased by two-fold, while FPN1 was increased by five-fold. Immunohistochemical (IHC) and immunofluorescence (IF) studies showed increased membrane localization of DMT1 (apical) and FPN1 (basolateral) in UC tissue. Iron uptake was also increased in UC distal colon compared to control. We conclude that patients with active UC have increased expression of colonic iron transporters and increased iron absorption, which may be targeted in the treatment of UC-related anemia.
\end{abstract}




\section{New and Noteworthy}

Our study examines expression of non-heme iron transporters in control and ulcerative colitis (UC) human colon. Apical DMT1 and basolateral FPN1 are abundantly expressed in the colons of healthy individuals. Patients with ulcerative colitis have increased colonic DMT1 and FPN1 transporter abundance and iron uptake, which may help compensate for iron deficiency anemia, a frequent complication of UC. 


\section{Introduction}

Ulcerative colitis (UC) is a chronic inflammatory bowel disease (IBD) that is characterized by mucosal inflammation of the colon $(9,32)$. Inflammation typically begins in the rectum and extends proximally in a continuous manner to involve a variable length of the large intestine (8). Symptoms include diarrhea, hematochezia, abdominal pain, tenesmus, and bloating $(16,47)$. While gastrointestinal symptoms are the hallmark of the disease, other complications can arise, such as primary sclerosing cholangitis, colorectal cancer, various autoimmune conditions, and anemia $(17,19)$.

Anemia in patients with UC is of particular importance because of its high incidence and impact on quality of life $(2,3,36)$. As many as $70 \%$ of patients newly diagnosed with UC will develop anemia, defined as a reduction in the amount of circulating red bloods cells, over the first 10 years $(22,40)$. Symptoms include weakness, fatigue, dizziness, malaise, and difficulty concentrating $(4,43)$. Iron deficiency is by far the most common cause of anemia in UC patients, largely due to blood loss in areas of ulceration and malabsorption $(7,39)$. The broad detrimental impact of iron deficiency anemia (IDA) can be attributed to the critical role of iron in many biological processes, such as redox reactions of the electron transport chain, DNA synthesis, and oxygen transport (28).

Iron handling is unique in that the body lacks a coordinated excretory mechanism (1). Homeostasis is therefore maintained at the level of absorption, the majority of which occurs in the duodenum $(42,48)$. Dietary iron comes in two forms, inorganic non-heme iron $(90 \%)$ and organic heme iron $(10 \%)$, which each have different absorption mechanisms (33). Inorganic iron, which exists in the ferric $\left(\mathrm{Fe}^{3+}\right)$ form, is first reduced to 
ferrous $\left(\mathrm{Fe}^{2+}\right)$ iron by duodenal cytochrome $\mathrm{b}$ (Dcytb) and then transported across the apical membrane via divalent metal transporter $1(\mathrm{DMT} 1)(10,18)$. Once inside the cell, iron is either stored as ferritin or exported across the basolateral membrane via ferroportin 1 (FPN1) (51).

The duodenum is the primary site of absorption, but the colon also contains iron transporters and can participate in iron absorption $(5,6,35,45)$. In fact, a recent study showed that DMT1 abundance in the colon was approximately equal to that in the duodenum, suggesting that the colon plays a more significant role in iron absorption than previously thought (52). It is known that duodenal DMT1 and FPN1 are increased in patients with UC, but there is conflicting evidence concerning the expression of these transporters in the colon. The purpose of this study was to investigate the expression and function of iron transporters in colonic tissue from UC patients and non-IBD controls. We hypothesize that colonic DMT1 and FPN1 abundance and iron absorption are increased in patients with active UC. 


\section{Materials and Methods}

\section{Subject Recruitment}

All experiments were approved by the Institutional Review Board at West Virginia University (WVU). Written informed consent was obtained. Adults 18 years and older who were previously scheduled for colonoscopy with biopsy and/or endoscopy with biopsy at WVU's Ruby Memorial Hospital were recruited into the study. Patients were enrolled during pre-op for their procedure with no preference given to a specific sex, age, or ethnicity. Participants were told the purpose of the study as well as the risks, benefits, and potential complications. Researchers had access to patient files including labs, medications, and diagnoses. Labs relevant to anemia status, hemoglobin $(\mathrm{Hb})$ and hematocrit (Hct), were pulled from patient charts as close to the time of the procedure as possible. We also noted relevant medications including 5-aminosalicylic acids (5-ASA), immunomodulators, corticosteroids, and biologic agents. Patients on different medication regimens were used for each set of experiments in order to minimize the confounding effect of various treatments.

\section{Human Tissue Collection}

Duodenal and colonic biopsies were taken by a board-certified gastroenterologist using an Olympus colonoscope (Olympus Corporation of the Americas, Center Valley, PA) and jumbo biopsy forceps. Separate biopsies were taken for diagnostic purposes and for use in this study. For protein and transcript analysis, segmental biopsies were taken from the

right, transverse, left colon, and rectum. Tissue for ${ }^{59} \mathrm{Fe}$ experiments was taken from the distal colon due to the propensity for UC to affect the latter segments of the colon. Following collection, the biopsies were placed in cold saline solution on ice and 
immediately transported to the lab. Colonoscopic images were also captured during the procedure.

\section{Histology}

Biopsies taken for diagnostic purposes were sent to the Pathology Department at West Virginia University (WVU) for analysis. Hematoxylin and eosin (H\&E) staining was performed according to standard protocol in order to assess disease activity. Segmental biopsies allowed disease status assessment throughout the large intestine. Control patients had normal tissue histology and no history of IBD. UC patients were previously diagnosed with UC and had active disease activity on biopsy, as determined by a boardcertified pathologist.

\section{RNA Isolation and RT-qPCR Analysis}

RNA was extracted from duodenal and colonic tissue immediately after collection using an RNEasy kit per manufacturer's instructions (Qiagen, Valencia, CA). Concentrated RNA was quantified using a Nanodrop 1000 (Thermo, Waltham, MA) and then stored at $-80^{\circ} \mathrm{C}$ until further use. Quantitative reverse transcription polymerase chain reaction (RTqPCR) analysis was performed using a one-step kit (New England Biolabs, Ipswich, MA). The protocol consisted of 10 minutes reverse transcription of RNA (50 ng/well) followed by quantitative PCR using a dsDNA-binding dye. DMT1, FPN1, and phosphoglycerate kinase (PGK; a housekeeping gene) gene specific custom forward and reverse primers (400 $\mathrm{nM}$ primers/well) were designed using the NCBI Primer-BLAST application (Table 1). The $\Delta \Delta \mathrm{Ct}$ method was used to determine fold change of transcripts in reference to PGK. PGK threshold cycles for each gene were subtracted from the threshold cycles of the transcripts of interest to determine the $\Delta \mathrm{Ct}$ value. The average $\Delta \mathrm{Ct}$ 
from the control samples was then subtracted from the $\Delta \mathrm{Ct}$ value of $\mathrm{UC}$ samples to obtain a $\Delta \Delta \mathrm{Ct}$ value. Fold changes for the transcripts of interest were calculated as $2^{-\Delta \Delta \mathrm{Ct}}$.

\section{Protein Isolation and Western Blot Analysis}

Biopsy specimens were placed in $150 \mu \mathrm{L}$ of radioimmunoprecipitation assay (RIPA) buffer containing full protease inhibitor cocktail (cOmplete, Mini, Sigma-Aldrich, St.

Louis, MO). The tissue was homogenized using a glass homogenizer, briefly sonicated, and then centrifuged at $12,500 \mathrm{RPM}$ for 15 minutes. Protein was stored at $-80^{\circ} \mathrm{C}$ until further use. On the day of immunoblotting, protein concentration was determined using the Pierce BCA protein quantification kit (Thermo, Waltham, MA). Samples were diluted to $1 \mu \mathrm{g} / \mu 1$ with deionized water and $4 \mathrm{x}$ Laemmli buffer (Bio-Rad, Hercules, CA) and then heated to $60^{\circ} \mathrm{C}$ for 10 minutes. Bolt 4-12\% Bis-Tris Plus Gels (Thermo, Waltham, MA) were loaded with $20 \mu \mathrm{g} /$ well of protein, run at $135 \mathrm{~V}$, and then transferred to a nitrocellulose membrane for one hour at $30 \mathrm{~V}$. Nitrocellulose membranes were blocked in $3 \% \mathrm{BSA}$ for one hour at room temperature followed by incubation with primary antibody overnight at $4^{\circ} \mathrm{C}$ : FPN1 1:1,000 (Alomone Labs, Jerusalem, Israel), DMT1 1:4,000 (Abcam, Cambridge, UK), $\beta$-actin 1:1,000 (Cell Signaling, Danvers, MA) (12, 27, 41, 49). The next morning, the membranes were washed five times for five minutes in TBST and then placed in goat-anti rabbit horseradish peroxidase-conjugated secondary antibody $(1: 20,000)$ for two hours at room temperature. The membranes were washed again and imaged on a G:Box Chemi XX9 (Syngene, Cambridge, UK). Target proteins were quantified using Image J and normalized to $\beta$-actin using densitometric analysis of band intensity. 


\section{Immunostaining}

Immunohistochemical (IHC) staining was performed on control and UC distal colonic epithelium at the University of Cincinnati. Sectioned tissues were incubated in DMT1 (1:50, Abcam- ab55735, Cambridge, UK) or FPN1 (1:200, Abcam- ab85370) primary antibody for one hour at $37^{\circ} \mathrm{C}$. The tissues were then placed in goat anti-rabbit horseradish-peroxidase conjugated secondary antibody $(1: 1,000)$ for one hour at room temperature. A chromogenic substrate was used for visualization of slides and images were captured on an AxioImager at 40x magnification (Carl Zeiss, Germany).

Immunofluorescence (IF) studies were performed on $15 \mu \mathrm{m}$ sections of distal colonic tissue. Formalin fixed sections hydrated in PBS for 30 minutes were permeabilized with PBS containing $0.1 \%$ triton (PBST) for 15 minutes. Tissue sections were incubated with 5\% goat serum to block nonspecific binding prior to incubation with DMT1 (Abcam, Cambridge, UK) or FPN1 (Alomone Labs, Jerusalem, Israel) primary antibodies (1:500) for 18 hours. Sections were washed with PBS (3x) then incubated in fluorescently labeled secondary antibody (DMT1: goat anti-mouse IgG Alexa Fluor 488, FPN1: goat anti-rabbit IgG Texas Red, 1:1,000, Thermo, Waltham, MA) for 2 hours at room temperature. The sections were washed again with PBS $(3 \mathrm{x})$ and images were captured using a confocal microscope (Zeiss 710, Oberkochen, Germany).

\section{Iron Uptake Studies}

Biopsies from the distal colonic epithelium of control subjects were weighed and incubated in DMEM at $37^{\circ} \mathrm{C}$ for 10 minutes. After this equilibration period, ${ }^{59} \mathrm{Fe}(\mathrm{NEN}$ Radiochemicals PerkinElmer, Waltham, MA) was added to the media for 2, 5, 10, 30, or 60 minutes. The tissue was washed 10x with PBS and whole tissue iron uptake was 
measured using a Tri-Card 4810 TR liquid scintillation analyzer (PerkinElmer, Waltham, MA). Uptake was reported as counts per minute (CPM) per gram (g) of tissue. Analysis

of ${ }^{59} \mathrm{Fe}$ uptake in control tissues revealed linear uptake kinetics between 2 and 10 minutes with saturation of uptake occurring by approximately 30 minutes (Figure $8 \mathrm{~A}$ ). ${ }^{59} \mathrm{Fe}$ uptake in control versus UC distal colonic epithelium was therefore evaluated at two and five minutes, as that corresponded to linear uptake.

\section{Statistics}

GraphPad Prism 6.0 (San Diego, CA) was used for statistical analyses. All results are expressed as means $\pm \mathrm{SE}$. Control and UC groups were compared using a Student's $t$-test. For analyses involving more than two groups, a one-way ANOVA was performed. Significance was determined using $\mathrm{p}<0.05$. 


\section{Results}

\section{Patient Demographics and Disease Status}

Colonic biopsies were taken from 26 control and 25 patients with UC. There was no significant difference in sex (male/female: control 12/14, UC 14/11) or age (control $42.5 \pm 3.7$, UC $50.7 \pm 3.5$ years, $p>0.10$ ) between the groups. Control colons exhibited normal gross morphological appearance on colonoscopy with pink mucosa, visible haustra, and no inflammation (Fig. 1, Top left panel). Histological evaluation revealed intact crypts with no evidence of pathology (Fig. 1, Bottom left panel). UC colons had macroscopically visible inflammation and ulceration (Fig 1; Top right panel) with destruction of crypt architecture and a large influx of inflammatory cells, including neutrophils and macrophages (Fig. 1, Bottom right panel).

Patients with UC had lower levels of $\mathrm{Hb}$ (control $14.81 \pm 0.35$ vs. UC $13.50 \pm$ $0.36, \mathrm{p}<0.05$ ) and Hct (control $43.39 \pm 0.95$ vs. UC $40.23 \pm 0.97, \mathrm{p}<0.05$ ) compared to controls. While most patients did not meet the criteria of anemia, there was a statistically significant reduction in $\mathrm{Hb}$ and Hct, suggesting iron deficiency with sub-clinical anemia.

\section{Localization of DMT1 Along Normal Human Colon Compared to Duodenum}

Animal studies have shown decreasing abundance of DMT1 and FPN1 from duodenum down the gastrointestinal tract to the colon (20). However, characterization of these transporters has not yet been described in humans. We focused our studies first on the apical iron importer, DMT1. Using the duodenum as a frame of reference, we evaluated the relative abundance of DMT1 in each distinct region of control colon (i.e. right colon, transverse colon, left colon, rectum). RT-qPCR analysis revealed that DMT1 specific mRNA abundance in the colon was approximately equal to that in duodenum, 
and that DMT1 transcript abundance was relatively uniform throughout the length of the colon (Fig. 2A: duodenum $1.06 \pm 0.15$, right colon $1.32 \pm 0.30$, transverse colon $0.80 \pm$ 0.16 , left colon $1.16 \pm 0.25$, rectum $1.03 \pm 0.19, \mathrm{n}=6, \mathrm{p}>0.50$ for all multiple comparisons). Similarly, DMT1 protein abundance in the colon was also found to be approximately equal to that in the duodenum and was relatively uniform throughout colonic segments (Fig. 2, B and C: duodenum $1.00 \pm 0.36$, right colon $0.75 \pm 0.10$, transverse colon $1.05 \pm 0.17$, left colon $0.84 \pm 0.17$, rectum $0.89 \pm 0.18 ; n=5, p>0.90$ for all multiple comparisons).

\section{DMT1 Expression in UC Compared to Control Distal Colon}

Once we confirmed the presence and established the localization of DMT1 in healthy human colons, we next sought to determine whether expression is altered in ulcerative colitis. All experiments were conducted in the distal colon, as this region is predominately affected in UC (24). Patients with UC had a two-fold increase in DMT1 mRNA abundance compared to controls (Fig. 3A: control $1.00 \pm 0.05$ vs. UC $2.22 \pm 0.60$, $\mathrm{n}=7$ for control, $\mathrm{n}=5$ for UC, $\mathrm{p}<0.05)$. DMT1 protein abundance was also doubled in

UC tissue (Fig. 3, B and C: control $1.02 \pm 0.23$ vs. UC $1.95 \pm 0.33, \mathrm{n}=5, \mathrm{p}<0.05$ ).

We performed immunohistochemistry (IHC) in order to determine whether the increased transporters were localized to the plasma membrane. DMT1 was diffusely located throughout the membrane in control distal colonocytes and was increased, largely on the apical membrane, in patients with active ulcerative colitis (Fig. 4, A and B). In order to identify the precise membrane specific localization, immunofluorescence (IF) studies were performed. As shown in Fig. 4C, DMT1 was primarily located on the apical and subapical membranes of surface and upper crypt cells in control colon. In UC colon, 
DMT1 expression was increased on the apical membrane of both surface and crypt cells (Fig. 4D).

\section{Localization of FPN1 Along Normal Human Colon Compared to Duodenum}

After examining changes in the iron import protein, DMT1, we next characterized the only known iron exporter, ferroportin. RT-qPCR analysis showed that FPN1 specific mRNA abundance was uniform throughout the length of the colon, although transcript abundance was about one-quarter that of the duodenum (Fig. 5A: duodenum 1.09 \pm 0.18 , right colon $0.34 \pm 0.11$, transverse colon $0.30 \pm 0.10$, left colon $0.32 \pm 0.11$, rectum 0.40 $\pm 0.15, \mathrm{n}=6, \mathrm{p}<0.01$ for multiple comparisons vs. duodenum, $\mathrm{p}>0.98$ for multiple comparisons within the colon). Western blot analysis of FPN1 revealed equal protein expression throughout the length of the colon, and similar to RT-qPCR findings, colonic protein levels were approximately one-quarter that of the duodenum (Fig. 5, B and C: duodenum $1.00 \pm 0.21$, right colon $0.31 \pm 0.05$, transverse colon $0.30 \pm 0.05$, left colon $0.25 \pm 0.05$, rectum $0.36 \pm 0.10, \mathrm{p}<0.05$ vs. duodenum, $\mathrm{n}=5, \mathrm{p}>0.99$ for all other multiple comparisons).

\section{FPN1 Expression in UC Compared to Control Distal Colon}

Patients with UC had a five-fold increase in FPN1 mRNA abundance in distal colonic epithelium compared to controls (Fig. 6A: control $1.07 \pm 0.14$ vs. UC $5.32 \pm$ $0.82, \mathrm{n}=7$ for control, $\mathrm{n}=5$ for $\mathrm{UC}, \mathrm{p}<0.05)$. FPN1 protein abundance in UC tissue was also approximately five times greater than control (Fig. 6, B and C: control 1.01 \pm 0.14 vs. UC $4.9 \pm 0.87, \mathrm{n}=6, \mathrm{p}<0.05)$. IHC showed that FPN1 was minimally expressed in control colon and was increased on the basolateral membrane in UC (Fig. 7, A and B). IF revealed that in control tissue, FPN1 was present on surface cell 
membranes, but similar to DMT1, was expressed to a lesser extent within the crypts (Fig 7C). In UC, FPN1 expression was increased on the basolateral membrane of surface cells and in the crypts (Fig. 7D).

\section{${ }^{59}$ Fe in Control vs. UC Distal Colonic Epithelium}

Finally, we sought to determine whether the increased DMT1 and FPN1 transporter abundance in UC tissue was correlated with increased iron uptake. In vitro

${ }^{59} \mathrm{Fe}$ uptake in control tissue was evaluated at 2, 5, 10, 30, and 60 minutes. Linear uptake occurred from 2 to 10 minutes and began to saturate by 30 minutes (Fig. $8 \mathrm{~A}, \mathrm{n}=6$ at 2 and 5 minutes, $\mathrm{n}=4$ at 10 minutes, $\mathrm{n}=3$ at 30 and 60 minutes). ${ }^{59} \mathrm{Fe}$ uptake into UC tissue was approximately double that of control at two and five minutes (Fig. 8B: control $8,853 \pm 1,547$ vs. UC $19,051 \pm 1,685$ at 2 minutes; control $16,022 \pm 1,431$ vs. UC 30,819 $\pm 2,315$ at 5 minutes, $\mathrm{n}=6$ for control, $\mathrm{n}=7$ for $\mathrm{UC}, \mathrm{p}<0.05)$. 


\section{Discussion}

Though the duodenum is the primary site for iron absorption, the colon is also equipped with the necessary iron transport machinery and is exposed to high levels of dietary iron $(21,30)$. Studies have shown the capacity for the human colon to participate in iron absorption and found that colonic DMT1 expression is approximately equal to that in the duodenum (52). However, a systematic analysis of the expression of these iron transporters through different segments of the colon (i.e. left colon, transverse colon, right colon, rectum) has not yet been reported in the literature.

By obtaining biopsies from patients scheduled for endoscopy or colonoscopy with biopsy, we were able to determine colonic iron transporter abundance in comparison to duodenal levels in control (non-IBD) patients. In line with previous studies, we found that DMT1 mRNA and protein abundance in the colon were approximately equal to that in the duodenum and were relatively uniform throughout the length of the colon (Fig. 2). FPN1 expression was also uniform throughout the colon, but its abundance was only about one-quarter that of the duodenum (Fig. 5). The lower colonic expression of FPN1 may explain why the rate of iron absorption in the colon is less than that of the duodenum. Additionally, it suggests that FPN1-medaited export is likely the ratelimiting step of colonic iron absorption.

Once we characterized expression of DMT1 and FPN1 in control colons, we next wanted to examine the expression of these transporters in patients with active UC because iron deficiency is such a common complication of the disease. Iron transporters are increased in the duodenum of patients with IBD, so we expected increased DMT1 and FPN1 in the colon, as well (44). In support of our hypothesis, we found that DMT1 and 
FPN1 mRNA and protein abundance were increased in the distal colons of patients with active ulcerative colitis (Fig. 3 and 6). DMT1 mRNA and protein levels were doubled, while FPN1 levels were five times greater in UC compared to control. The significant increase in FPN1 to approximately the same abundance as control duodenum suggests that patients with active UC may be able to up-regulate colonic iron absorption to near duodenal levels.

One previous study evaluated the expression of iron transporters in IBD and found that DMT1 was decreased in the inflamed mucosa of active UC, in opposition to our findings (52). Investigators did not specify which part of the colon the biopsies came from nor whether changes were determined in the same segment of the colon for each group, which may explain the discrepancy. Further, changes in protein abundance were not evaluated. By contrast, our group examined both mRNA and protein abundance and only compared control and UC tissue taken from the distal colon in order to maintain consistency.

After establishing that distal colonic DMT1 and FPN1 transporter abundance were increased in UC patient biopsies, we next sought to localize DMT1 and FPN1 within the membrane. IHC staining showed increased apical DMT1 and basolateral FPN1 in UC distal colon. IF was also carried out to allow for better localization of transporters. DMT1 and FPN1 were found on surface cells in control distal colon, but few transporters were located within the crypts. Patients with UC were confirmed to have increased apical DMT1 and basolateral FPN1 on surface cells and increased expression of transporters within the crypts (Figs. 4 and 7). 
Localization of DMT1 and FPN1 to apical and basolateral membranes, respectively, in UC, lends credence to the possibility that these transporters can contribute to iron absorption. To demonstrate this functionality in vitro, we analyzed ${ }^{59} \mathrm{Fe}$ uptake in control versus UC distal colonic epithelium. We first determined the time course for iron uptake in control tissue and then compared uptake in control and UC tissue at two and five minutes, as that corresponded to linear uptake. At both two and five minutes, ${ }^{59} \mathrm{Fe}$ uptake in UC tissue was approximately double that of control, supporting the notion that the increased transporters in UC patients are functional and able to facilitate enhanced iron absorption (Fig. 8).

The mechanism underlying increased colonic expression of iron transporters in UC is likely tied to whole body regulation of iron homeostasis via hepcidin, the main iron regulatory hormone that is produced in the liver in response to high iron levels and inflammation $(14,15,23,50)$. Hepcidin leads to the internalization and degradation of FPN1, thereby inhibiting iron absorption in the intestine and preventing the release of iron from hepatocytes and macrophages in times of iron overload $(11,37)$. Iron deficiency is also a key regulator of hepcidin production. When serum iron is low, soluble hemojuvelin binds to and inhibits the bone morphogenetic protein (BMP)/SMAD pathway of hepcidin synthesis (13). Additionally, impaired erythropoietic activity, as seen in anemia, down-regulates hepcidin mRNA abundance $(25,34)$.

Although we did not measure hepcidin levels, we can infer that circulating hepcidin is reduced in the patients with ulcerative colitis. UC patients had lower levels of $\mathrm{Hb}$ and Hct compared to controls, indicating subclinical anemia, which would lessen hepcidin production via the pathways described above. In fact, hepcidin has been shown 
to be reduced in patients with IBD, demonstrating that iron deficiency is the key regulator of hepcidin production regardless of inflammatory status (31). We therefore predict that the enhanced colonic iron absorption in patients with UC is the result of reduced hepcidin levels leading to increased expression of FPN1. FPN1-mediated export is likely the ratelimiting step of colonic iron absorption, so maximizing FPN1 expression is the key to enhancing iron absorption in the colon.

The functional significance of increased colonic iron absorption in patients with active UC is that the colon could help alleviate iron deficiency. Under normal physiological conditions, the colon may play only a small role in iron absorption, however, in the times of deficiency, colonic iron absorption may increase to near duodenal levels.

The enhanced colonic absorptive capacity in patients with active UC suggests that they are prime candidates for oral iron supplementation. In general, some physicians have shied away from prescribing oral iron to patients with $\mathrm{UC}$, as there is evidence to suggest that it may exacerbate disease activity $(29,46)$. However, recent findings reveal no difference in gastrointestinal symptoms following oral iron supplementation compared to intravenous (IV) administration in IBD patients $(26,38)$. Oral iron remains the preferred treatment for iron deficiency anemia because of its safety, efficacy, and convenience. Increased colonic iron absorption in UC, as the data from this study suggests, provides support for the use of oral iron supplementation as the first line treatment of iron deficiency anemia in patients with ulcerative colitis.

In conclusion, non-heme iron transporters DMT1 and FPN1 are abundantly expressed in human colon and are increased in patients with active UC. These findings 
suggest that the colon plays a more significant role in iron absorption than previously thought and that colonic iron absorption may become particularly important in times of deficiency. Perhaps the colon can even be targeted for iron absorption as a novel treatment for iron deficiency anemia. 


\section{References}

1. Abbaspour N, Hurrell R, Kelishadi R. Review on iron and its importance for human health. J Res Med Sci 19: 164-74, 2014.

2. Alves RA, Miszputen SJ, Figueiredo MS. Anemia in inflammatory bowel disease: prevalence, differential diagnosis and association with clinical and laboratory variables. Sao Paulo Med J 132: 140-6, 2014.

3. Atuğ Ö, Kani HT, Banzragch M, İmeryüz N, Akın H. Incidence rate of anemia in inflammatory bowel diseases. Turk J Gastroenterol 27: 143-8, 2016.

4. Bermejo F, García-López S. A guide to diagnosis of iron deficiency and iron deficiency anemia in digestive diseases. World J Gastroenterol 15: 4638-43, 2009.

5. Blachier F, Vaugelade P, Robert V, Kibangou B, Canonne-Hergaux F, Delpal S, Bureau F, Blottière H, Bouglé $\mathbf{D}$. Comparative capacities of the pig colon and duodenum for luminal iron absorption. Can J Physiol Pharmacol 85: 185-92, 2007.

6. Bouglé D, Vaghefi-Vaezzadeh N, Roland N, Bouvard G, Arhan P, Bureau F, Neuville D, Maubois JL. Influence of short-chain fatty acids on iron absorption by proximal colon. Scand J Gastroenterol 37: 1008-11, 2002.

7. Chaubal A, Pandey V, Choksi D, Poddar P, Ingle M, Phadke A, Sawant P. Anemia in patients with ulcerative colitis in remission: A study from western India. Indian J Gastroenterol 36: 361-365, 2017.

8. Collins P, Rhodes J. Ulcerative colitis: diagnosis and management. BMJ 333: 340-3, 2006.

9. Conrad K, Roggenbuck D, Laass MW. Diagnosis and classification of ulcerative 
colitis. Autoimmun Rev 13: 463-6, 2014.

10. Conrad ME, Umbreit JN. Pathways of iron absorption. Blood Cells Mol Dis 29: $336-55,2000$.

11. De Domenico I, Ward DM, Langelier C, Vaughn MB, Nemeth E, Sundquist WI, Ganz T, Musci G, Kaplan J. The molecular mechanism of hepcidinmediated ferroportin down-regulation. Mol Biol Cell 18: 2569-78, 2007.

12. Donovan A, Lima CA, Pinkus JL, Pinkus GS, Zon LI, Robine S, Andrews NC. The iron exporter ferroportin/Slc40a1 is essential for iron homeostasis. Cell Metab 1: 191-200, 2005.

13. Fleming MD. The regulation of hepcidin and its effects on systemic and cellular iron metabolism. Hematol. Am. Soc. Hematol. Educ. Progr. (2008). doi: 10.1182/asheducation-2008.1.151.

14. Ganz T. Hepcidin, a key regulator of iron metabolism and mediator of anemia of inflammation. Blood 102: 783-788, 2003.

15. Ganz T, Nemeth E. Hepcidin and iron homeostasis. Biochim Biophys Acta 1823: 1434-43, 2012.

16. Garud S, Peppercorn MA. Review: Ulcerative colitis: current treatment strategies and future prospects. Therap Adv Gastroenterol 2: 99-108, 2009.

17. Guagnozzi D, Lucendo AJ. Anemia in inflammatory bowel disease: a neglected issue with relevant effects. World J Gastroenterol 20: 3542-51, 2014.

18. Gunshin H, Mackenzie B, Berger U V, Gunshin Y, Romero MF, Boron WF, Nussberger S, Gollan JL, Hediger MA. Cloning and characterization of a mammalian proton-coupled metal-ion transporter. Nature 388: 482-8, 1997. 
19. Halling ML, Kjeldsen J, Knudsen T, Nielsen J, Hansen LK. Patients with inflammatory bowel disease have increased risk of autoimmune and inflammatory diseases. World J Gastroenterol 23: 6137-6146, 2017.

20. Hubert N, Hentze MW. Previously uncharacterized isoforms of divalent metal transporter (DMT)-1: Implications for regulation and cellular function. Proc Natl Acad Sci 99: 12345-12350, 2002.

21. Jacobs A. Haemopoietic factors Iron absorption. J clin PathRoy Coll Path) 24: $55-59,1971$.

22. Khan N, Patel D, Shah Y, Yang Y-X. Factors Predicting Testing and Treatment of Iron Deficiency in a Nationwide Cohort of Anemic UC Patients. Inflamm Bowel Dis 22: 2894-2901, 2016.

23. Knutson MD. Iron-sensing proteins that regulate hepcidin and enteric iron absorption. Annu Rev Nutr 30: 149-71, 2010.

24. Koutroubakis IE. Recent advances in the management of distal ulcerative colitis. World J Gastrointest Pharmacol Ther 1: 43-50, 2010.

25. Kwapisz J, Slomka A, Zekanowska E. Hepcidin and Its Role in Iron Homeostasis. EJIFCC 20: 124-8, 2009.

26. Lee T, Clavel T, Smirnov K, Schmidt A, Lagkouvardos I, Walker A, Lucio M, Michalke B, Schmitt-Kopplin P, Fedorak R, Haller D. Oral versus intravenous iron replacement therapy distinctly alters the gut microbiota and metabolome in patients with IBD. Gut 66: 863-871, 2017.

27. Li H, Jiang S, Yang C, Yang S, He B, Ma W, Zhao R. Long-Term Dexamethasone Exposure Down-Regulates Hepatic TFR1 and Reduces Liver Iron 
Concentration in Rats. Nutrients 9, 2017.

28. Lieu PT, Heiskala M, Peterson PA, Yang Y. The roles of iron in health and disease. Mol Aspects Med 22: 1-87, 2001.

29. Maghsudlu M, Nasizadeh S, Toogeh GR, Zandieh T, Parandoush S, Rezayani M. Short-term ferrous sulfate supplementation in female blood donors. Transfusion 48: 1192-1197, 2008.

30. Marciano R, Santamarina AB, de Santana AA, Silva M de LC, Amancio OMS, do Nascimento CM da PO, Oyama LM, de Morais MB. Effects of prebiotic supplementation on the expression of proteins regulating iron absorption in anaemic growing rats. Br J Nutr 113: 901-908, 2015.

31. Mecklenburg I, Reznik D, Fasler-Kan E, Drewe J, Beglinger C, Hruz P, Swiss IBD Cohort Study Group. Serum hepcidin concentrations correlate with ferritin in patients with inflammatory bowel disease. J Crohns Colitis 8: 1392-7, 2014.

32. Monstad I, Hovde O, Solberg IC, A Moum B. Clinical course and prognosis in ulcerative colitis: results from population-based and observational studies. Ann Gastroenterol 27: 95-104, 2014.

33. Muñoz M, Villar I, García-Erce JA. An update on iron physiology. World $J$ Gastroenterol 15: 4617-26, 2009.

34. Nicolas G, Chauvet C, Viatte L, Danan JL, Bigard X, Devaux I, Beaumont C, Kahn A, Vaulont S. The gene encoding the iron regulatory peptide hepcidin is regulated by anemia, hypoxia, and inflammation. $J$ Clin Invest 110: 1037-44, 2002.

35. OHKAWARA Y, BAMBA M, NAKAI I, KINKA S, MASUDA M. The 
absorption of iron from the human large intestine. Gastroenterology 44: 611-4, 1963.

36. Patel D, Trivedi C, Khan N. Management of Anemia in Patients with Inflammatory Bowel Disease (IBD). Curr Treat Options Gastroenterol 16: 112$128,2018$.

37. Ramey G, Deschemin J-C, Durel B, Canonne-Hergaux F, Nicolas G, Vaulont S. Hepcidin targets ferroportin for degradation in hepatocytes. Haematologica 95: $501-4,2010$.

38. Rizvi S, Schoen RE. Supplementation with oral vs. intravenous iron for anemia with IBD or gastrointestinal bleeding: is oral iron getting a bad rap? Am J Gastroenterol 106: 1872-9, 2011.

39. Rogler G, Vavricka S. Anemia in inflammatory bowel disease: an underestimated problem? Front Med 1: 58, 2014.

40. Sankaran VG, Weiss MJ. Anemia: progress in molecular mechanisms and therapies. Nat Med 21: 221-30, 2015.

41. Sato M, Miyanishi K, Tanaka S, Sakurada A, Sakamoto H, Kawano Y, Takada K, Kobune M, Kato J. Increased Duodenal Iron Absorption through Upregulation of Ferroportin 1 due to the Decrement in Serum Hepcidin in Patients with Chronic Hepatitis C. Can J Gastroenterol Hepatol 2018: 2154361, 2018.

42. Silva B, Faustino P. An overview of molecular basis of iron metabolism regulation and the associated pathologies. Biochim Biophys Acta - Mol Basis Dis 1852: 1347-1359, 2015.

43. Soppi ET. Iron deficiency without anemia - a clinical challenge. Clin case reports 
6: 1082-1086, 2018

44. Sukumaran A, James J, Janardhan HP, Amaladas A, Suresh LM, Danda D, Jeyeseelan V, Ramakrishna BS, Jacob M. Expression of iron-related proteins in the duodenum is up-regulated in patients with chronic inflammatory disorders. $\mathrm{Br}$ J Nutr 111: 1059-68, 2014.

45. Takeuchi K, Bjarnason I, Laftah AH, Latunde-Dada GO, Simpson RJ, McKie AT. Expression of iron absorption genes in mouse large intestine. Scand $J$ Gastroenterol 40: 169-77, 2005.

46. Tolkien Z, Stecher L, Mander AP, Pereira DIA, Powell JJ. Ferrous sulfate supplementation causes significant gastrointestinal side-effects in adults: A systematic review and meta-analysis. PLoS One 10: 1-20, 2015.

47. Waljee AK, Joyce JC, Wren PA, Khan TM, Higgins PDR. Patient reported symptoms during an ulcerative colitis flare: a Qualitative Focus Group Study. Eur J Gastroenterol Hepatol 21: 558-64, 2009.

48. Wallace DF. The Regulation of Iron Absorption and Homeostasis. Clin Biochem Rev 37: 51-62, 2016.

49. Wallace DF, Harris JM, Subramaniam VN. Functional analysis and theoretical modeling of ferroportin reveals clustering of mutations according to phenotype. Am J Physiol Cell Physiol 298: C75-84, 2010.

50. Wang C-Y, Babitt JL. Liver iron sensing and body iron homeostasis. Blood 133: 18-29, 2019.

51. Ward DM, Kaplan J. Ferroportin-mediated iron transport: expression and regulation. Biochim Biophys Acta 1823: 1426-33, 2012. 
52. Wu W, Song Y, He C, Liu C, Wu R, Fang L, Cong Y, Miao Y, Liu Z. Divalent metal-ion transporter 1 is decreased in intestinal epithelial cells and contributes to the anemia in inflammatory bowel disease. Sci Rep 5: 16344, 2015. 


\section{Figure Captions}

Figure 1: Morphological and histological analyses of control and ulcerative colitis (UC) human colons. Images of control (top left panel) and UC (top right panel) colons were captured during colonscopy. Control colons exhibited pink mucosa with no signs of inflammation, while UC colons had visible inflammation and ulceration. Hematoxylin and eosin (H\&E) staining of control (bottom left panel) and UC (bottom right panel) colonic biopsy specimens. Control colons contained highly organized crypts, while UC colons exhibited destruction of crypt architecture, crypt abscesses, and numerous inflammatory cells (neutrophils and macrophages). Typical images presented represent data acquired from 6 different control and UC patients.

Figure 2: Divalent metal transporter 1 (DMT1) mRNA abundance and protein expression in control human colon segments with respect to duodenum. [A] RT-qPCR analysis revealed that DMT1 mRNA abundance throughout the colon was approximately equal to that in the duodenum $(\mathrm{n}=6, \mathrm{p}>0.50$ for all multiple comparisons). [B] Western blot analysis of FPN1 in epithelial cell homogenates from duodenum and colon. Western blots were quantified via densitometry and normalized to $\beta$-actin. [C] Quantitative analyses indicated that the relative protein abundance of DMT1 in colon segments was not significantly different from that in the duodenum $(n=5, p>0.90$ for all multiple comparisons). Duodenal DMT1 protein expression was quite variable between patients.

Figure 3: Increased divalent metal transporter 1 (DMT1) mRNA abundance and protein expression in ulcerative colitis (UC) distal colon. [A]: RT-qPCR analysis revealed a two- 
fold increase in DMT1 mRNA abundance in UC tissue compared to control (control $\mathrm{n}=$ 7, $\mathrm{UC} \mathrm{n}=5, \mathrm{p}<0.05)$. [B]: Representative images of western blots for DMT1 and $\beta$-actin in control and UC tissue. [C]: Quantitative analyses of DMT1, normalized to $\beta$-actin, showed that DMT1 protein abundance in UC patients was approximately double that of controls $(\mathrm{n}=5, \mathrm{p}<0.05){ }^{*} \mathrm{p}<0.05$ compared to control.

Figure 4: Cell and membrane specific localization of divalent metal transporter 1 (DMT1) in control and ulcerative colitis (UC) human distal colon. [A] Immunohistochemical (IHC) staining revealed that DMT1 was diffusely present on the apical membrane of control tissue (arrows). [B] DMT1 was increased, largely on the apical membrane, in UC colon (arrows). [C] Immunofluorescence (IF) studies demonstrated that in control colons, DMT1 (green) was present primarily on the surface cells and upper crypt cells (bracket). [D] In UC colon, DMT1 staining was increased on the apical membrane of surface cells (arrows) and within the crypts (asterisk). Cell nuclei were localized with blue staining Hoeschst33342. Similar images were obtained from three different control and UC colon specimens for each staining method. IHC images were captured at 40x magnification. Scale bars in IF images represent $50 \mu \mathrm{m}$.

Figure 5: Ferroportin 1 (FPN1) mRNA abundance and protein expression in control human colon segments with respect to duodenum. [A] RT-qPCR analysis revealed that FPN1 mRNA abundance in the colon was reduced compared to the duodenum, but did not significantly differ throughout the length of the colon $(n=6, p<0.01$ for multiple comparisons vs. duodenum, $\mathrm{p}>0.98$ for multiple comparisons within the large intestine). 
[B] Western blot analysis of FPN1 in epithelial cell homogenates from duodenum and colon. Western blots were quantified via densitometry and normalized to $\beta$-actin. [C] Quantitative analyses showed that FPN1 abundance in the colon was about one-quarter that of the duodenum, but its abundance did not significantly differ within the colon ( $\mathrm{n}=$ 5, $\mathrm{p}<0.05$ vs. duodenum, $\mathrm{p}>0.99$ for all other multiple comparisons). ${ }^{*} \mathrm{p}<0.05$ compared to duodenum.

Figure 6: Increased ferroportin 1 (FPN1) mRNA abundance and protein expression in ulcerative colitis (UC) distal colon. [A] RT-qPCR analysis revealed a 5-fold increase in FPN1 mRNA abundance in UC tissue compared to control (control $n=5, \mathrm{UC} n=7, \mathrm{p}<$ 0.05). [B] Western blot analysis of FPN1, normalized to $\beta$-actin, in control and UC distal colonic epithelium. [C] Quantitative analyses of western blots revealed that FPN1 protein abundance in UC tissue was five times greater than control $(n=6, p<0.05) . * p<0.05$ compared to control.

Figure 7: Cell and membrane specific localization of ferroportin 1 (FPN1) in control and ulcerative colitis (UC) distal colon. [A] Immunohistochemical (IHC) staining revealed that FPN1 was minimally present on the basolateral membrane of control colon (arrows). [B] FPN1 expression was increased, largely on the basolateral membrane, of UC colon (arrows). There were also more immune cells in the lamina propria (asterisk). [C] Immunofluorescence (IF) studies revealed that FPN1 (red) was present primarily on surface cells and upper crypt cells (bracket). [D] In UC, FPN1 was increased on both the basal (arrows) and lateral (arrow heads) membranes of surface cells. FPN1 staining was 
also substantially increased on the basolateral membrane of crypt cells (asterisk). Cell nuclei were localized with blue staining Hoeschst33342. Similar images were obtained from three different control and UC colon specimens for each staining method. IHC images were captured at 40x magnification. Scale bars in IF images represent $50 \mu \mathrm{m}$.

Figure 8: Increased ${ }^{59} \mathrm{Fe}$ uptake in UC distal colonic epithelium. [A] Time course of ${ }^{59} \mathrm{Fe}$ uptake in control tissue expressed as counts per minute (CPM) per gram (g) of tissue. Linear uptake occurred between 2 and 10 minutes and became saturated by 30 minutes ( $\mathrm{n}$ $=3-6$ for each time point). $[\mathbf{B}]{ }^{59} \mathrm{Fe}$ uptake in $\mathrm{UC}$ tissue was approximately double that of control at 2 and 5 minutes $(n=6-7, p<0.005) .{ }^{*} p<0.05$ compared to control. 


\section{Tables}

Table 1: Divalent metal transporter 1 (DMT1), ferroportin 1 (FPN1), and phosphoglycerate kinase 1 (PGK1) gene specific primers

\begin{tabular}{|l|l|c|c|}
\hline \multirow{2}{*}{$\begin{array}{l}\text { Gene } \\
\text { DMT1 }\end{array}$} & Primers (Forward and Reverse) & Product length (bp) & Melting Temp $\left({ }^{\circ} \mathrm{C}\right)$ \\
\hline \multirow{2}{*}{$\begin{array}{l}\text { FPN1 } \\
\text { NM_014585.5 }\end{array}$} & F: CTCCCGGAATATGGAGCCC & \multirow{2}{*}{126} & F: 59.32 \\
\cline { 2 - 2 } $\begin{array}{l}\text { PGK1 } \\
\text { NM_000291.4 }\end{array}$ & F: ATCTTCTGTTCAGGACCCAGC & & R: 59.72 \\
\cline { 2 - 2 } & F: CAGTCACCGATGATGCTTGGGGAGATCGG & \multirow{2}{*}{147} & F: 60.16 \\
\cline { 2 - 2 } & R: GCTCGGCTTTAACCTTGTTCC & \multirow{2}{*}{137} & R: 60.53 \\
\cline { 2 - 2 }
\end{tabular}

Human DMT1, FPN1, and PGK1 gene specific forward (F) and reverse (R) primers were designed based on mRNA sequences obtained from the NCBI primer-blast application. 
Figures

Figure 1

\section{Control}
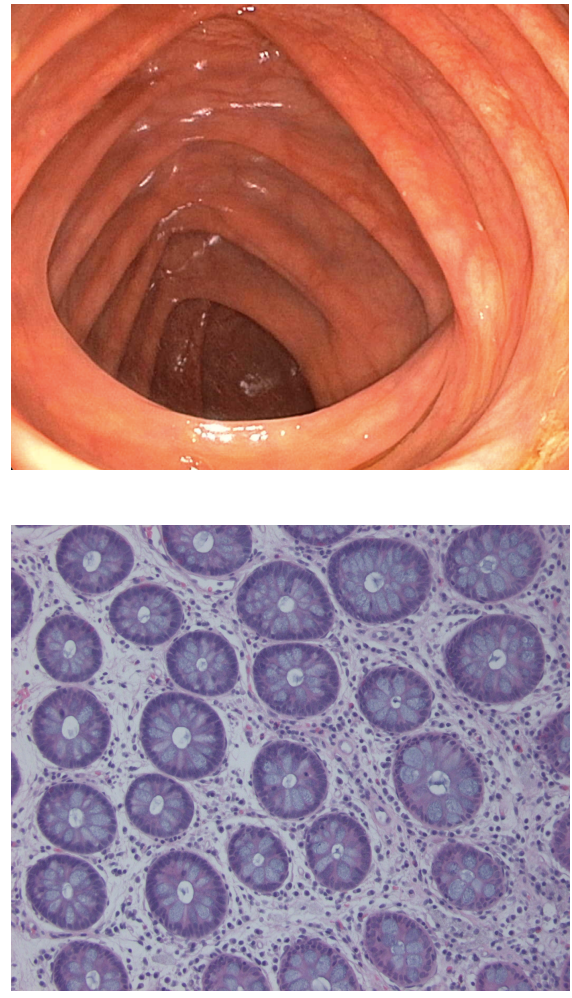

UC
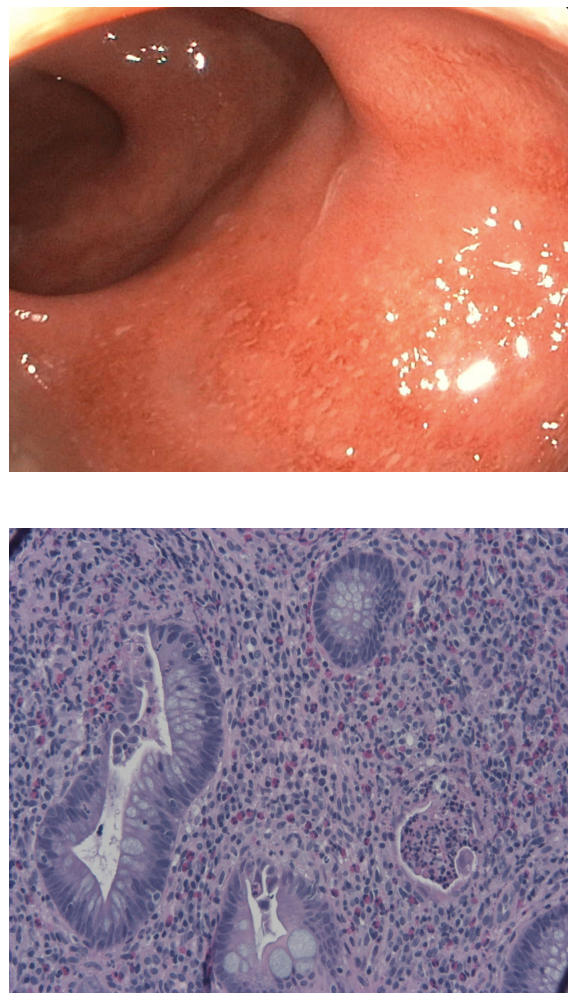
Figure 2
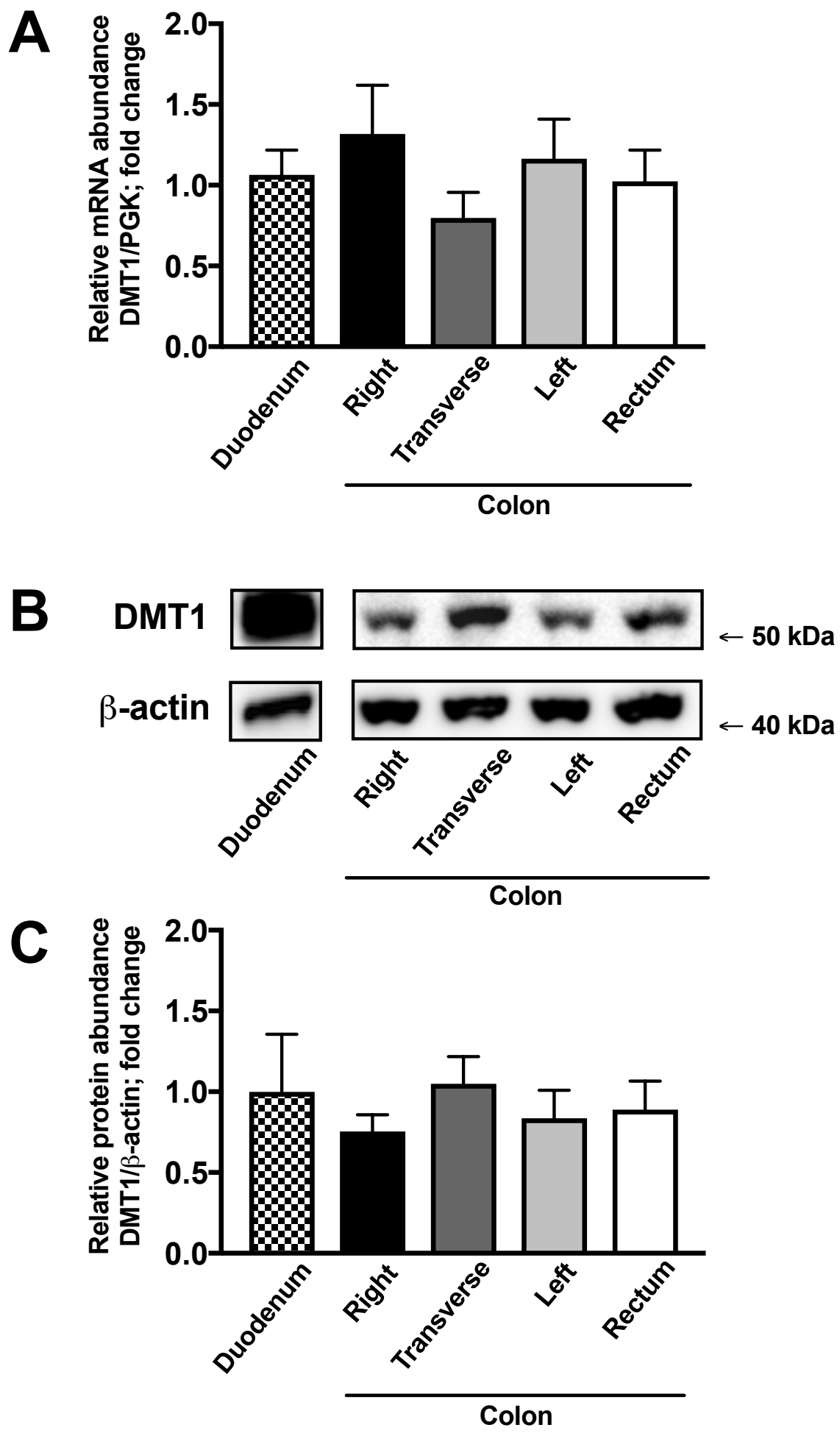
Figure 3
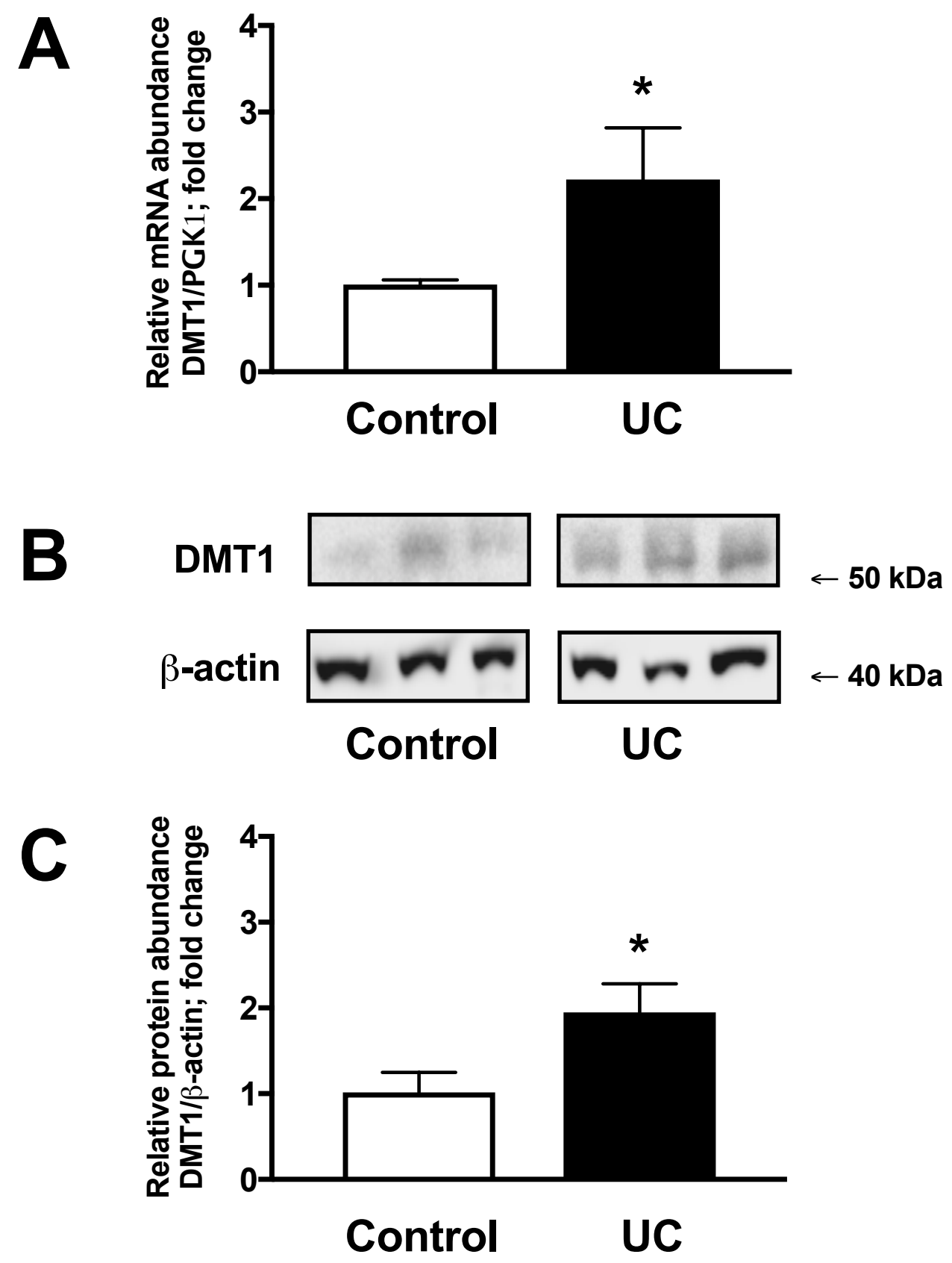
Figure 4

\section{Control}

A

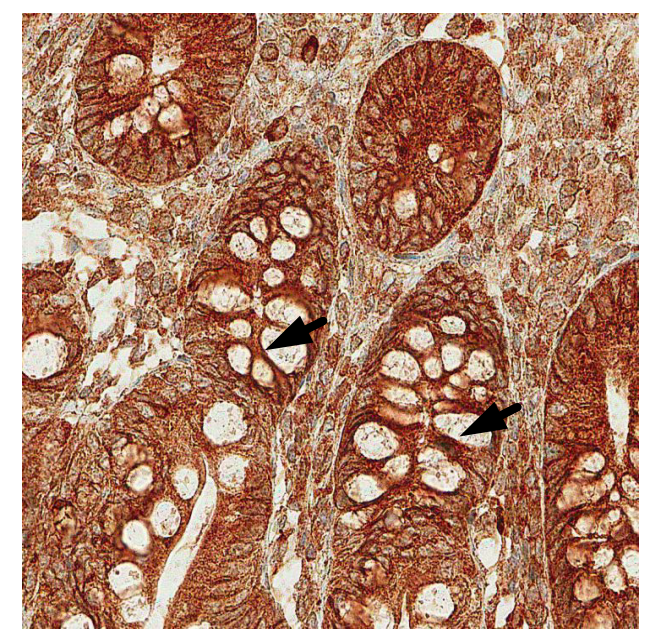

C

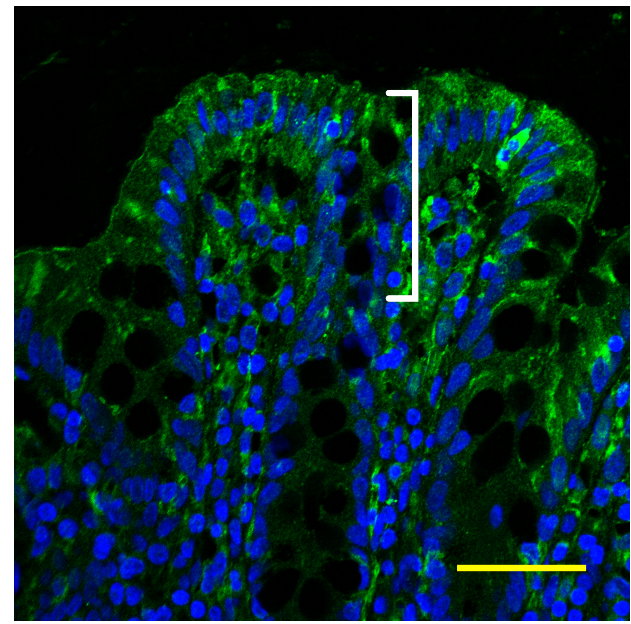

UC

B

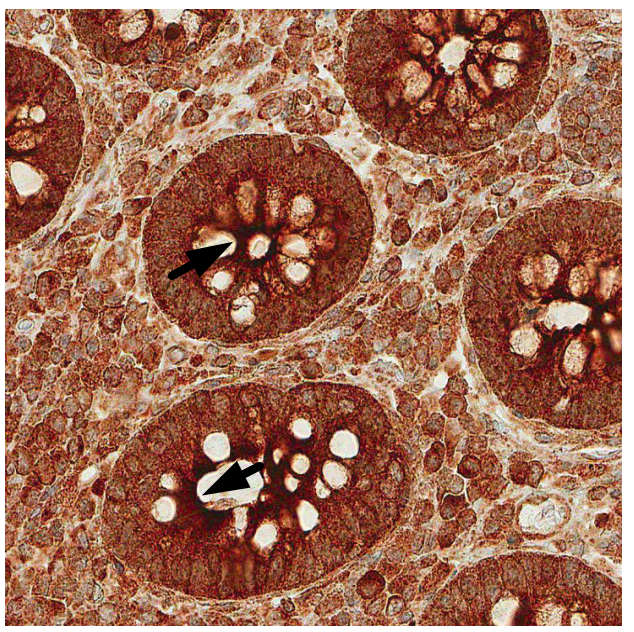

D

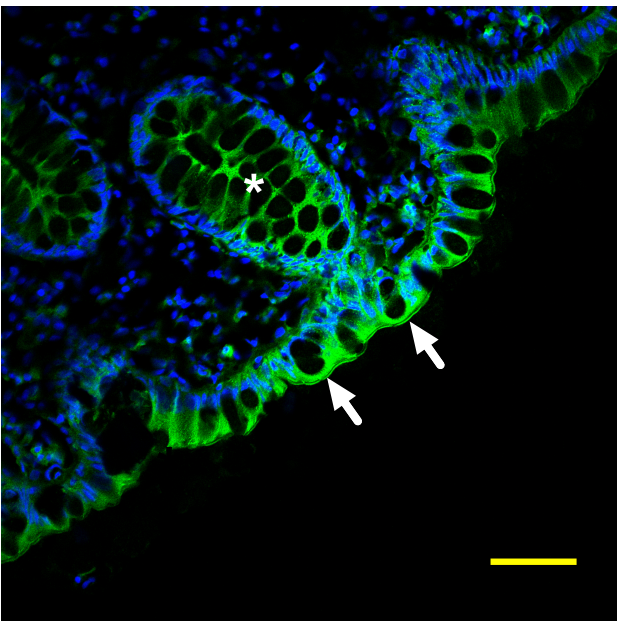


Figure 5

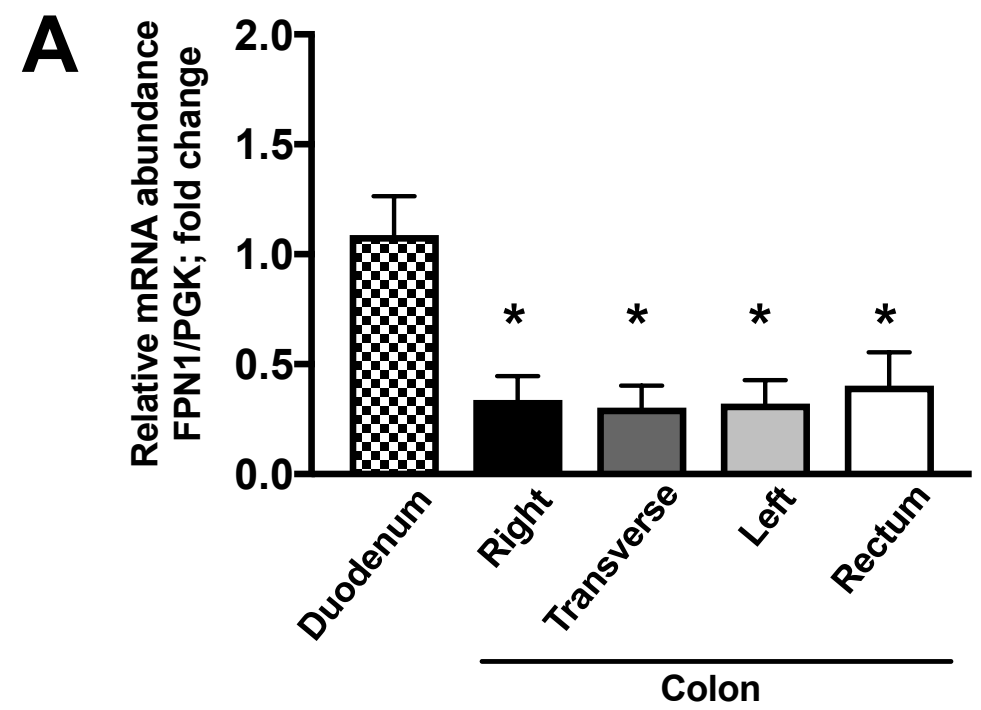

B FPN1 $\square \leftarrow 70 \mathrm{kDa}$
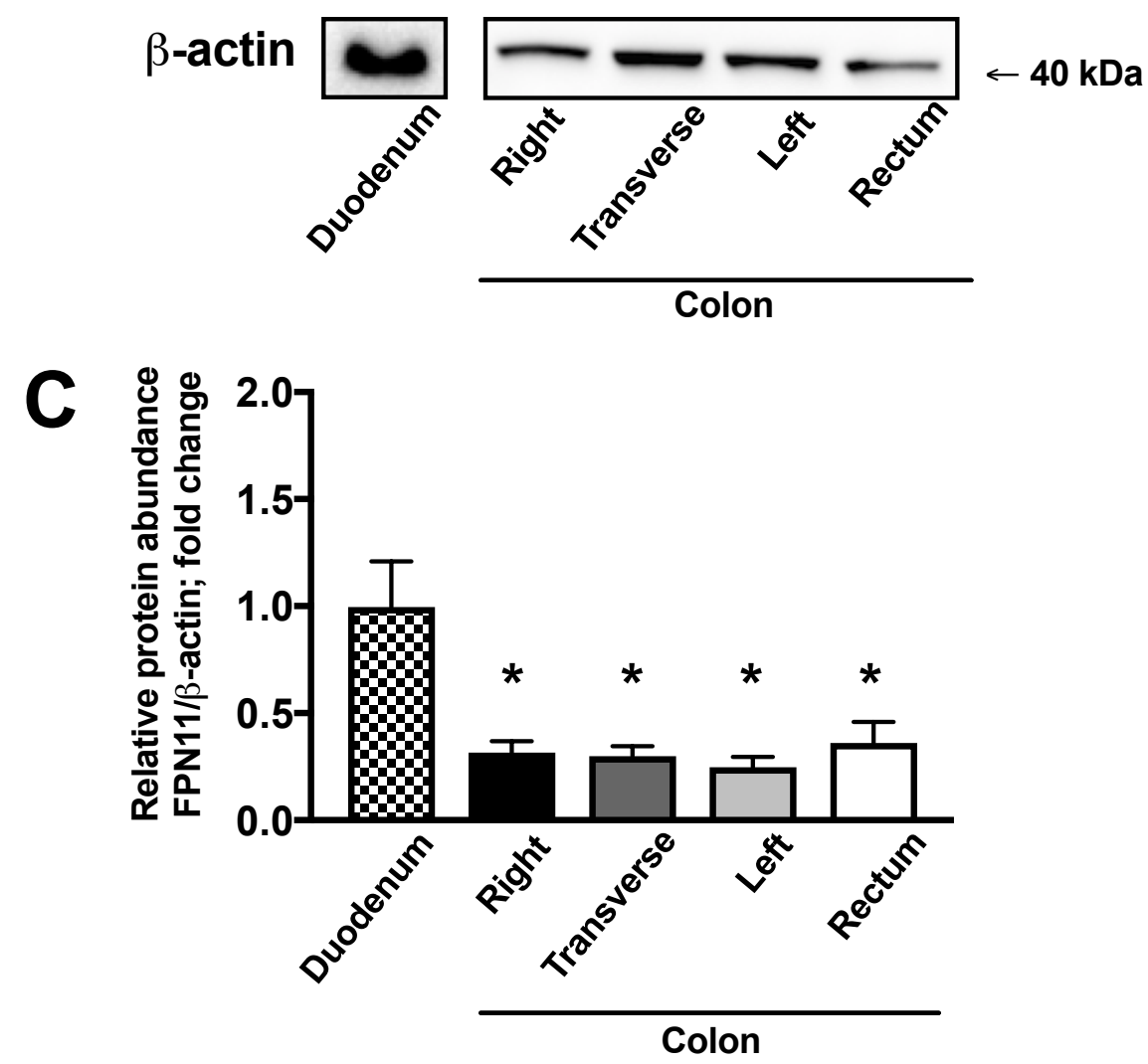
Figure 6
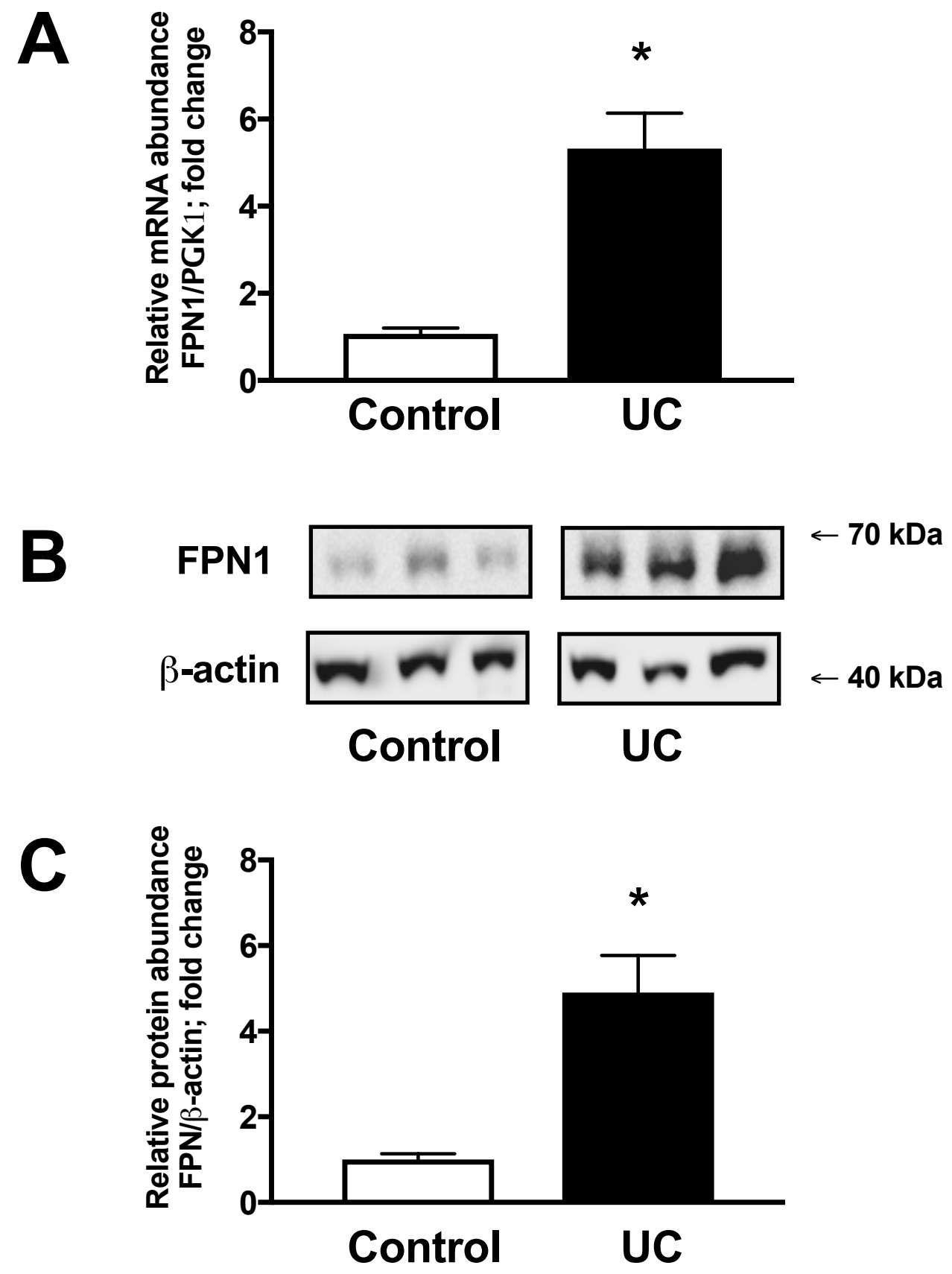
Figure 7

\section{Control}
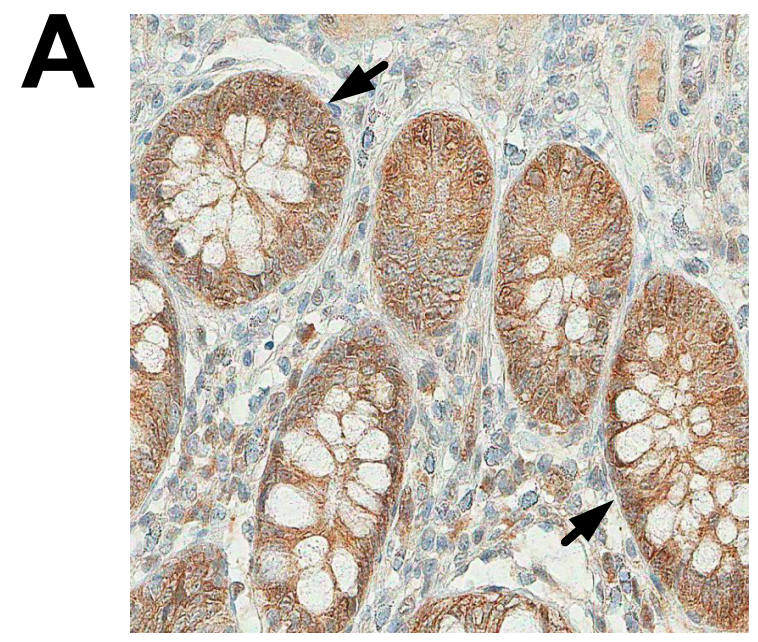

C

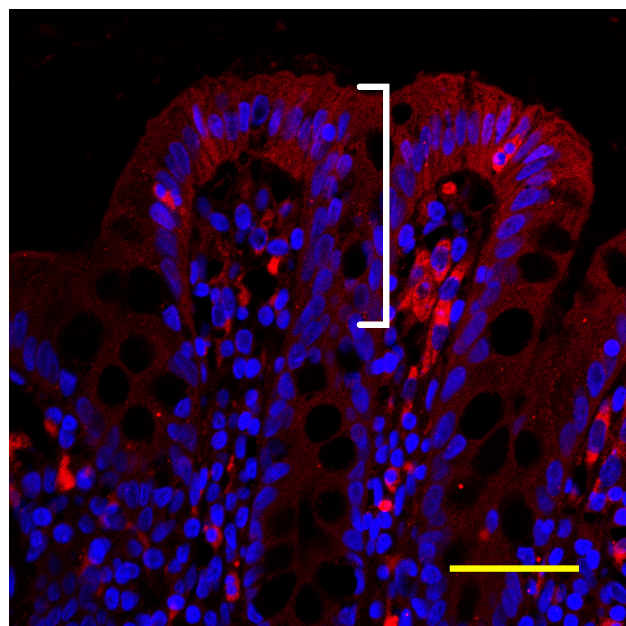

\section{UC}
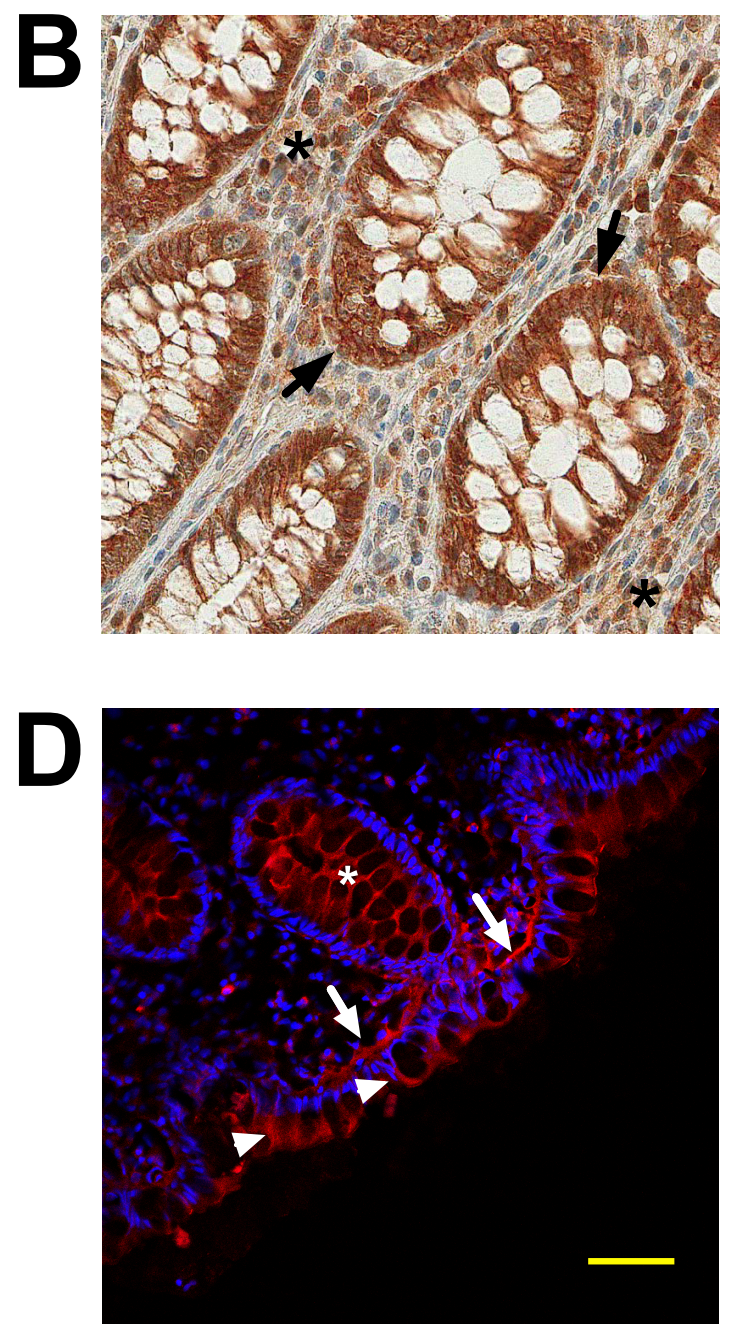
Figure 8
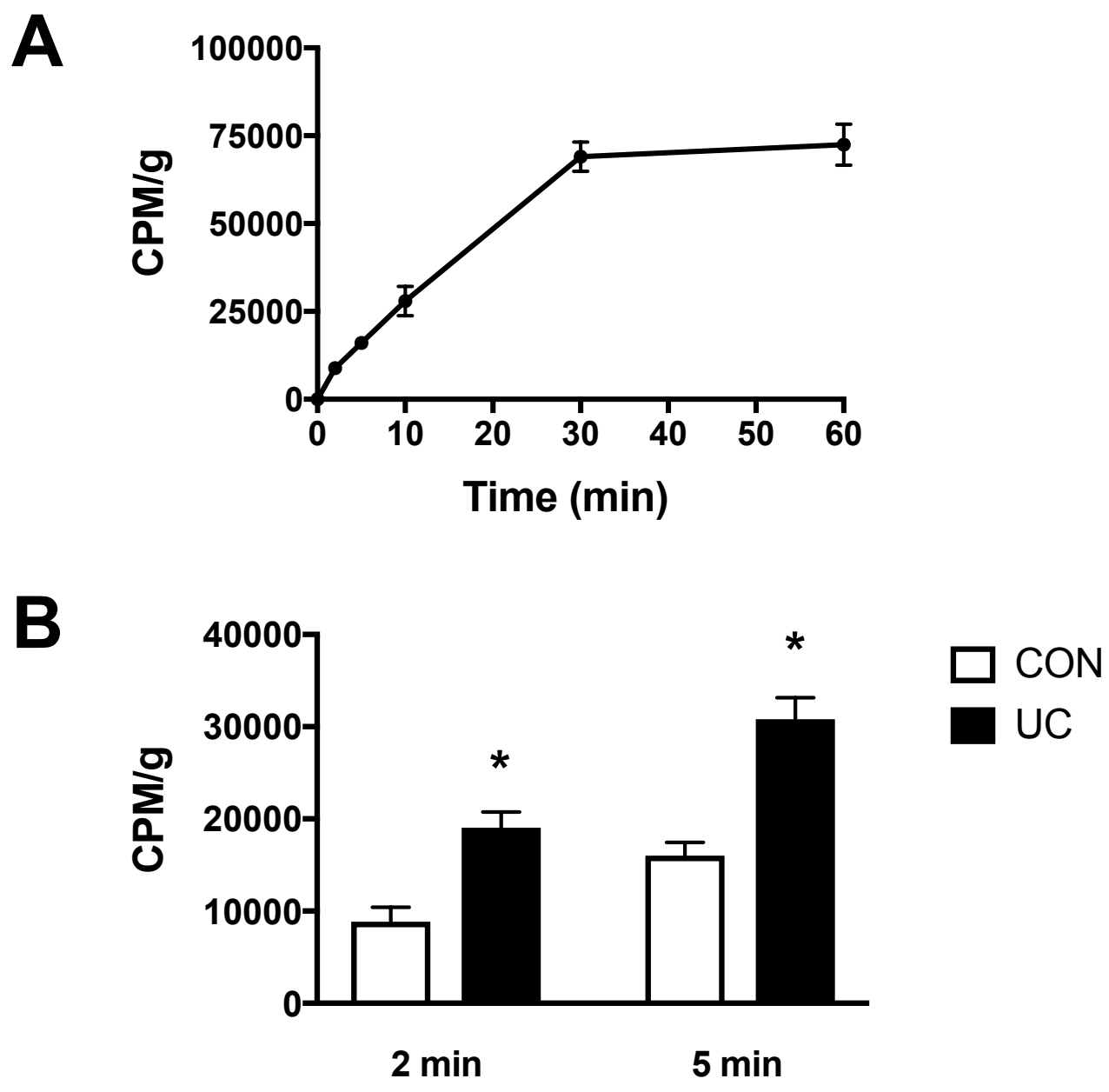


\section{Section C}

Oral iron supplementation exacerbates dextran sulfate sodium (DSS)-induced colitis and leads to pathogenic changes in the microbiome 


\section{Background}

\section{Animal Models of Colitis}

There are a variety of inflammatory bowel disease (IBD) animals models: chemically induced colitis, cell transfer, and genetically engineered knockouts (16). Chemical induction is achieved by administering trinitrobenzene sulfonic acid (TNBS) rectally or dextran sulfate sodium (DSS) in the drinking water (24). TNBS activates nucleotide-binding oligomerization domain-containing protein 2 (NOD2) and best recapitulates Crohn's disease, while DSS better recapitulates ulcerative colitis (UC) (2, 5). Cell transfer models involve the intraperitoneal injection of $\mathrm{CD}^{+} \mathrm{T}$ cells isolated via flow cytometry (16). Finally, genetically engineered models have been created by knocking out various IBD-associated genes including interleukin-10 (IL-10), signal transducer and activator of transcription 3 (STAT3), and human leukocyte antigen B27 (HLA-B27), among others (17).

We chose to use DSS in our study because it is a inexpensive, quick, and effective method to reproducibly induce an ulcerative-like phenotype in mice (5). Another benefit of DSS is that you can easily control the extent of colitis based on the concentration and duration of exposure. The molecular weight of DSS is an important factor in colitis induction, with the most severe colitis resulting from $40 \mathrm{kDa}$ DSS. We therefore used the 36-50 $\mathrm{kDa}$ formulation of DSS for this study, which was administered in the drinking water for six days, followed by one day of recovery.

Mouse strain also has an impact on DSS colitis induction. BALB/c mice were selected because they mount a predominantly T helper cell 2 (Th2)-type immune response, which is most similar to human ulcerative colitis (26). 


\section{Oral Iron Supplementation in Ulcerative Colitis}

As detailed previously, iron deficiency anemia (IDA) is a frequent complication of ulcerative colitis. Up to $70 \%$ of UC patients develop anemia within the first 10 years after diagnosis (12). Oral iron supplementation is the first line treatment for IDA, but this can be problematic because oral iron is associated with gastrointestinal side effects and may exacerbate disease activity in UC (7). Other groups, however, have found no association between oral iron and increased disease activity $(1,8)$. Additional research is needed to determine the safety of prescribing oral iron supplementation to patients with ulcerative colitis, as well as potential causal mechanisms between iron and disease exacerbation.

\section{Microbiome in Healthy Adults}

The microbiome is composed of $10^{14}$ resident microorganisms (bacteria, fungi, viruses, and protozoa) (23). Bacteria found in healthy adults come from four main phyla: Firmicutes, Bacteriodetes, Proteobacteria, and Actinobacteria (6). The Firmicutes are gram-positive and made up of two main classes: bacillales and clostridia (95\%) (22). Bacteriodetes are gram-negative and comprise the majority of the bacteria in the gut of most individuals (25). Actinobacteria are gram-positive and include Streptomyces, actinomyces, proprionobacteria, corynebacteria, among others (3). Finally, Proteobacteria are divided into alpha, beta, gamma, delta, and epsilon groups and include a lot of pathogenic bacteria, such as E. coli, pseudomonas, and Neisseria (21). 


\section{Microbiome in Ulcerative Colitis}

Profound differences in microbial composition and diversity have been found in patients with ulcerative colitis compared to their healthy counterparts, but there is much debate about whether microbial dysbiosis is a primary causal instigator of intestinal inflammation or whether inflammation is the driving force that causes shifts in the microbiome $(9,15)$. Recent evidence suggests that both likely occur with the microbiome of UC patients characterized by increased pathogenic bacteria and decreased species richness (14). Specifically, a reduction in Firmicutes and increase in Bacteriodetes and facultative anaerobes is known to occur (10).

The reduction in Firmicutes bacteria is particularly detrimental because this phylum contains an extremely important group of microbes known as butyrate-producing bacteria (BPB). Butyrate is the primary energy source for colonocytes, suppresses inflammation, and increases mucin production, so adequate production is necessary (4). Patients with UC experience a reduction in butyrate producers leading to decreased butyrate levels, uptake, and oxidation (19). Most BPB are members of clostridial cluster IV or XIVa (20).

\section{Effect of Iron Supplementation on the Microbiome}

Ulcerative colitis has a negative impact on microbiome composition, as does oral iron supplementation. Several studies in African school children have shown that iron fortification decreases the abundance of beneficial commensal bacteria, such as Bifidobacteria and Lactobacilli, and increases the abundance of Enterobacteria, including E. coli $(11,18)$. High iron has also been associated with decreased butyrate-producing 
bacteria (13). Iron supplementation to patients with ulcerative colitis may therefore be particularly dangerous, as those patients already have a pathogenic microbial profile that could be further negatively altered. 


\section{References}

1. Abhyankar A, Moss AC. Iron Replacement in Patients with Inflammatory Bowel Disease: A Systematic Review and Meta-analysis. Inflamm Bowel Dis 21: 1976$81,2015$.

2. Antoniou E, Margonis GA, Angelou A, Pikouli A, Argiri P, Karavokyros I, Papalois A, Pikoulis E. The TNBS-induced colitis animal model: An overview. Ann Med Surg 11: 9-15, 2016.

3. Binda C, Lopetuso LR, Rizzatti G, Gibiino G, Cennamo V, Gasbarrini A. Actinobacteria: A relevant minority for the maintenance of gut homeostasis. Dig Liver Dis 50: 421-428, 2018.

4. Canani RB, Costanzo M Di, Leone L, Pedata M, Meli R, Calignano A. Potential beneficial effects of butyrate in intestinal and extraintestinal diseases. World J Gastroenterol 17: 1519-28, 2011.

5. Chassaing B, Aitken JD, Malleshappa M, Vijay-Kumar M. Dextran sulfate sodium (DSS)-induced colitis in mice. Curr Protoc Immunol 104: Unit 15.25., 2014.

6. D'Argenio V, Salvatore F. The role of the gut microbiome in the healthy adult status. Clin Chim Acta 451: 97-102, 2015.

7. Erichsen K, Hausken T, Ulvik RJ, Svardal A, Berstad A, Berge RK. Ferrous fumarate deteriorated plasma antioxidant status in patients with Crohn disease. Scand J Gastroenterol 38: 543-8, 2003.

8. Gisbert JP, Bermejo F, Pajares R, Pérez-Calle J-L, Rodríguez M, Algaba A, Mancenido N, de la Morena F, Carneros JA, McNicholl AG, González-Lama 
$\mathbf{Y}$, Maté J. Oral and intravenous iron treatment in inflammatory bowel disease: hematological response and quality of life improvement. Inflamm Bowel Dis 15: 1485-91, 2009.

9. Halfvarson J, Brislawn CJ, Lamendella R, Vázquez-Baeza Y, Walters WA, Bramer LM, D'Amato M, Bonfiglio F, McDonald D, Gonzalez A, McClure EE, Dunklebarger MF, Knight R, Jansson JK. Dynamics of the human gut microbiome in inflammatory bowel disease. Nat Microbiol 2: 17004, 2017.

10. Hansen J, Gulati A, Sartor RB. The role of mucosal immunity and host genetics in defining intestinal commensal bacteria. Curr Opin Gastroenterol 26: 564-71, 2010.

11. Jaeggi T, Kortman GAM, Moretti D, Chassard C, Holding P, Dostal A, Boekhorst J, Timmerman HM, Swinkels DW, Tjalsma H, Njenga J, Mwangi A, Kvalsvig J, Lacroix C, Zimmermann MB. Iron fortification adversely affects the gut microbiome, increases pathogen abundance and induces intestinal inflammation in Kenyan infants. Gut 64: 731-42, 2015.

12. Khan N, Patel D, Shah Y, Yang Y-X. Factors Predicting Testing and Treatment of Iron Deficiency in a Nationwide Cohort of Anemic UC Patients. Inflamm Bowel Dis 22: 2894-2901, 2016.

13. Krebs NF, Sherlock LG, Westcott J, Culbertson D, Hambidge KM, Feazel LM, Robertson CE, Frank DN. Effects of different complementary feeding regimens on iron status and enteric microbiota in breastfed infants. $J$ Pediatr 163: 416-23, 2013.

14. Kump P, Wurm P, Gröchenig HP, Wenzl H, Petritsch W, Halwachs B, 
Wagner M, Stadlbauer V, Eherer A, Hoffmann KM, Deutschmann A, Reicht

G, Reiter L, Slawitsch P, Gorkiewicz G, Högenauer C. The taxonomic

composition of the donor intestinal microbiota is a major factor influencing the

efficacy of faecal microbiota transplantation in therapy refractory ulcerative colitis. Aliment Pharmacol Ther 47: 67-77, 2018.

15. Michail S, Durbin M, Turner D, Griffiths AM, Mack DR, Hyams J, Leleiko

$\mathbf{N}$, Kenche H, Stolfi A, Wine E. Alterations in the gut microbiome of children with severe ulcerative colitis. Inflamm Bowel Dis 18: 1799-808, 2012.

16. Mizoguchi A. Animal Models of Inflammatory Bowel Disease. 2012, p. 263-320.

17. Mizoguchi A, Mizoguchi E. Animal models of IBD: linkage to human disease. Curr Opin Pharmacol 10: 578-87, 2010.

18. Paganini D, Zimmermann MB. The effects of iron fortification and supplementation on the gut microbiome and diarrhea in infants and children: a review. Am J Clin Nutr 106: 1688S-1693S, 2017.

19. De Preter V, Arijs I, Windey K, Vanhove W, Vermeire S, Schuit F, Rutgeerts P, Verbeke K. Impaired butyrate oxidation in ulcerative colitis is due to decreased butyrate uptake and a defect in the oxidation pathway. Inflamm Bowel Dis 18: $1127-36,2012$.

20. Rivière A, Selak M, Lantin D, Leroy F, De Vuyst L. Bifidobacteria and Butyrate-Producing Colon Bacteria: Importance and Strategies for Their Stimulation in the Human Gut. Front Microbiol 7: 979, 2016.

21. Rizzatti G, Lopetuso LR, Gibiino G, Binda C, Gasbarrini A. Proteobacteria: A Common Factor in Human Diseases. Biomed Res Int 2017: 9351507, 2017. 
22. Seong CN, Kang JW, Lee JH, Seo SY, Woo JJ, Park C, Bae KS, Kim MS. Taxonomic hierarchy of the phylum Firmicutes and novel Firmicutes species originated from various environments in Korea. J Microbiol 56: 1-10, 2018.

23. Singh RK, Chang H-W, Yan D, Lee KM, Ucmak D, Wong K, Abrouk M, Farahnik B, Nakamura M, Zhu TH, Bhutani T, Liao W. Influence of diet on the gut microbiome and implications for human health. J Transl Med 15: 73, 2017.

24. Waldner MJ, Neurath MF. Chemically induced mouse models of colitis. Curr Protoc Pharmacol Chapter 5: Unit 5.55, 2009.

25. Wexler AG, Goodman AL. An insider's perspective: Bacteroides as a window into the microbiome. Nat Microbiol 2: 17026, 2017.

26. Yang F, Wang D, Li Y, Sang L, Zhu J, Wang J, Wei B, Lu C, Sun X. Th1/Th2 Balance and Th17/Treg-Mediated Immunity in relation to Murine Resistance to Dextran Sulfate-Induced Colitis. J Immunol Res 2017: 7047201, 2017. 


\section{Specific Aims}

(1) Determine if oral iron supplementation exacerbates dextran sulfate sodium (DSS)induced colitis. Balb/c mice with and without DSS colitis will be given standard chow or a diet supplemented with ferrous sulfate for one week. We will examine changes in disease activity by monitoring body weight, colon length, fecal consistency and blood content, histology, and cytokine production.

(2) Examine changes in microbiome composition following oral iron supplementation in animals with DSS-induced colitis. Terminal restriction fragment length polymorphism (TRFLP) will be utilized to determine changes in the microbiome, particularly butyrateproducing bacteria (BPB). 
Oral iron supplementation exacerbates dextran sulfate sodium (DSS)-induced colitis and leads to pathogenic changes in the microbiome

Running title: Oral iron exacerbates DSS colitis

Emily A. Minor ${ }^{1,2}$, Amanda B. Stewart ${ }^{3}$, Justin T. Kupec ${ }^{4}$, Andrew J. Nickerson ${ }^{1,2}$, Julianna S. Martin ${ }^{5}$, Vazhaikkurichi M. Rajendran ${ }^{2,3}$

${ }^{1}$ Departments of Physiology and Pharmacology, ${ }^{2}$ Biochemistry, ${ }^{3}$ Orthopaedics, and

${ }^{4}$ Medicine, Section of Digestive Diseases, West Virginia University School of Medicine, Morgantown, West Virginia, USA; ${ }^{5}$ Department of Biology, Bethany College, Bethany, West Virginia, USA

Keywords: terminal restriction fragment length polymorphism (TRFLP), butyrateproducing bacteria (BPB), ferrous sulfate 


\begin{abstract}
Ulcerative colitis (UC) is a chronic inflammatory bowel disease (IBD) that is characterized by diarrhea, abdominal pain, and bloody, mucous-laden stools. Blood loss is severe enough to cause iron deficiency anemia (IDA) in one third of patients, making it the most common extra-intestinal manifestation of UC. Oral iron supplementation is the first line treatment for IDA, but there is a debate about whether oral iron is safe to give patients with UC. Some studies have found that oral iron exacerbates disease activity, while others say it is well tolerated and efficacious. The purpose of this study was to determine whether oral iron exacerbates dextran sulfate sodium (DSS)-induced colitis in mice, a model that effectively recapitulates ulcerative colitis. We hypothesize that iron supplemented chow will increase disease activity and lead to pathogenic changes in the microbiome in mice with DSS colitis. Iron supplementation resulted in a higher disease activity index (DAI), lower percent dry weight of feces, and increased inflammatory cytokines compared to DSS alone. However, there was no difference in colonic lengths or histological scores between the DSS and DSS + iron groups. We conclude that iron supplementation does increase colitis severity, though further experiments are needed to determine the extent of disease exacerbation and whether the same effect occurs in humans. Ongoing experiments will also determine whether iron alters microbiome composition, which could partially explain changes in disease activity.
\end{abstract}




\section{Introduction}

Ulcerative colitis (UC) is a chronic inflammatory bowel disease (IBD) that is characterized by bloody, mucous-laden stools $(18,19)$. Symptoms include diarrhea, abdominal pain, bloating, and tenesmus (34). The exact etiology of UC is unknown, but it is thought to result from a complex interplay between the environment, genetic susceptibility, and microbial dysbiosis, all of which contribute to a chronic inflammatory state in the colon (3). Approximately one million people in the United States have been diagnosed with ulcerative colitis, a number that has been rising over the past several decades $(13,31)$. The disease affects less than one percent of the population, but it imposes a tremendous economic burden, estimated to be between $\$ 8.1$ and $\$ 14.9$ billion annually in the US alone, largely due to frequent physician visits and hospitalizations, complications necessitating surgery, and expensive therapeutics $(12,36)$.

Though disease activity is limited to the colonic mucosa, the amount of inflammation and blood loss is severe enough to cause iron deficiency in $60-80 \%$ of patients (21). One third of people go on to develop anemia, making iron deficiency anemia (IDA) the most common extraintestinal manifestation of UC (52). Iron is an essential nutrient, so deficiency leads to a myriad of negative outcomes (7). Symptoms of IDA include weakness, fatigue, difficulty regulating body temperature, and impaired cognitive performance (5). The widespread detrimental impact of iron deficiency can be attributed to the fact that iron is involved in many important physiological processes including redox reactions of the electron transport chain, oxygen transport, and DNA synthesis $(1,17)$. 
Oral iron supplementation is the first line treatment for IDA, but its use is controversial (42). In non-IBD patients, oral iron administration is associated with gastrointestinal side effects such as nausea, flatulence, diarrhea, and constipation (52). In patients with ulcerative colitis, oral iron has been shown to exacerbate disease activity, leading to poor medication compliance and relapse of anemia $(33,50)$. Increased disease activity following oral iron administration in animal models of colitis has also been observed $(9,10)$. However, other studies have found no such association between oral iron and increased disease activity in patients with UC $(30,49)$.

We sought to determine whether oral iron supplementation increases disease activity in an animal model of colitis. Dextran sulfate sodium (DSS) was used to induce colitis in BALB/c mice over a one-week timeframe. The exact mechanism by which DSS induces colitis is not known, but it produces symptoms and histological changes consistent with ulcerative colitis and is favored because of its simplicity, rapidity, and reproducibility $(11,14,16)$. BALB/c mice were selected because they have a predominantly T helper cell 2 (Th2)-type immune response when exposed to DSS, which most accurately reflects ulcerative colitis in humans (59). We assessed changes in disease activity using multiple parameters and also investigated whether iron alters microbial composition, which might help explain the changes in disease activity.

We hypothesize that oral iron supplementation will increase disease activity and lead to pathogenic changes in the microbiome. Specifically, we expect to see a reduction in butyrate-producing bacteria (BPB), a heterogeneous group of microbes that generate butyrate, a short chain fatty acid (SCFA) that promotes colonic health $(8,58)$. BPB largely belong to Clostridium cluster $I V$ and $X I V a$ in the phylum Firmicutes, and include 
microbes such as Faecalibacterium prausnitzii and Roseburia spp (25, 32). Adequate butyrate production is important because butyrate is the main energy source for colonocytes, induces mucin production, and has various anti-inflammatory effects (15, $23,60)$. Patients with UC are known to have decreased butyrate, so we expect the mice with DSS colitis to have fewer BPB than controls $(29,35,44)$. Iron is also known to reduce the amount of BPB, so we hypothesize that the mice with DSS-induced colitis fed an iron supplemented diet will have an even further reduction in butyrate producers (28).

Changes in microbial composition will be assessed via terminal restriction fragment length polymorphism (TRFLP). This technique enables identification and quantitative analysis of microbes based on their terminal restriction fragment size (53, 55). Polymerase chain reaction (PCR) is conducted using fluorescently labeled primers that amplify the $16 \mathrm{~S}$ ribosomal ribonucleic acid (rRNA) gene and then the product is restriction digested and run on a sequencer (46). Microbial Community Analysis (MiCA), an online database that performs virtual PCRs and restriction digestions, was utilized for selection of primers and restriction enzymes (48). 


\section{Materials and Methods}

\section{Animals}

All experiments were approved by the Institutional Animal Care and Use Committee at West Virginia University. Male BALBc/AnNCrl mice (7 weeks old, Charles River, NY) were selected because they mount a predominantly T helper 2 (Th2)-type immune response when exposed to DSS, which best replicates human ulcerative colitis (59). The mice were given two weeks to acclimate to the animal facility prior to use in experiments and then randomly divided into four groups:

Control groups:

(1) Control (Con) animals received standard chow and standard drinking water.

(2) Iron (Fe) only animals received iron supplemented chow and standard drinking water.

DSS groups:

(3) DSS only (DSS) animals received standard chow and drinking water with 5\% DSS.

(4) DSS plus iron (DSS+Fe) animals received iron supplemented chow and drinking water with 5\% DSS.

There were six animals per group, housed three to a cage on a 12 hour light-dark cycle.

\section{Induction of Colitis and Iron Supplemented Diet}

The mice were concurrently given the iron-supplemented diet for seven days and DSS

(molecular weight 36-50 kDa, MP Biomedicals, Solon, $\mathrm{OH}$ ) for six days followed by one day of standard drinking water. Standard chow (2018 Teklad Global 18\% Protein Rodent Diet, Huntingdon, UK) contained 200 parts per million (ppm) ferrous sulfate, while the 
iron supplemented diet (2018 Teklad Global 18\% Protein Rodent Custom Diet, Huntingdon, UK) contained 600 ppm ferrous sulfate. Food and water were available ad libitum and consumption was tracked daily for each cage. On the eighth day, animals were anesthetized with $5 \%$ isoflurane prior to euthanasia via cervical dislocation.

\section{Disease Activity Index}

Disease activity index (DAI) was calculated daily for each animal as the average of three parameters: weight loss, stool consistency, and fecal blood content, as adapted from other groups $(26,57)$. Scores were defined as follows:

- Weight loss: 0 (no loss), 1 (1-5\% loss), 2 (5-10\% loss), 3 (10-15\% loss), 4 (>15\% loss)

- Stool consistency: 0 (normal, firm pellet), 2 (loose, sticky, very soft pellet), 4 (diarrhea and/or mucous)

- Fecal blood content: 0 (none), 1 (hemoccult positive), 2 (flecks of blood), 3 (gross blood), 4 (gross blood + blood on anus)

Hemoccult blood was evaluated from two fecal pellets per animal per day (Hemoccult SENSA, Beckman Coulter, Brea, CA).

\section{Colon Lengths}

On the day of animal sacrifice, colons were removed via careful dissection and length was determined from cecum to anus, as described elsewhere (61). Colonic shortening was used a maker of increased inflammation and also occurs in ulcerative colitis patients (20, $22,43)$.

\section{Percent Fecal Dry Weight}


Fecal pellets were collected daily from each animal for determination of percent fecal dry weight and for use in TRFLP experiments. Following collection, feces were immediately placed on ice and transported to the lab. Fecal pellets were frozen in liquid nitrogen and then placed at $-80^{\circ} \mathrm{C}$ for a minimum of 24 hours. Pellets were weighed (wet weight), lyophilized for 24 hours, and then a dry weight was determined. Percent fecal dry weight was calculated as [(dry weight/wet weight) $\mathrm{x} 100]$. A lower percent fecal dry weight indicates a looser stool and increased disease activity.

\section{Isolation of Colonic Epithelial Cells}

Colons were removed and rinsed with cold PBS. The distal colon was separated and opened along the mesenteric border, cut into small segments $(\sim 2 \mathrm{~mm})$, and then rinsed with cold PBS five times. Tissue segments were placed in PBS with $5 \mathrm{mM}$ ethylenediaminetetraacetic acid (EDTA) and gently rocked at $37^{\circ} \mathrm{C}$ for 30 minutes. Following this incubation period, the tissue was washed in cold PBS fives times and then vigorously shaken in $5 \mathrm{~mL}$ of PBS. The disrupted colonic crypts and epithelial cells were pelleted by spinning down the supernatant at $1,000 \mathrm{~g}$ for fives minutes.

\section{RT-qPCR Analysis of Colitis-Associated Cytokines}

An RNEasy kit (Qiagen, Valencia, CA) was used to extract RNA from isolated colonic epithelial cells immediately after collection. RNA was quantified with a Nanodrop 1000 (Thermo Fisher Scientific, Waltham, MA) and then stored at $-80^{\circ} \mathrm{C}$. Quantitative reverse transcription polymerase chain reaction (RT-qPCR) analysis was carried out using a onestep kit (New England Biolabs, Ipswich, MA) consisting of 10 minutes reverse transcription of RNA (50 ng/well) followed by quantitative PCR using a dsDNA-binding dye. Gene specific custom forward and reverse primers ( $400 \mathrm{nM}$ primers/well) for 
various ulcerative colitis-associated cytokines were created using the NCBI PrimerBLAST application (Table 1). Fold changes of transcripts were calculated using the $\Delta \Delta \mathrm{Ct}$ method in reference to the housekeeping gene beta-actin ( $\beta$-actin). $\Delta \mathrm{Ct}$ was calculated by subtracting $\beta$-actin threshold cycles from the threshold cycles of the transcripts of interest. The average $\Delta \mathrm{Ct}$ from the control samples was then subtracted from the $\Delta \mathrm{Ct}$ value of the group of interest to obtain a $\Delta \Delta \mathrm{Ct}$ value. Finally, fold changes were calculated as $2^{-\Delta \Delta \mathrm{Ct}}$.

\section{Histology}

A small piece of intact distal colon was fixed in 10\% neutral-buffered formalin for 24 hours and then sent to the Translational Pathology Department at West Virginia University for histological analysis. The tissue was paraffin embedded, mounted on glass slides ( $5 \mu \mathrm{M}$ thick sections), and hematoxylin and eosin (H\&E) stained according to standard protocol. A board-certified pathologist who was blinded to treatment condition scored the slides based on a scoring system modified from a pervious study (51). An average score was calculated for each group based on extent of inflammatory cell infiltrate and tissue damage:

- Cell infiltration (0- occasional inflammatory cells in the lamina propria, 2-confluence of inflammatory cells extending into the mucosa, 3- transmural extension of inflammatory cells)

- Tissue damage (0- no damage, 1- partial loss of crypts in large areas, 2- partial to total loss of crypts with epithelium intact, 3- total loss of crypts with epithelium lost).

\section{DNA Extraction and Polymerase Chain Reaction (PCR)}

Microbial DNA was extracted from $\sim 50 \mathrm{mg}$ of lyophilized feces using a commercially 
available bead beader kit (Quick-DNA Fecal/Soil Microbe Kit, Zymo Research, Irvine, CA) and quantified using a Nanodrop 1000 (Thermo Fisher Scientific, Waltham, MA). A $50 \mu \mathrm{L}$ PCR reaction was prepared with 1X Taq Master Mix (Apex 2X Taq Master Mix, Clear, Genesee Scientific, San Diego, CA), 150 ng of DNA, forward 5' FAM-labeled degenerate primer: AGMGTTYGATYMTGGCTCAG $(\mathrm{Y}=\mathrm{C}$ or $\mathrm{T}, \mathrm{M}=\mathrm{A}$ or $\mathrm{C})$ and reverse 5' NED-labeled primer: ATTACCGCGGCTGCTGG. The primers were adapted from Walker et al (56). PCR conditions were as follows: $95^{\circ} \mathrm{C}$ for 5 minutes, 10 cycles of $95^{\circ} \mathrm{C}$ for 30 seconds, $57^{\circ} \mathrm{C}$ for 30 seconds, and $72^{\circ} \mathrm{C}$ for 90 seconds, 10 cycles of $95^{\circ} \mathrm{C}$ for 30 seconds, $51^{\circ} \mathrm{C}$ for 30 seconds, and $72^{\circ} \mathrm{C}$ for 90 seconds, 25 cycles of $95^{\circ} \mathrm{C}$ for 30 seconds, $49^{\circ} \mathrm{C}$ for 30 seconds, and $72^{\circ} \mathrm{C}$ for 90 seconds followed by $72^{\circ} \mathrm{C}$ for 10 minutes. Products were expected between 173 and 530 base pairs.

\section{Terminal Restriction Fragment Length Polymorphism (TRFLP)}

A DNA clean and concentrator kit was used to remove primer-dimers and all products less than 50 base pairs (Zymo Research, Irvine, CA). PCR products were then digested in a $50 \mathrm{uL}$ reaction using $0.5 \mathrm{uL}$ of HpyCH4V or $1 \mathrm{uL}$ of Hpy188I CutSmart enzymes, $1 \mathrm{X}$ CutSmart Buffer, (New England Biolabs, Ipswich, MA) and 6 uL of product. Restriction digestion was carried out at $37^{\circ} \mathrm{C}$ for one hour followed by 20 minutes at $65^{\circ} \mathrm{C}$ for enzyme inactivation. Restriction fragments were visualized using a $2 \%$ agarose gel. TRFLP was carried out on an ABI Prism 310 Genetic Analyzer (Thermo Fisher Scientific, Waltham, MA) with POP-4 polymer and a $37 \mathrm{~cm}$ short read capillary. Products $(2 \mathrm{uL})$ were co-loaded with $12 \mathrm{uL}$ formamide (Thermo Fisher Scientific, Waltham, MA) and 0.5 uL ROX-500 size standard (Red DNA Size Standard, Molecular Cloning Laboratories, San Francisco, CA) per reaction. Samples were run at $60^{\circ} \mathrm{C}$ for 35 
minutes. GeneScan analysis software was used for fragment analysis to determine peak height and area. TRFLP Analysis Expedited (Trex) was used to align peaks and cleanse the data, Microbial Community Analysis III (MiCA III) to identify species, and APLAUS+ to determine relative abundance and community structure.

\section{Statistics}

Statistical analyses were performed using Graph Pad Prism 6.0 (San Diego, CA). When comparing more than two groups, a one-way ANOVA was used with $n=6$ for each group. Results are expressed as means $\pm \mathrm{SE}$ with significance set at $\mathrm{p}<0.05$. 


\section{Results}

\section{Daily Food and Water Consumption}

Food and water consumption was tracked daily for each group. Day 1 corresponds to the food and water consumption from 0-24 hours, Day 2 for 24-48 hours, and so on. Food consumption was approximately 15 grams of chow per group per day, which equates to about 2.5 grams of chow per animal (Fig. 1A). All groups ate approximately the same amount, indicating that differential food consumption could not explain differences in weight gain. Additionally, we can conclude that the groups receiving the iron-supplemented chow consumed the same total amount of iron.

Water consumption was more variable, ranging from 20 to 30 milliliters of water per day per group, or roughly three to five milliliters per animal each day (Fig. 1B). Importantly, the DSS groups (DSS and DSS+Fe) drank approximately the same volume throughout the duration of the study. DSS was provided in the drinking water, so we can conclude that the groups receiving DSS received the same total amount of DSS.

\section{Oral Iron Supplementation Exacerbates DSS colitis}

Changes in disease activity were monitored using multiple assays. Disease Activity Index (DAI) was determined daily for each animal, which is calculated as the average of three parameters: weight loss, stool consistency, and fecal blood content. The mice received a score from zero to four for each parameter, as detailed in the figure (Fig. 2A). The average daily score for the control groups (control and iron only) remained approximately zero for the duration of the study (Fig. 2B). The DAI for the DSS groups (DSS only and DSS+Fe) steadily increased throughout the study. On Day 7, the DSS groups had a DAI of approximately 2.2, which was significantly higher than the control 
groups $(\mathrm{p}<0.05)$. The DSS+Fe group had a DAI of 3.1, which was higher than all other groups $(\mathrm{p}<0.05)$. In order to determine which parameters contributed most to changes in disease activity, the total DAI was broken down into each separate parameter on Day 7 (Fig. 2C). DSS groups had a significantly higher score on all parameters compared to control groups $(\mathrm{p}<0.05)$. Weight loss contributed the least to total DAI, and there was no significant difference between the DSS groups, while stool consistency and fecal blood content contributed much more to DAI and the DSS+Fe group had a significantly higher score than DSS only $(\mathrm{p}<0.05)$.

Colon lengths were determined on the day of animal sacrifice as a marker for inflammation, where colonic shortening correlates with increased inflammation and disease activity. Representative images of colons from each group demonstrated that the colons from the DSS groups (DSS only and DSS+Fe) were significantly shorter than the colons from the control groups (control and iron only) (Fig. 3A). Quantification of colon lengths revealed that control colons were approximately $12.62 \pm 0.22$ centimeters long, iron only colons were $12.38 \pm 0.57$, DSS only colons were $8.37 \pm 0.09$, and DSS $+\mathrm{Fe}$ colons were $7.38 \pm 0.21$ centimeters (Fig. 3B). Colons from the DSS groups were significantly shorter than the control groups, but there was no difference in colonic length between DSS only and DSS+Fe $(\mathrm{p}<0.05)$.

We also determined the percent dry weight of feces on Day 1 and Day 7. A lower percent fecal dry weight indicates a looser stool and higher disease activity. On Day 1, all groups had a percent fecal dry weight of approximately $45 \%$, and there was no significant difference between the groups (Fig. 4A, p >0.05). On Day 7, the percent dry weight of the control groups remained $45 \%$, while the fecal dry weight of the DSS only group was 
reduced to $38 \%(\mathrm{p}<0.05$ compared to control groups) and the DSS+Fe group to $31 \%$ (Fig. 4B, p $<0.05$ compared to all other groups).

Cytokines that are involved in the development of colitis were also evaluated via RT-qPCR analysis. TNF $\alpha$ is the hallmark of DSS colitis, while IL-6 and IL-17 are associated with disease onset and progression (11). Relative mRNA abundance of all cytokines was increased in the DSS groups compared to the control groups (Fig 5, A-C, p $<0.05)$. TNF $\alpha$ and IL-6 were increased to a greater extent in the DSS+Fe group compared to DSS only $(\mathrm{p}<0.05)$.

Histological changes were determined via H\&E staining. The control groups contained highly organized test tube-shaped crypts (Fig. 6, A and B). DSS groups exhibited loss of crypt architecture and an influx of inflammatory cells (Fig. 6, C and D). The calculated histology score for the DSS groups was higher than for the control groups, but there was no significant difference between DSS only and DSS+Fe (Fig. 6E, p < $0.05)$.

\section{Oral Iron Supplementation Alters Microbiome Composition}

Experiments to determine changes in the microbiome are ongoing. Primers and restriction enzymes have been selected and verified, but we are still optimizing PCR conditions. 


\section{Discussion}

Iron deficiency anemia (IDA) is a frequent complication of ulcerative colitis (UC) that results from a combination of fecal blood loss and impaired iron absorption $(2,37)$. Oral iron supplementation is the first line treatment for IDA, but its use is not without controversy (40). In otherwise healthy individuals, oral iron is associated with gastrointestinal side effects that sometimes compromise treatment compliance and efficacy $(4,38,54)$. In patients with UC, oral iron has been shown to exacerbate disease activity. Other groups, however, have found no such association between oral iron and increased disease activity, and have, therefore, deemed oral iron to be well tolerated and efficacious in treating UC-related anemia $(30,39)$.

The purpose of this study was to determine whether oral iron supplementation exacerbates disease activity in an animal model of colitis. We hypothesized that oral iron would exacerbate DSS-induced colitis and lead to pathogenic changes in the microbiome. BALB/c mice with and without DSS colitis were provided standard chow or chow supplemented with ferrous sulfate for one week as part of an acute experimental study. Fecal pellets were collected and disease activity was monitored daily for each animal. DSS groups (DSS only and DSS+Fe) had increased disease activity on all parameters compared to control groups (control and iron only), as evidenced by increased disease activity indices (DAI), shorter colons, lower percent fecal dry weight, increased inflammatory cytokines, and higher histology scores (Figs. 2-6). The DSS animals developed symptoms and histological changes consistent with UC, confirming the validity of the experimental model. Specifically, the DSS animals experienced weight 
loss, bloody, mucous-laden diarrhea, and destruction of colonic crypts with a large influx of inflammatory cells.

Compared to DSS alone, the DSS+Fe group developed even more significant disease activity on multiple parameters, including a higher DAI, lower percent fecal dry weight, and increased inflammatory cytokines. However, there was no difference in colonic lengths or histology scores between the DSS groups. We conclude that iron supplementation does exacerbate DSS colitis, but we cannot determine whether the observed changes would occur in humans, nor whether symptoms would be noticeably worsened in patients with UC.

The mechanism by which iron exacerbates colitis is likely tied to its generation of reactive oxygen species (ROS) via the Fenton and Haber-Weiss reactions (6). ROS can directly damage lipids, proteins, and deoxyribonucleic acid (DNA), and can also recruit inflammatory cells via the up-regulation of adhesion molecules and generation of chemotactic factors $(24,27)$. We also hypothesized that iron would lead to pathogenic changes in the microbiome, which may partially explain the increased disease activity in the DSS+Fe group. TRFLP experiments are ongoing to determine whether that is the case.

DSS-induced colitis is a great way to study ulcerative colitis in vitro, however, it is just a model and, therefore, cannot fully capture the intricacies of the disease in humans. One major concern is that the mechanism by which DSS induces colitis may magnify the negative effects of iron supplementation. DSS is a colitogen that is directly toxic to colonocytes, so DSS colitis may be more amenable to iron-induced damage than 
is the case in humans with UC $(41,45)$. The only way to definitely determine whether oral exacerbates UC is to conduct a human clinical trial (see future directions).

The significance of this study is that clinicians perhaps need to reconsider using oral iron supplementation as the first line treatment for IDA in patients with ulcerative colitis. Increased disease activity and pathogenic changes in the microbiome may be major contraindications to the use of oral iron in UC patients. Gastrointestinal side effects are reversible upon discontinuation of the oral iron, but disruption in microbial composition can leave a lasting negative impact. Pathogenic changes in the microbiome can cause an inflammatory response that leads to relapse of colitis or failure to respond to therapy (47). Physicians could avoid this myriad of negative outcomes by simply using intravenous (IV) iron supplementation as the first line treatment for IDA. Guidelines for clinician prescribing and insurance coverage of IV iron would need to be addressed in order to encourage the use of IV iron supplementation to treat UC-related anemia.

Iron deficiency anemia is a common complication of ulcerative colitis that is most commonly treated with oral iron supplementation. We found that iron supplemented chow increases disease activity in mice with DSS colitis, and, therefore, conclude that oral iron supplementation also likely exacerbates ulcerative colitis. 


\section{References}

1. Abbaspour N, Hurrell R, Kelishadi R. Review on iron and its importance for human health. J Res Med Sci 19: 164-74, 2014.

2. Akhuemonkhan E, Parian A, Miller K, Hanauer S, Hutfless S. Prevalence and screening for anaemia in mild to moderate Crohn's disease and ulcerative colitis in the United States, 2010-2014. BMJ open Gastroenterol 4: e000155, 2017.

3. Aleksandrova K, Romero-Mosquera B, Hernandez V. Diet, Gut Microbiome and Epigenetics: Emerging Links with Inflammatory Bowel Diseases and Prospects for Management and Prevention. Nutrients 9, 2017.

4. Bayraktar UD. Treatment of iron deficiency anemia associated with gastrointestinal tract diseases. World J Gastroenterol 16: 2720, 2010.

5. Brunner C, Wuillemin WA. [Iron deficiency and iron deficiency anemia symptoms and therapy]. Ther Umsch 67: 219-23, 2010.

6. Bystrom LM, Guzman ML, Rivella S. Iron and reactive oxygen species: friends or foes of cancer cells? Antioxid Redox Signal 20: 1917-24, 2014.

7. Cairo G, Bernuzzi F, Recalcati S. A precious metal: Iron, an essential nutrient for all cells. Genes Nutr 1: 25-39, 2006.

8. Canani RB, Costanzo M Di, Leone L, Pedata M, Meli R, Calignano A. Potential beneficial effects of butyrate in intestinal and extraintestinal diseases. World J Gastroenterol 17: 1519-28, 2011.

9. Carrier J, Aghdassi E, Cullen J, Allard JP. Iron supplementation increases disease activity and vitamin $\mathrm{E}$ ameliorates the effect in rats with dextran sulfate sodium-induced colitis. J Nutr 132: 3146-50, 2002. 
10. Carrier J, Aghdassi E, Platt I, Cullen J, Allard JP. Effect of oral iron supplementation on oxidative stress and colonic inflammation in rats with induced colitis. Aliment Pharmacol Ther 15: 1989-99, 2001.

11. Chassaing B, Aitken JD, Malleshappa M, Vijay-Kumar M. Dextran sulfate sodium (DSS)-induced colitis in mice. Curr Protoc Immunol 104: Unit 15.25., 2014.

12. COHEN RD, YU AP, WU EQ, XIE J, MULANI PM, CHAO J. Systematic review: the costs of ulcerative colitis in Western countries. Aliment Pharmacol Ther 31: 693-707, 2010.

13. Dahlhamer JM, Zammitti EP, Ward BW, Wheaton AG, Croft JB. Prevalence of Inflammatory Bowel Disease Among Adults Aged $\geq 18$ Years - United States, 2015. MMWR Morb Mortal Wkly Rep 65: 1166-1169, 2016.

14. Das S, Batra S, Rachagani S. Mouse Model of Dextran Sodium Sulfate (DSS)induced Colitis. BIO-PROTOCOL 7, 2017.

15. Donohoe DR, Garge N, Zhang X, Sun W, O'Connell TM, Bunger MK, Bultman SJ. The microbiome and butyrate regulate energy metabolism and autophagy in the mammalian colon. Cell Metab 13: 517-26, 2011.

16. Eichele DD, Kharbanda KK. Dextran sodium sulfate colitis murine model: An indispensable tool for advancing our understanding of inflammatory bowel diseases pathogenesis. World J Gastroenterol 23: 6016-6029, 2017.

17. Ems T, Huecker MR. Biochemistry, Iron Absorption. 2018.

18. Fakhoury M, Negrulj R, Mooranian A, Al-Salami H. Inflammatory bowel disease: clinical aspects and treatments. J Inflamm Res 7: 113-20, 2014. 
19. Feuerstein JD, Cheifetz AS. Ulcerative colitis: epidemiology, diagnosis, and management. Mayo Clin Proc 89: 1553-63, 2014.

20. Frick J-S, MacManus CF, Scully M, Glover LE, Eltzschig HK, Colgan SP. Contribution of Adenosine A2B Receptors to Inflammatory Parameters of Experimental Colitis. J Immunol 182: 4957-4964, 2009.

21. Gisbert JP, Gomollón F. Common misconceptions in the diagnosis and management of anemia in inflammatory bowel disease. Am J Gastroenterol 103: 1299-307, 2008.

22. Han F, Zhang H, Xia X, Xiong H, Song D, Zong X, Wang Y. Porcine $\beta$ defensin 2 attenuates inflammation and mucosal lesions in dextran sodium sulfateinduced colitis. J Immunol 194: 1882-93, 2015.

23. Hatayama H, Iwashita J, Kuwajima A, Abe T. The short chain fatty acid, butyrate, stimulates MUC2 mucin production in the human colon cancer cell line, LS174T. Biochem Biophys Res Commun 356: 599-603, 2007.

24. Jaeschke H. Mechanisms of oxidant stress-induced acute tissue injury. Proc Soc Exp Biol Med 209: 104-11, 1995.

25. Jiang S, Xie S, Lv D, Zhang Y, Deng J, Zeng L, Chen Y. A reduction in the butyrate producing species Roseburia spp. and Faecalibacterium prausnitzii is associated with chronic kidney disease progression. Antonie Van Leeuwenhoek 109: 1389-96, 2016.

26. Kim JJ, Shajib MS, Manocha MM, Khan WI. Investigating intestinal inflammation in DSS-induced model of IBD. J Vis Exp , 2012.

27. Kohgo Y, Ikuta K, Ohtake T, Torimoto Y, Kato J. Body iron metabolism and 
pathophysiology of iron overload. Int J Hematol 88: 7-15, 2008.

28. Krebs NF, Sherlock LG, Westcott J, Culbertson D, Hambidge KM, Feazel LM, Robertson CE, Frank DN. Effects of different complementary feeding regimens on iron status and enteric microbiota in breastfed infants. J Pediatr 163: 416-23, 2013.

29. Kumari R, Ahuja V, Paul J. Fluctuations in butyrate-producing bacteria in ulcerative colitis patients of North India. World J Gastroenterol 19: 3404-14, 2013.

30. Lee T, Clavel T, Smirnov K, Schmidt A, Lagkouvardos I, Walker A, Lucio M, Michalke B, Schmitt-Kopplin P, Fedorak R, Haller D. Oral versus intravenous iron replacement therapy distinctly alters the gut microbiota and metabolome in patients with IBD. Gut 66: 863-871, 2017.

31. Loftus E V. Clinical epidemiology of inflammatory bowel disease: Incidence, prevalence, and environmental influences. Gastroenterology 126: 1504-17, 2004.

32. Lopetuso LR, Scaldaferri F, Petito V, Gasbarrini A. Commensal Clostridia: leading players in the maintenance of gut homeostasis. Gut Pathog 5: 23, 2013.

33. Lugg S, Beal F, Nightingale $\mathbf{P}$, Bhala $\mathbf{N}$, Iqbal T. Iron treatment and inflammatory bowel disease: What happens in real practice? J Crohn's Colitis 8: 876-880, 2014.

34. Lynch WD, Hsu R. Colitis, Ulcerative. 2018.

35. Machiels K, Joossens M, Sabino J, De Preter V, Arijs I, Eeckhaut V, Ballet V, Claes K, Van Immerseel F, Verbeke K, Ferrante M, Verhaegen J, Rutgeerts P, Vermeire S. A decrease of the butyrate-producing species Roseburia hominis 
and Faecalibacterium prausnitzii defines dysbiosis in patients with ulcerative colitis. Gut 63: 1275-83, 2014.

36. Mehta F. Report: economic implications of inflammatory bowel disease and its management. Am J Manag Care 22: s51-60, 2016.

37. Mücke V, Mücke MM, Raine T, Bettenworth D. Diagnosis and treatment of anemia in patients with inflammatory bowel disease. Ann Gastroenterol 30: 15-22, 2017.

38. Muñoz M, Gómez-Ramírez S, Bhandari S. The safety of available treatment options for iron-deficiency anemia. Expert Opin Drug Saf 17: 149-159, 2018.

39. Nielsen OH, Ainsworth M, Coskun M, Weiss G. Management of IronDeficiency Anemia in Inflammatory Bowel Disease: A Systematic Review. Medicine (Baltimore) 94: e963, 2015.

40. Niepel D, Klag T, Malek NP, Wehkamp J. Practical guidance for the management of iron deficiency in patients with inflammatory bowel disease. Therap Adv Gastroenterol 11: 175628481876907, 2018.

41. Oh SY, Cho K-A, Kang JL, Kim KH, Woo S-Y. Comparison of experimental mouse models of inflammatory bowel disease. Int J Mol Med 33: 333-40, 2014.

42. Okam MM, Koch TA, Tran M-H. Iron Supplementation, Response in IronDeficiency Anemia: Analysis of Five Trials. Am J Med 130: 991.e1-991.e8, 2017.

43. Parray FQ, Wani ML, Malik AA, Wani SN, Bijli AH, Irshad I, Nayeem-UIHassan. Ulcerative colitis: a challenge to surgeons. Int J Prev Med 3: 749-63, 2012.

44. De Preter V, Arijs I, Windey K, Vanhove W, Vermeire S, Schuit F, Rutgeerts 
P, Verbeke K. Impaired butyrate oxidation in ulcerative colitis is due to decreased butyrate uptake and a defect in the oxidation pathway. Inflamm Bowel Dis 18: 1127-36, 2012.

45. Saiz ML, Cibrian D, Ramírez-Huesca M, Torralba D, Moreno-Gonzalo O, Sánchez-Madrid F. Tetraspanin CD9 Limits Mucosal Healing in Experimental Colitis. Front Immunol 8: 1854, 2017.

46. Scheidegger EMD, Fracalanzza SAP, Teixeira LM, Cardarelli-Leite P. RFLP analysis of a PCR-amplified fragment of the 16S rRNA gene as a tool to identify Enterococcus strains. Mem Inst Oswaldo Cruz 104: 1003-8, 2009.

47. Shen Z-H, Zhu C-X, Quan Y-S, Yang Z-Y, Wu S, Luo W-W, Tan B, Wang XY. Relationship between intestinal microbiota and ulcerative colitis: Mechanisms and clinical application of probiotics and fecal microbiota transplantation. World $J$ Gastroenterol 24: 5-14, 2018.

48. Shyu C, Soule T, Bent SJ, Foster JA, Forney LJ. MiCA: a web-based tool for the analysis of microbial communities based on terminal-restriction fragment length polymorphisms of 16S and 18S rRNA genes. Microb Ecol 53: 562-70, 2007.

49. de Silva AD, Tsironi E, Feakins RM, Rampton DS. Efficacy and tolerability of oral iron therapy in inflammatory bowel disease: a prospective, comparative trial. Aliment Pharmacol Ther 22: 1097-105, 2005.

50. SILVA AD, TSIRONI E, FEAKINS RM, RAMPTON DS. Efficacy and tolerability of oral iron therapy in inflammatory bowel disease: a prospective, comparative trial. Aliment Pharmacol Ther 22: 1097-1105, 2005. 
51. Smith P, Mangan NE, Walsh CM, Fallon RE, McKenzie ANJ, van Rooijen N, Fallon PG. Infection with a helminth parasite prevents experimental colitis via a macrophage-mediated mechanism. J Immunol 178: 4557-66, 2007.

52. Stein J, Dignass AU. Management of iron deficiency anemia in inflammatory bowel disease - a practical approach. Ann Gastroenterol 26: 104-113, 2013.

53. Tiquia SM. Using terminal restriction fragment length polymorphism (T-RFLP) analysis to assess microbial community structure in compost systems. Methods Mol Biol 599: 89-102, 2010.

54. Tolkien Z, Stecher L, Mander AP, Pereira DIA, Powell JJ. Ferrous Sulfate Supplementation Causes Significant Gastrointestinal Side-Effects in Adults: A Systematic Review and Meta-Analysis. PLoS One 10: e0117383, 2015.

55. De Vrieze J, Ijaz UZ, Saunders AM, Theuerl S. Terminal restriction fragment length polymorphism is an "old school" reliable technique for swift microbial community screening in anaerobic digestion. Sci Rep 8: 16818, 2018.

56. Walker AW, Martin JC, Scott P, Parkhill J, Flint HJ, Scott KP. 16S rRNA gene-based profiling of the human infant gut microbiota is strongly influenced by sample processing and PCR primer choice. Microbiome 3: 26, 2015.

57. Wang R, Wang L, Luo Y, Wang D, Du R, Du J, Wang Y. Maggot protein ameliorates dextran sulphate sodium-induced ulcerative colitis in mice. Biosci Rep 38, 2018.

58. Wong JMW, de Souza R, Kendall CWC, Emam A, Jenkins DJA. Colonic health: fermentation and short chain fatty acids. J Clin Gastroenterol 40: 235-43, 2006. 
59. Yang F, Wang D, Li Y, Sang L, Zhu J, Wang J, Wei B, Lu C, Sun X. Th1/Th2 Balance and Th17/Treg-Mediated Immunity in relation to Murine Resistance to Dextran Sulfate-Induced Colitis. J Immunol Res 2017: 7047201, 2017.

60. Yin L, Laevsky G, Giardina C. Butyrate suppression of colonocyte NF-kappa B activation and cellular proteasome activity. J Biol Chem 276: 44641-6, 2001.

61. Zhang Z, Wu X, Cao S, Wang L, Wang D, Yang H, Feng Y, Wang S, Li L. Caffeic acid ameliorates colitis in association with increased Akkermansia population in the gut microbiota of mice. Oncotarget 7: 31790-9, 2016. 


\section{Figure Captions}

Figure 1: Total daily food and water consumption per group of animals per day. [A] Each group of animals ( $\mathrm{n}=6$ per group) consumed approximately 15 grams of chow each day, which equates to roughly 2.5 grams eaten per mouse per day. Food consumption remained consistent between groups throughout the duration of the study. We can therefore conclude that the two groups receiving the iron-supplemented diet received approximately the same total amount of iron. [B] Total daily water consumption was slightly more variable throughout the duration of the study (between 20 and 30 milliliters per group per day). Importantly, the animals receiving dextran sulfate sodium (DSS)supplemented drinking water consumed roughly the same amount of fluids, and thus, received the same amount of DSS.

Figure 2: Disease activity index (DAI). [A] The table depicts the scoring system used to determine DAI, calculated as the average of weight loss, stool consistency, and fecal blood content. Each animal was scored daily on each parameter. [B] The control groups (con and $\mathrm{Fe}$ ) had a DAI of approximately zero throughout the duration of the study. The DAI of the DSS groups (DSS only and DSS+Fe) steadily increased throughout the duration of the study, reaching a maximum score on Day 7 of 2.2 and 3.1, respectively. The DAI for DSS only animals on day 7 was higher than both control groups, while the DSS+Fe group was significantly higher than all other groups. [C] DAI score on Day 7 for each parameter. The DSS groups had higher scores on all three parameters compared to the control groups. Weight loss contributed a small amount to total DAI and there was no significant difference between the DSS groups, while stool consistency and fecal blood 
content contributed more to DAI and were higher for the DSS+Fe group compared to DSS alone. $\mathrm{n}=6$ for all groups, ${ }^{*} \mathrm{p}<0.05$ compared to control groups (con and Fe), $\$ \mathrm{p}<$ 0.05 compared to DSS only.

Figure 3: Colon lengths measured from cecum to anus on the day of animal sacrifice. [A] Representative images of excised colons from each group. [B] Group data of colon lengths. The average length of a control (con) colon was $12.62 \pm 0.22$ centimeters, an iron $(\mathrm{Fe})$ only colon $12.38 \pm 0.57$, a DSS only colon $8.37 \pm 0.09$, and a DSS+Fe colon $7.38 \pm 0.21$. DSS only and DSS+Fe colons were significantly shorter than control colons (con and Fe groups). $\mathrm{n}=6$ for all groups, ${ }^{*} \mathrm{p}<0.05$ compared to control groups (con and $\mathrm{Fe})$.

Figure 4: Percent dry weight of feces on Day 1 and Day 7. [A] On Day 1, the average percent fecal dry weight was the same for all groups $(\sim 45 \%)$. [B] On Day 7 , the percent fecal dry weight for the control groups (con and Fe) remained approximately $45 \%$. The DSS only group had a lower percent fecal dry weight than the control groups (38\%), and the DSS + Fe group was lower than all other groups $(31 \%) . \mathrm{n}=6$ for all groups, $* \mathrm{p}<0.05$ compared to control groups (con and Fe), $\$ \mathrm{p}<0.05$ compared to DSS only.

Figure 5: RT-qPCR analysis of cytokines involved in the development of colitis. [A] Relative mRNA abundance of TNF $\alpha$ was increased in the DSS groups (DSS only and $\mathrm{DSS}+\mathrm{Fe}$ ) compared to control groups (con and Fe), and was significantly higher in the DSS+Fe group compared to DSS alone. [B] IL-6 mRNA abundance was also increased in 
the DSS groups compared to control groups, and was highest in the DSS+Fe group. [C] IL-17 mRNA abundance was higher in the DSS+Fe group compared to the control groups. $\mathrm{n}=6$ for all groups, ${ }^{*} \mathrm{p}<0.05$ compared to control groups (con and Fe), $\$ \mathrm{p}<$ 0.05 compared to DSS only.

Figure 6: Hemotoxylin and eosin (H\&E) staining of mouse distal colonic epithelium. [A] Control (con) colons exhibited highly organized test tube-shaped crypts. [B] The iron (Fe) only group also exhibited highly organized crypts with no visible inflammation. [C] DSS only colons depicted loss of crypt architecture with an influx of inflammatory cells. [D] DSS+Fe colons also experienced crypt destruction and inflammatory cell infiltrate. [E] Histology scoring was completed by a board-certified pathologist as the average of two parameters: inflammatory cell infiltrate and tissue damage. Control groups (con and $\mathrm{Fe}$ ) had an average score of $0.17 \pm 0.17$, DSS only $2.00 \pm 0.0$, and DSS+Fe $2.33 \pm 0.33$. The histology score for the DSS groups (DSS and DSS+Fe) was higher than the control groups, but was not significantly different between the DSS groups. $\mathrm{n}=3$ for all groups, $* \mathrm{p}<0.05$ compared to control groups (con and Fe). 


\section{Tables}

Table 1: Tumor necrosis factor alpha (TNF $\alpha$ ), interleukin 6 (IL-6), interleukin 17 (IL-17), and beta-actin ( $\beta$-actin) gene specific primers

\begin{tabular}{|c|c|c|c|}
\hline Gene & Primers (Forward and Reverse) & Product length (bp) & Melting Temp $\left({ }^{\circ} \mathrm{C}\right)$ \\
\hline \multirow{2}{*}{$\begin{array}{l}\text { TNF } \alpha \\
\text { NM_013693.3 }\end{array}$} & F: GTAGCCCACGTCGTAGCAAA & \multirow{2}{*}{137} & F: 60.39 \\
\hline & R: ACAAGGTACAACCCATCGGC & & $\mathrm{R}: 60.32$ \\
\hline \multirow{2}{*}{$\begin{array}{l}\text { IL-6 } \\
\text { NM_031168 }\end{array}$} & F: TGAGAAAAGAGTTGTGCAATGG & \multirow{2}{*}{168} & F: 57.43 \\
\hline & R: GGTACTCCAGAAGACCAGAGG & & $\mathrm{R}: 58.90$ \\
\hline \multirow{2}{*}{$\begin{array}{l}\text { IL-17 } \\
\text { NM_010552.3 }\end{array}$} & F: CATGACTACACCCACCTCCC & \multirow{2}{*}{185} & F: 59.46 \\
\hline & R: CCTGTCATTTTGTCCAATTCATCG & & R: 59.90 \\
\hline \multirow{2}{*}{$\begin{array}{l}\beta \text {-actin } \\
\text { NM_007393.5 }\end{array}$} & F: AGATCAAGATCATTGCTCCTCC & \multirow{2}{*}{165} & F: 57.65 \\
\hline & R: AGTAACAGTCCGCCTAGAAGC & & R: 59.52 \\
\hline
\end{tabular}

Mouse TNF $\alpha$, IL-6, IL-17, and $\beta$-actin gene specific forward (F) and reverse (R) primers were designed using mRNA sequences obtained from the NCBI primer-blast application. 
Figures

Figure 1

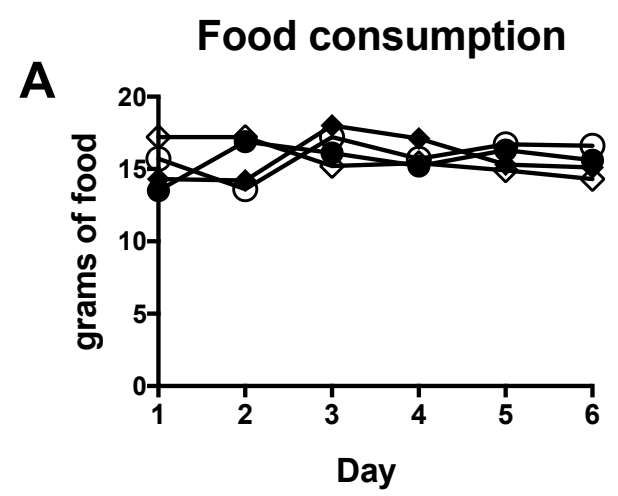

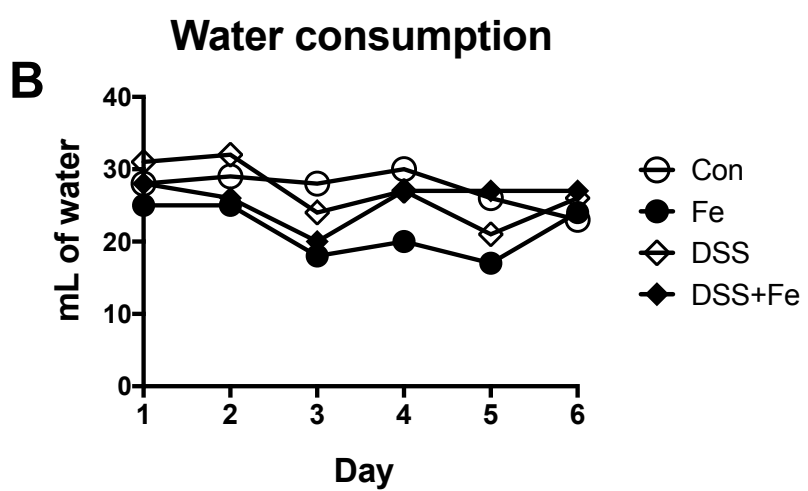


Figure 2

A

\begin{tabular}{|c|c|c|c|c|c|}
\hline & Weight loss & & Stool Consistency & & Fecal blood \\
\hline 0 & None & 0 & Normal, firm pellet & 0 & None \\
\hline 1 & $1-5 \%$ & & & 1 & Hemoccult positive \\
\hline 2 & $5-10 \%$ & 2 & Loose, sticky, very soft & 2 & Flecks of blood \\
\hline 3 & $10-15 \%$ & & & 3 & Gross blood \\
\hline 4 & $>15 \%$ & 4 & Diarrhea and/or mucous & 4 & Gross blood + bloody anus \\
\hline
\end{tabular}

B

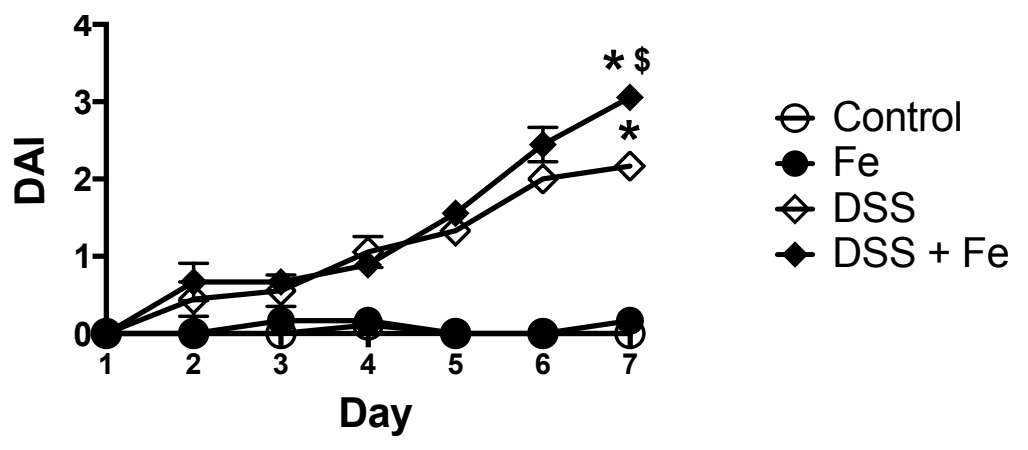

C

Weight loss

Stool consistency

Fecal blood
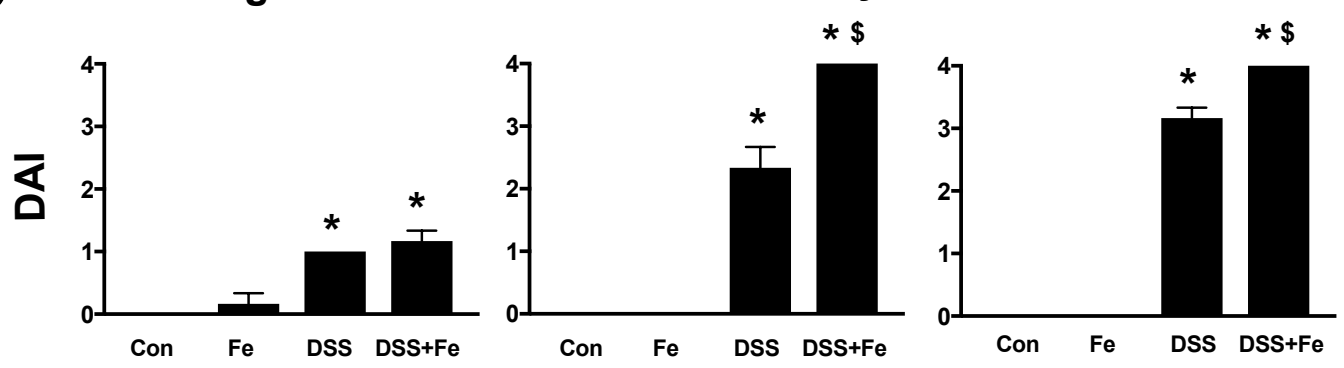
Figure 3
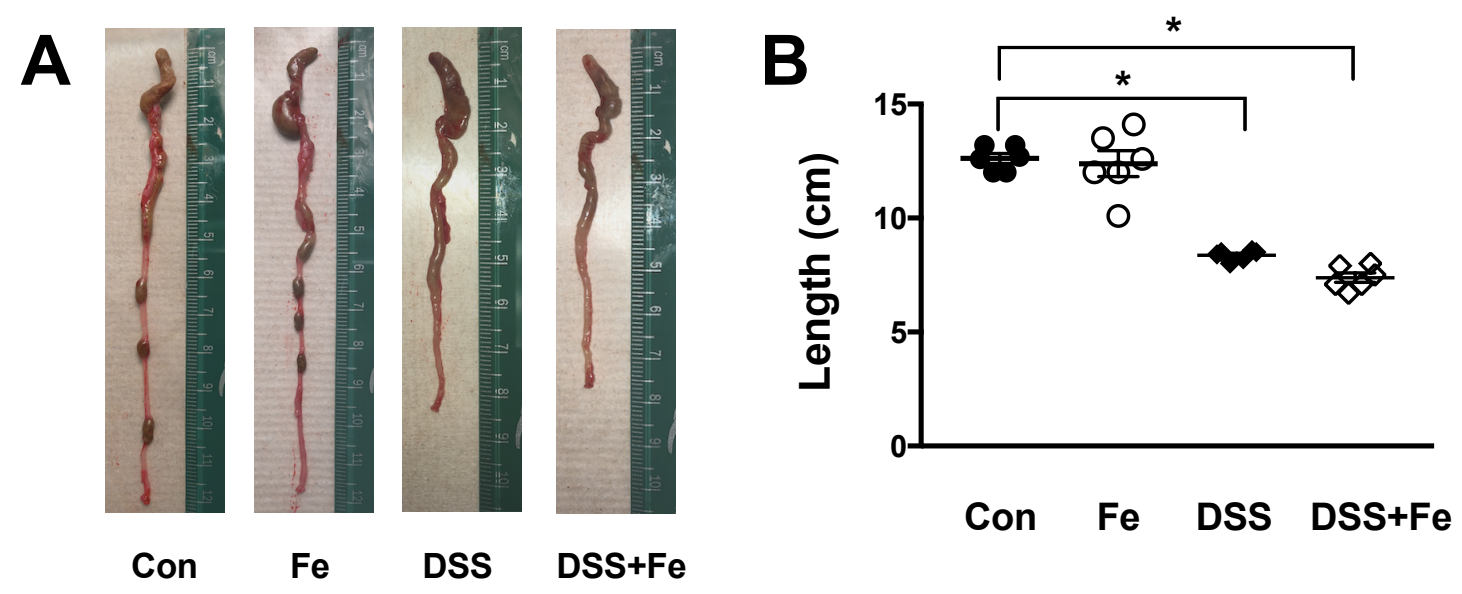
Figure 4
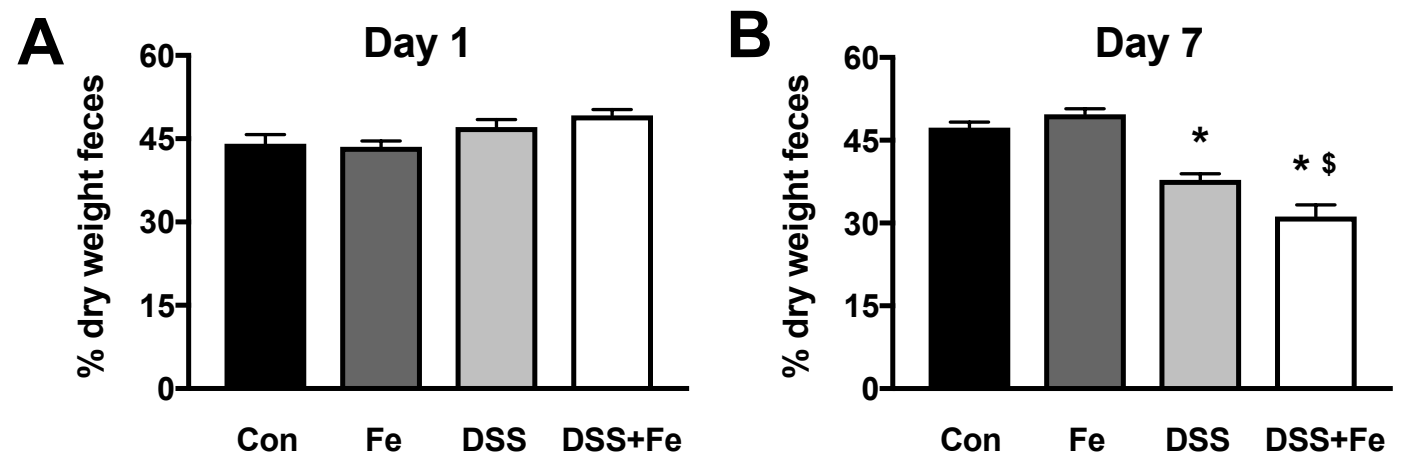
Figure 5
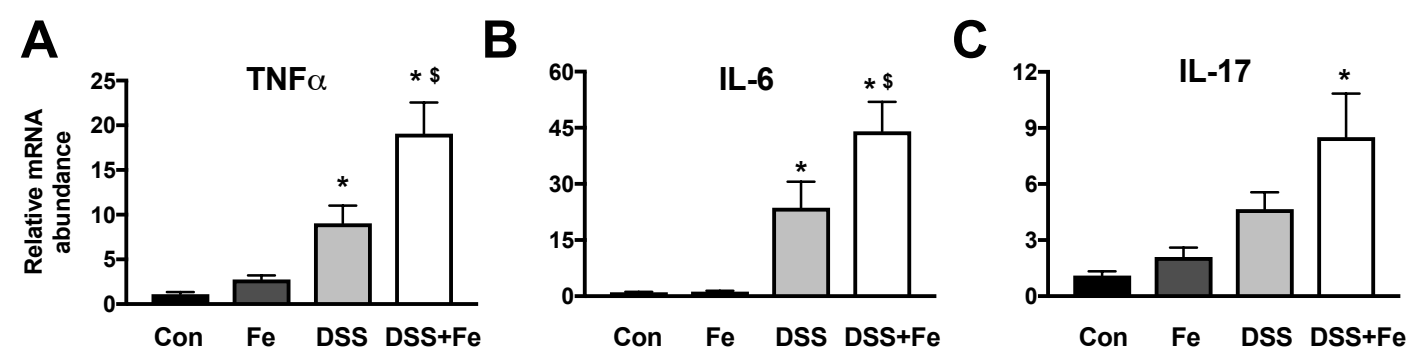
Figure 6
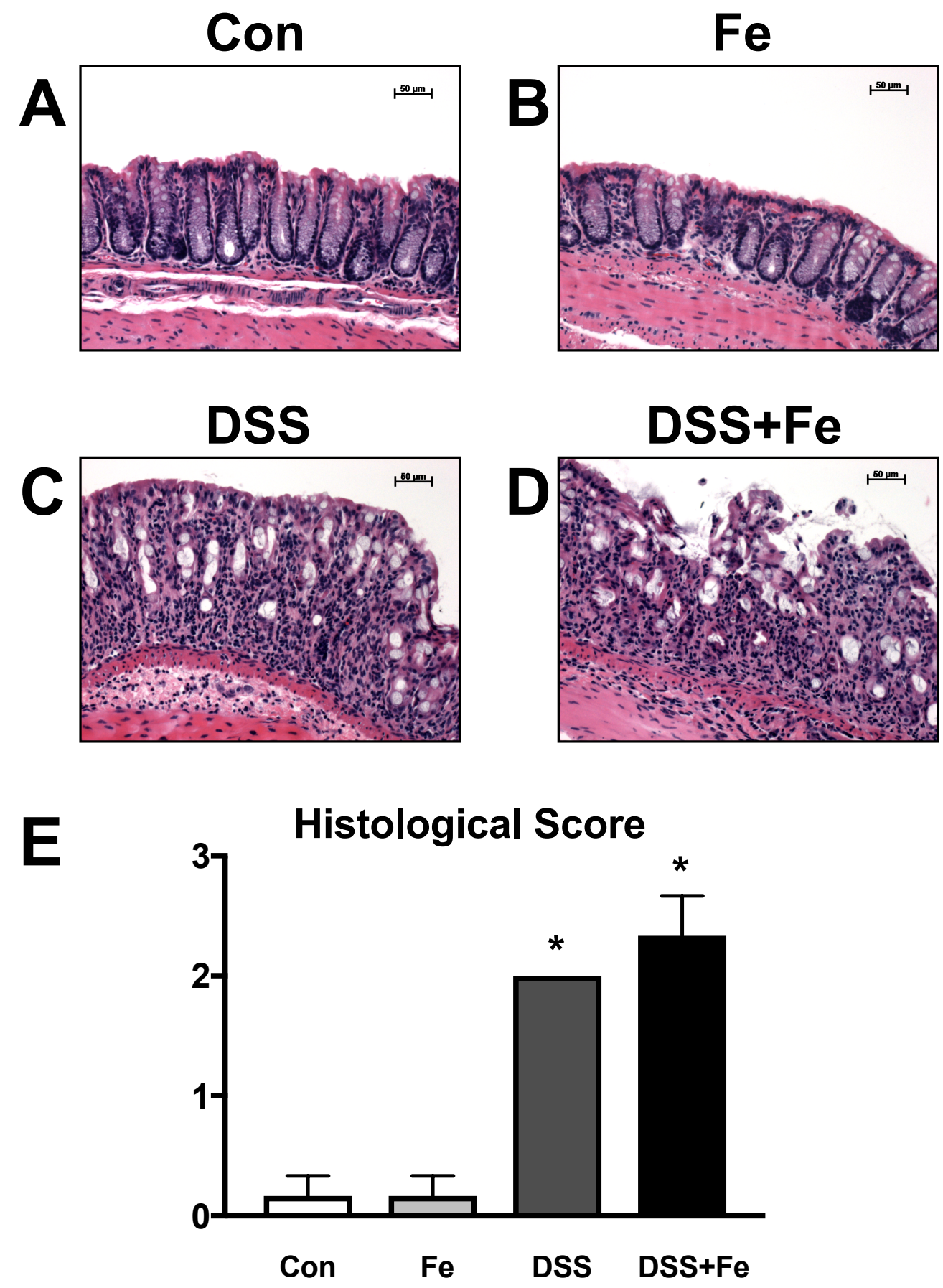


\section{Section D}

\section{Conclusions and Future Directions}




\section{Conclusions}

In Chapter II, we made significant headway in understanding colonic iron absorption in healthy individuals and those with ulcerative colitis (UC). The colon has been shown to contribute to iron absorption in experiments dating as far back as the 1960s (13). However, very little research had been done since then to understand the role of the colon in iron absorption and whole body iron homeostasis. We are the first group to show that DMT1 and FPN1 are expressed in equal abundance throughout the length of the colon. While colonic DMT1 mRNA and protein are equal to duodenal levels, FPN1 abundance is only about one-quarter that of the duodenum. We therefore conclude that FPN1-mediated transport of iron across the basolateral is the rate-limiting step of colonic iron absorption and that the key to maximizing colonic iron absorption is to increase expression of FPN1.

Our group also studied expression of these transporters in patients with UC because iron deficiency anemia (IDA) is a common complication of the disease and can be challenging to treat. We found that DMT1 and FPN1 mRNA and protein abundance are increased in the distal colons of patients with active ulcerative colitis. DMT1 expression is doubled, while FPN1 expression is approximately five times greater than control. The significant increase in FPN1 is especially important because FPN1 is the rate-limiting step of colonic iron absorption. Colonic FPN1 abundance is increased to approximately duodenal levels in patients with UC, suggesting that the colon can increase its absorptive capacity to match that of the duodenum.

The mechanism underlying the increased expression of iron transporters in UC patients is likely tied to whole body regulation of iron homeostasis via hepcidin, a liver- 
derived hormone released in times of iron overload and inflammation (15). Hepcidin leads to the internalization and degradation of FPN1, thereby limiting iron absorption in the intestines and release of iron from hepatocytes and macrophages (6). On the flip side, in times of iron deficiency, hepcidin levels are decreased to maximize the amount of FPN1.

Hepcidin was previously thought to be increased in UC because it is a chronic inflammatory condition (14). However, recent advances have shown that iron deficiency is the key regulator of hepcidin production regardless of inflammatory status and that hepcidin is actually decreased in patients with ulcerative colitis $(2,3,12)$. Decreased hepcidin in UC would allow increased FPN1 expression and increased iron absorption, as observed in this study.

The functional significance of increased expression of colonic iron transporters in $\mathrm{UC}$ is that the colon could help alleviate iron deficiency. In healthy individuals, the colon may play only a small role in iron absorption, but in times of deficiency its absorptive capacity can increase to meet demand. It may also mean that the colon can be targeted for iron absorption in other diseases that are frequently associated with IDA, such as celiac disease.

Once we found that there are increased iron transporters in the colons of patients with active ulcerative colitis, we next wanted to determine the safety of prescribing oral iron supplementation to UC patients. There is a debate in the literature about whether oral iron produces gastrointestinal side effects and worsens ulcerative colitis $(10,11)$. Recent studies have found that oral iron does not increase disease activity and is equally as 
efficacious as intravenous (IV) iron $(7,9)$. In order to study this for ourselves, we carried out an animal study, as detailed in Chapter III.

Animals with and without DSS-induced colitis were provided either standard chow (200 ppm ferrous sulfate) or an iron-supplemented diet (600 ppm ferrous sulfate). We tracked changes in disease activity using several well-established parameters including disease activity index (DAI), colon length, percent dry weight of feces, cytokine profiling, and hematoxylin and eosin (H\&E) staining. Animals with DSSinduced colitis given an iron-supplemented diet had increased DAI and inflammatory cytokines and decreased percent dry weight of feces compared to DSS alone. However, there was no change in colon length or H\&E staining.

We conclude that oral iron exacerbates DSS colitis, but the extent to which it does remains unclear. Additionally, we are unsure whether the changes in DSS-induced colitis accurately reflect what is seen in human ulcerative colitis because DSS is just a model and therefore does not perfectly recapitulate UC. DSS acts as a colitogen, which may enable iron to alter disease activity in a way that would not occur in ulcerative colitis. Future studies in humans are needed to determine whether oral iron truly does exacerbate UC disease activity (see below). 


\section{Future Directions}

Future studies will examine colonic iron absorption in other pertinent digestive diseases, such as celiac disease. Celiac disease is a gluten-sensitive autoimmune condition that leads to severe inflammation in the small intestine (8). Iron deficiency anemia (IDA) is often the presenting clinical feature because duodenal villi are severely damaged and iron absorption is impaired (5). We, therefore, expect increased expression of colonic iron transporters to help compensate for iron deficiency. This study could be accomplished by obtaining IRB approval to collect colonic biopsy specimens from patients with suspected or diagnosed celiac disease. RT-qPCR, Western blot analysis, iron uptake studies, and immunostaining could then be performed on the biopsy specimens to determine abundance and localization of DMT1 and FPN1.

It would also be interesting to study colonic iron transporters in patients who have had a roux-en-Y gastric bypass for weight loss purposes (16). These patients have the stomach shrunk down and attached to the jejunum, completely bypassing the duodenum where iron absorption typically occurs (1). We would expect colonic iron absorption to be increased in these patients, as well. This could be studied in animals via a locationspecific knockout or by performing bypass surgery.

In addition to characterizing colonic iron absorption in various other conditions, we also plan to finish our animal study that seeks to determine whether oral iron exacerbates DSS colitis. We specifically want to know whether iron causes pathogenic changes in the microbiome. Terminal restriction fragment length polymorphism (TRFLP) is being carried out using specially designed degenerate primers in order to be able to detect changes in as many species as possible. We are particularly interested in whether 
iron impacts the amount of butyrate-producing bacteria (BPB) because butyrate, a short chain fatty acid (SCFA), promotes colonic health and has various anti-inflammatory effects (4).

The animal study is a good first step in evaluating the safety of oral iron supplementation, but a human clinical trial is needed in order to definitively determine whether oral iron exacerbates UC disease activity. We have already obtained IRB approval for this study (Protocol \# 1711842175- "The effect of oral iron administration on the microbiome of patients with ulcerative colitis").

\section{HUMAN CLINICAL TRIAL}

The clinical trial is setup very similarly to the animal study with four groups: control, control + iron, $\mathrm{UC}, \mathrm{UC}+$ iron. Control groups will be given a placebo twice a day for two weeks, while iron groups will be given $325 \mathrm{mg}$ ferrous sulfate. Disease activity will be monitored using the Modified Mayo Scoring System. Fecal samples will be collected at the beginning and end of the two-week treatment window to determine changes in the microbiome via TRFLP analysis.

\section{Procedures}

1. Recruiting- Patients will be recruited during a previously scheduled office visit or will be identified via a chart review and contacted by phone to see if they are interested in participating in the study.

2. Consent- Written informed consent will be obtained during a visit to see Dr. Kupec at the Digestive Diseases clinic at WVU. Patients recruited via chart review and phone call will be brought into the clinic free of charge to complete the enrollment process. 
3. Collecting data- Patients will be given all the necessary supplies during the office visit to be able to complete the study. They will be given enough medication (iron or placebo) to last for the full 2 weeks of the study free of charge. Dr. Kupec will give them the necessary supplies to collect 2 fecal samples and will help them complete the pre-survey. The patients will provide the first fecal sample either in office or at their earliest convenience. Once they have provided the first sample they will begin taking their assigned medication twice a day for two weeks. On day 14 they will return to clinic to provide the second fecal sample and complete the post-survey with the help of Dr. Kupec.

4. How findings will be shared- All samples will be de-identified using a numbering system. Identifiable information will not be used in the final manuscript.

\section{Standard of Care}

Participants enrolled in this study will be given a standard dose of oral iron supplementation ( $325 \mathrm{mg}$ ferrous sulfate). This medication is available over the counter and is the first line treatment for iron deficiency anemia. Should the patient experience any adverse symptoms, such as gastrointesintal distress, they will be told to discontinue the medication, as is standard practice.

\section{Group Assignment}

Subjects with no known colonic pathology (control) or subjects with active UC will be randomly assigned to receive oral iron or a placebo using an online randomization program (graph pad). Dr. Kupec will be responsible for randomizing patients and will not inform them or the other researchers who is receiving what medication. 


\section{Drug/Substance/Biologic}

The placebo contains no active ingredients. Ferrous sulfate $325 \mathrm{mg}$ is commercially available over the counter and is used to treat iron deficiency anemia, the most common extra intestinal manifestation of ulcerative colitis. $325 \mathrm{mg}$ twice a day is a standard dose. Possible side effects include mild gastrointestinal symptoms such as nausea, bloating, and diarrhea. There are no known serious adverse effects associated with iron supplementation. If the patient is experiencing any distress or discomfort they can stop taking the medication at any time. Both medications (ferrous sulfate and placebo) will be kept in a locked cabinet in the Digestive Diseases clinic at WVU. The clinic is temperature controlled and we will comply with the recommended storage conditions of the medications.

\section{Risk Assessment}

This study is classified as more than minimal risk, and therefore, required full board review and monitoring for harm. The placebo drug does not have any active ingredients, so there are no risks or discomforts associated with its use. Ferrous sulfate is commercially available over the counter and is considered safe for use. The body has a mechanism that only allows absorption of iron that is needed, so any excess iron will be passed through the digestive system and excreted in the feces. Oral iron supplementation is associated with some adverse gastrointestinal symptoms, including nausea, constipation, upset stomach, flatulence, black or tarry stools, and diarrhea. The potential risks are expected to be minimal in occurrence and severity.

Patients will be told about potential side effects of oral iron supplementation prior to being enrolled in the study. These include gastrointestinal symptoms such as bloating, 
abdominal pain, and diarrhea. Some mild GI discomfort is expected, but if the symptoms persist or become excessive patients will be told to contact their gastroenterologist (Dr. Kupec) and may discontinue the medication. Discontinuing the medication will be sufficient to stop symptoms. Monitoring for harm will occur on a case-by-case basis and will depend on patients self reporting their symptoms.

\section{Subjects}

In order to participate in this study, patients must be at least 18 years of age. Exclusion criteria includes patients currently receiving iron supplementation, antibiotic use or blood transfusion in the past 3 months, infectious diseases (such as HIV and hepatitis), and history of intolerance to oral iron supplementation. The control group will consist of patients with no known colonic pathology. The active ulcerative colitis group will have active disease activity on biopsy or positive clinical symptoms, as determined by a gastroenterologist.

Selection of patients for participation in this study will be equitable across race, gender, ethnicity, etc. All patients presenting to the digestive diseases clinic who fit with the inclusion criteria will be considered for participation in this study. No preference will be given for a specific sex, gender, ethnicity, etc. As long as the patient is 18 years or older they may be recruited into the study.

\section{Data Protection}

Samples will be deidentified using a numbering system. The first number will correlate to the patient enrolled and the second number will indicate the sample. For example, patient 3-1 will be patient \#3, sample 1 (day 0). 3-2 will be patient \#3, sample 2 (day 14). The data will be kept for as long as Dr. Rajendran maintains an active lab at 
WVU (5+ years). All physical data will be kept in non-patient care areas of WVU

Hospital or the Health Sciences Center in a locked file cabinet behind a locked door. All electronic data will be stored on computers that are password protected. Electronic data is stored in software that requires a password to access and a password for login. Physical

data will be destroyed using locked shredder bins. Electronic data that needs to be deleted will be done so using an IT protocol.

\section{Financial Considerations}

The subjects will be provided a $\$ 25$ gift card upon completion of the study.

\section{Institutional Biosafety Approval (IBC)}

IBC approval has been obtained (protocol 17-11-03). 


\section{References}

1. Abdeen G, le Roux CW. Mechanism Underlying the Weight Loss and Complications of Roux-en-Y Gastric Bypass. Review. Obes Surg 26: 410-21, 2016.

2. Arnold J, Sangwaiya A, Bhatkal B, Geoghegan F, Busbridge M. Hepcidin and inflammatory bowel disease: dual role in host defence and iron homoeostasis. Eur J Gastroenterol Hepatol 21: 425-9, 2009.

3. Bergamaschi G, Di Sabatino A, Albertini R, Costanzo F, Guerci M, Masotti M, Pasini A, Massari A, Campostrini N, Corbella M, Girelli D, Corazza GR. Serum hepcidin in inflammatory bowel diseases: biological and clinical significance. Inflamm Bowel Dis 19: 2166-72, 2013.

4. Canani RB, Costanzo M Di, Leone L, Pedata M, Meli R, Calignano A. Potential beneficial effects of butyrate in intestinal and extraintestinal diseases. World J Gastroenterol 17: 1519-28, 2011.

5. Freeman HJ. Iron deficiency anemia in celiac disease. World J Gastroenterol 21: 9233-8, 2015.

6. Ganz T, Nemeth E. Hepcidin and iron homeostasis. Biochim Biophys Acta 1823: $1434-43,2012$.

7. Gisbert JP, Bermejo F, Pajares R, Pérez-Calle J-L, Rodríguez M, Algaba A, Mancenido N, de la Morena F, Carneros JA, McNicholl AG, González-Lama Y, Maté J. Oral and intravenous iron treatment in inflammatory bowel disease: hematological response and quality of life improvement. Inflamm Bowel Dis 15: 1485-91, 2009. 
8. Gujral N, Freeman HJ, Thomson ABR. Celiac disease: prevalence, diagnosis, pathogenesis and treatment. World J Gastroenterol 18: 6036-59, 2012.

9. Lee T, Clavel T, Smirnov K, Schmidt A, Lagkouvardos I, Walker A, Lucio M, Michalke B, Schmitt-Kopplin P, Fedorak R, Haller D. Oral versus intravenous iron replacement therapy distinctly alters the gut microbiota and metabolome in patients with IBD. Gut 66: 863-871, 2017.

10. Lee TW, Kolber MR, Fedorak RN, van Zanten SV. Iron replacement therapy in inflammatory bowel disease patients with iron deficiency anemia: A systematic review and meta-analysis. J Crohn's Colitis 6: 267-275, 2012.

11. Mahalhal A, Williams JM, Johnson S, Ellaby N, Duckworth CA, Burkitt MD, Liu X, Hold GL, Campbell BJ, Pritchard DM, Probert CS. Oral iron exacerbates colitis and influences the intestinal microbiome. PLoS One 13: e0202460, 2018.

12. Mecklenburg I, Reznik D, Fasler-Kan E, Drewe J, Beglinger C, Hruz P, Swiss IBD Cohort Study Group. Serum hepcidin concentrations correlate with ferritin in patients with inflammatory bowel disease. J Crohns Colitis 8: 1392-7, 2014.

13. OHKAWARA Y, BAMBA M, NAKAI I, KINKA S, MASUDA M. The absorption of iron from the human large intestine. Gastroenterology 44: 611-4, 1963.

14. Oustamanolakis $\mathbf{P}$, Koutroubakis IE, Messaritakis I, Malliaraki N, Sfiridaki A, Kouroumalis EA. Serum hepcidin and prohepcidin concentrations in inflammatory bowel disease. Eur J Gastroenterol Hepatol 23: 262-8, 2011.

15. Ruchala $\mathbf{P}$, Nemeth E. The pathophysiology and pharmacology of hepcidin. 
Trends Pharmacol Sci 35: 155-61, 2014.

16. Suter M, Donadini A, Romy S, Demartines N, Giusti V. Laparoscopic Roux-enY gastric bypass: significant long-term weight loss, improvement of obesityrelated comorbidities and quality of life. Ann Surg 254: 267-73, 2011. 
Chapter II

Case Reports 
Section A

Chronic, Recreational Chloroform-Induced Liver Injury 


\section{Chronic, Recreational Chloroform-Induced Liver Injury}

Emily A. Minor ${ }^{1}$, Mackenzie S. Newman ${ }^{1}$, Justin T. Kupec ${ }^{2}$

${ }^{1}$ Department of Physiology and Pharmacology, West Virginia University School of Medicine, Morgantown, WV, USA, ${ }^{2}$ Department of Digestive Diseases, West Virginia University School of Medicine, Morgantown, WV, USA

Published online in Case Reports in Hepatology on September 10, 2018

PMID: 30275992

DOI: $10.1155 / 2018 / 1619546$ 


\begin{abstract}
Historically used as an anesthetic, chloroform is a halogenated hydrocarbon that is associated with central nervous system depression, arrhythmias, and hepatotoxicity. It is no longer used clinically, but accidental and intentional poisonings still occur. We report a case of chronic chloroform abuse leading to severe hepatotoxicity in a 26-year-old male graduate student. The patient presented to the emergency department with a three-day history of abdominal pain, dehydration, and scleral icterus. He drank several beers the night before the onset of symptoms, but denied taking acetaminophen, ibuprofen, or other drugs. An extensive work-up revealed an aspartate aminotransferase (AST) of 13,527 $\mathrm{U} / \mathrm{L}$ and alanine aminotransferase (ALT) of 8,745 U/L, but the cause of his liver injury could not be determined. It was not until many months later that the patient admitted to inhaling chloroform in the weeks leading up to his illness.
\end{abstract}




\section{Introduction}

Chloroform is no longer used to induce anesthesia, but it is commonly used as a solvent in laboratory settings and poisonings still occur. There are several cases that describe chloroform-induced hepatotoxicity following suicide attempts, but this is the first known report of chronic, recreational chloroform abuse $(1,2)$. The patient was a graduate student who inhaled chloroform obtained from his laboratory for several months leading up to his hospitalization. He did not disclose that initially because he did not feel comfortable discussing his drug use. Herein we describe the clinical presentation of chronic exposure to chloroform and highlight the importance of establishing a strong rapport with patients in order for there to be an open and honest dialogue about substance abuse. 


\section{Case Presentation}

A 26-year-old male graduate student presented to the emergency department with a three-day history of nausea, vomiting, and abdominal pain. He additionally complained of dark urine with sediments, dehydration, and scleral icterus. Laboratory evaluation revealed an aspartate aminotransferase (AST) of 13,527 U/L, alanine aminotransferase (ALT) of $8,745 \mathrm{U} / \mathrm{L}$, and ferritin of $>40,000 \mathrm{ng} / \mathrm{mL}$. His total bilirubin was $5.5 \mathrm{mg} / \mathrm{dL}$ and international normalized ratio (INR) was 1.95, suggesting a chronic liver injury (Table 1). The patient reported drinking four to five beers the night before the onset of symptoms but denied taking acetaminophen, ibuprofen, or other drugs. He was given intravenous saline and admitted to the hospital for further evaluation.

Given his presentation and significant transaminase elevation, drug-induced hepatitis or viral hepatitis was suspected, while ischemic hepatopathy was unlikely. Right upper quadrant ultrasound was unremarkable. Acetaminophen, salicylate, and tricyclic levels were negative. Mononucleosis, human immunodeficiency virus, cytomegalovirus, antinuclear antibody, and viral hepatitis panel were also negative. Herpes simplex and varicella zoster IgG were positive, likely due to prior infection or immunization.

He remained stable during hospitalization and his liver enzymes began to trend downward, so he was discharged two days after admission. At six-week gastroenterology follow-up visit, his liver enzymes had returned to normal and he reported complete resolution of symptoms. The remainder of the pending laboratory evaluation (smooth muscle antibodies and hemochromatosis testing) returned negative. 
The etiology of this patient's hepatitis remained unknown until many months later he admitted to inhaling chloroform. He described recreational huffing, to the point of unconsciousness, twice weekly over several months. This information was not volunteered at the time of presentation because the patient was embarrassed and did not feel comfortable discussing substance abuse with his physicians. 


\section{Discussion}

Chloroform is a volatile organic compound that is commonly used as a solvent, cleanser for plastic compounds, and acrylic adhesive (3). Exposures can occur accidentally or intentionally in various occupational settings including cleanrooms, laboratories, and factories. Several cases describe hepatotoxicity from acute chloroform exposure, but we provide the first known report of severe hepatitis resulting from chronic, recreational chloroform abuse. The liver enzyme elevations seen in our patient were significantly higher than those following acute consumption (AST 1,160 U/L, ALT 3,560 U/L) and suicide attempts (AST 1,513 U/L, ALT 2,717 U/L) [1, 2]. Regardless of the intent of use, liver injury is largely the result of phosgene, a toxic metabolite formed via cytochrome P450 2E1 (4). Phosgene participates in acylation reactions with proteins, carbohydrates, and lipids, which depletes glutathione stores and leads to severe oxidative damage and ultimately hepatocellular steatosis and necrosis (5). Concomitant alcohol consumption, as seen in our patient, magnifies this effect via cytochrome P450 enzyme induction (6).

The patient experienced significant transaminase elevation, but physicians could not determine the cause because they were missing key information. People with access to chemicals, either professionally or educationally, should receive a thorough occupational history and any exposures should be classified and quantified. For example, chloroform poisoning should be considered in graduate students, cleaners, and factory workers with unexplained liver injury. If questions arise about treatment, physicians should then reference the material safety data sheets (MSDS). In addition, completion of 
a social history to establish comorbid conditions or behaviors will allow accurate guidance for further testing or care.

The nonspecific nature of the patient's symptoms and his undisclosed drug use made it hard to establish the correct diagnosis. People who use illicit substances are often reluctant to divulge such information because of the stigma associated with drug use. In order to overcome this, healthcare providers must establish a strong, professional rapport with patients so that there can be an open and honest dialogue. Additionally, a thorough occupational history can help uncover potential exposures. In conclusion, chloroform and other halogenated hydrocarbons can lead to severe hepatotoxicity and should be considered in certain populations who present with unexplained liver injury. 


\section{Consent}

Written informed consent was obtained from the patient. 
Table 1

Laboratory findings.

\begin{tabular}{|c|c|c|c|c|c|c|}
\hline & $\begin{array}{c}\text { Reference } \\
\text { range }\end{array}$ & $\begin{array}{c}\text { Day of } \\
\text { admission } \\
(14: 00) \\
\end{array}$ & $\begin{array}{c}\text { Day of } \\
\text { admission } \\
(20: 00)\end{array}$ & $\begin{array}{c}\text { Hospital } \\
\text { day } 1\end{array}$ & $\begin{array}{c}\text { Hospital } \\
\text { day } 2\end{array}$ & $\begin{array}{c}6 \text { week } \\
\text { follow- } \\
\text { up }\end{array}$ \\
\hline AST & $8-48 \mathrm{U} / \mathrm{L}$ & 13,527 & 9,319 & 5,137 & 2,140 & 23 \\
\hline ALT & $0-55 \mathrm{U} / \mathrm{L}$ & 8,745 & 5,985 & & 3,994 & 29 \\
\hline $\begin{array}{l}\text { Bilirubin } \\
\text { (Total) }\end{array}$ & $\begin{array}{l}0.3-1.3 \\
\mathrm{mg} / \mathrm{dL}\end{array}$ & 5.5 & 3.9 & 7.4 & 7.6 & 0.7 \\
\hline $\begin{array}{l}\text { Bilirubin } \\
\text { (Conjugated) }\end{array}$ & $\begin{array}{l}0.0-0.3 \\
\mathrm{mg} / \mathrm{dL}\end{array}$ & 3.5 & 2.6 & 4.7 & 5.4 & 0.3 \\
\hline $\mathrm{LDH}$ & $\begin{array}{c}125-220 \\
\mathrm{U} / \mathrm{L}\end{array}$ & 3250 & & & & \\
\hline $\begin{array}{l}\text { Prothrombin } \\
\text { Time }\end{array}$ & $\begin{array}{c}8.7-13.2 \\
\text { sec }\end{array}$ & 21.7 & & 22.2 & 16 & \\
\hline INR & $0.8-1.2$ & 1.95 & & 1.99 & 1.45 & \\
\hline Ferritin & $\begin{array}{l}20-300 \\
\mathrm{ng} / \mathrm{mL}\end{array}$ & & & $>40,000$ & & 503 \\
\hline Ammonia & $\begin{array}{r}15-50 \\
\text { umol/L }\end{array}$ & 120 & & & 47 & \\
\hline Urine Protein & $0 \mathrm{mg} / \mathrm{dL}$ & 30 & & & & \\
\hline Urobilinogen & $0 \mathrm{mg} / \mathrm{dL}$ & 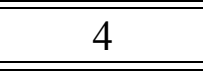 & & & & \\
\hline
\end{tabular}




\section{References}

1. Choi S. H. Diagnostic radiopacity and hepatotoxicity following chloroform ingestion: a case report. Emergency Medicine Journal. 2006;23(5):394-395. doi:

10.1136/emj.2005.027466.

2. Sridhar N., Krishnakishore C., Sandeep Y., Sriramnaveen P., Manjusha Y., Sivakumar V. Chloroform poisoning-a case report. Renal Failure. 2011;33(10):1037-1039. doi: 10.3109/0886022X.2011.618920.

3. Kang Y. J., Ahn J., Hwang Y. Acute liver injury in two workers exposed to chloroform in cleanrooms: a case report. Annals of Occupational and Environmental Medicine. 2014;26(1) doi: 10.1186/s40557-014-0049-5.

4. Fang C., Behr M., Xie F., et al. Mechanism of chloroform-induced renal toxicity: Noninvolvement of hepatic cytochrome P450-dependent metabolism. Toxicology and Applied Pharmacology. 2008;227(1):48-55. doi: 10.1016/j.taap.2007.10.014.

5. Hardison L. S., Wright E., Pizon A. F. Phosgene Exposure: A Case of Accidental Industrial Exposure. Journal of Medical Toxicology. 2014;10(1):51-56. doi: 10.1007/s13181-013-0319-6.

6. Sweeney B. P., Bromilow J. Liver enzyme induction and inhibition: implications for anaesthesia. Anaesthesia. 2006;61(2):159-177. doi: 10.1111/j.1365-2044.2005.04462.x. 
Section B

Successful Treatment of Coin Ingestion Using Esophageal Bougienage 


\section{Successful Treatment of Coin Ingestion Using Esophageal Bougienage}

Emily A. Minor ${ }^{1}$, Haley D. Frauen ${ }^{2}$, and Joseph J. Minardi ${ }^{2}$

Departments of ${ }^{1}$ Physiology and Pharmacology and ${ }^{2}$ Emergency Medicine, West Virginia University School of Medicine, Morgantown, WV, USA

Keywords: bougie, foreign body ingestion, pediatric 


\begin{abstract}
Coin ingestion is a common problem in pediatrics. Previously it was treated via endoscopic removal, however, newer techniques allow for advancement of the coin into the stomach to be passed naturally. We present a case of coin ingestion by a 14-monthold boy that was treated by esophageal bougienage. A bougie (long, fixed rod) inserted into the child's esophagus successfully propelled the coin into the stomach without need for a pediatric gastroenterologist nor the risks associated with anesthesia. The patient was discharged 30 minutes after the procedure and eventually passed the coin on his own without complications. Esophageal bougienage would be particularly useful in rural emergency departments that lack the resources of pediatric endoscopy and could have avoided the costly transfer of this patient to a larger facility.
\end{abstract}




\section{Introduction}

Foreign body ingestion is a significant public health concern that results in tens of thousands of emergency room visits and approximately 1,500 deaths annually (1). Coins are the most commonly ingested object by children, accounting for approximately $60 \%$ of cases (2). Historically, the gold standard treatment for coin ingestion was endoscopic removal, but other methods have proven to be more cost effective and are equally safe and efficacious (3-5). We present a case where a coin lodged in the esophagus was successfully treated with esophageal bougienage. 


\section{Case Presentation}

A 14-month-old male child presented to an emergency department (ED) in rural West Virginia with the chief complaint of refusing perioral (PO) intake, drooling, and spitting up. His mother suspected that he might have ingested something, as he was known to frequently put objects in his mouth. On examination, the patient did not appear to be in acute distress and his vitals were stable. An anterior-posterior x-ray demonstrated a coin-shaped object in the cervical esophagus (Figure 1A). The child was transferred to a larger, more equipped hospital for care.

Esophageal bougienage using a 30 French weighted Hurst bougie was performed by a physician in the ED. The patient remained vitally stable throughout the procedure with a respiration rate of 32 , heart rate of 152 , oxygen saturation of $96 \%$, and breath sounds equal bilaterally. The coin was successfully advanced into the stomach, as evidenced by x-ray (Figure 1B). Following the procedure, the child tolerated PO intake and was discharged after 30 minutes of supervision. The patient eventually passed the coin with no complications. 


\section{Discussion}

Coin ingestion should be considered in young children presenting to the emergency department (ED) with dysphagia and odynophagia (6). Diagnosis is achieved via radiographic evaluation, which enables identification and localization of the foreign body (7). The thoracic inlet is the most common site of impaction due to esophageal narrowing, as was the case in our patient (8). A variety of techniques can be used to remove the object, but the most rapid and cost effective method is esophageal bougienage (9). This procedure involves sticking a bougie, a long fixed rod, into the esophagus to dislodge the coin. Once in the stomach, the coin then passes through the remainder of the digestive tract and is excreted in the feces.

There are many benefits to esophageal bougienage compared to other treatment options. The average length of hospitalization for a patient who undergoes endoscopic removal is 22.7 hours versus 2.15 hours spent by those who receive bougienage (10). It is also substantially less expensive, with an average price tag that is $1 / 10$ the cost of endoscopy (3). Additionally, bougienage doesn't require sedation, therefore lowering the risk of complications (11).

Esophageal bougienage would be particularly useful in rural EDs that lack pediatric endoscopy, thus necessitating transport to another hospital (7). Our patient was transferred to a larger hospital that was more than 30 miles away, which delayed treatment and was costly for the family and the healthcare system. Esophageal bougienage is the preferred treatment in such settings because it can be performed anywhere without any specialists. 
In conclusion, we present a case of pediatric coin ingestion that was successfully treated with esophageal bougienage. Bougineange is a safe, rapid, and cost-effective means to treat foreign body ingestion and may be particularly useful in rural care settings. 


\section{References}

1. Lai MW, Klein-Schwartz W, Rodgers GC, Abrams JY, Haber DA, Bronstein AC, et al. 2005 Annual Report of the American Association of Poison Control Centers' national poisoning and exposure database. Clin Toxicol (Phila) [Internet]. 2006;44(6-7):803-932. Available from:

http://www.ncbi.nlm.nih.gov/pubmed/17015284

2. Jackson RM, Hawkins DB. Coins in the esophagus. What is the best management? Int J Pediatr Otorhinolaryngol [Internet]. 1986 Dec;12(2):127-35. Available from: http://www.ncbi.nlm.nih.gov/pubmed/3570679

3. Heinzerling NP, Christensen MA, Swedler R, Cassidy LD, Calkins CM, Sato TT. Safe and effective management of esophageal coins in children with bougienage. Surgery [Internet]. 2015 Oct;158(4):1065-70-2. Available from: http://www.ncbi.nlm.nih.gov/pubmed/26239181

4. Dahshan AH, Kevin Donovan G. Bougienage versus endoscopy for esophageal coin removal in children. J Clin Gastroenterol [Internet]. 41(5):454-6. Available from: http://www.ncbi.nlm.nih.gov/pubmed/17450025

5. Dahshan AH, Kevin Donovan G. Bougienage versus endoscopy for esophageal coin removal in children. J Clin Gastroenterol. 2007;41(5):454-6.

6. Varadharajan K, Magill J, Patel K. An ingested foreign body: two sides of the same coin? Case Reports [Internet]. 2014 Apr 9;2014(apr09 1):bcr2014204431bcr2014204431. Available from: http://casereports.bmj.com/cgi/doi/10.1136/bcr2014-204431

7. Mohr NM, Harland KK, Shane DM, Miller SL, Torner JC. Potentially Avoidable 
Pediatric Interfacility Transfer Is a Costly Burden for Rural Families: A Cohort Study. Newgard CD, editor. Acad Emerg Med [Internet]. 2016 Aug;23(8):885-94. Available from: http://doi.wiley.com/10.1111/acem.12972

8. Joyamaha D, Conners GP. Managing Pediatric Foreign Body Ingestions. Mo Med [Internet]. 112(3):181-6. Available from:

http://www.ncbi.nlm.nih.gov/pubmed/26168587

9. Arms JL, Mackenberg-Mohn MD, Bowen M V., Chamberlain MC, Skrypek TM, Madhok M, et al. Safety and Efficacy of a Protocol Using Bougienage or Endoscopy for the Management of Coins Acutely Lodged in the Esophagus: A Large Case Series. Ann Emerg Med [Internet]. 2008 Apr;51(4):367-72. Available from: http://inkinghub.elsevier.com/retrieve/pii/S0196064407015089

10. Calkins CM, Christians KK, Sell LL. Cost analysis in the management of esophageal coins: endoscopy versus bougienage. J Pediatr Surg [Internet]. 1999 Mar;34(3):412-4. Available from:

http://www.ncbi.nlm.nih.gov/pubmed/10211643

11. Emslander HC, Bonadio W, Klatzo M. Efficacy of esophageal bougienage by emergency physicians in pediatric coin ingestion. Ann Emerg Med [Internet]. 1996 Jun;27(6):726-9. Available from: http://www.ncbi.nlm.nih.gov/pubmed/8644959 


\section{Figures}
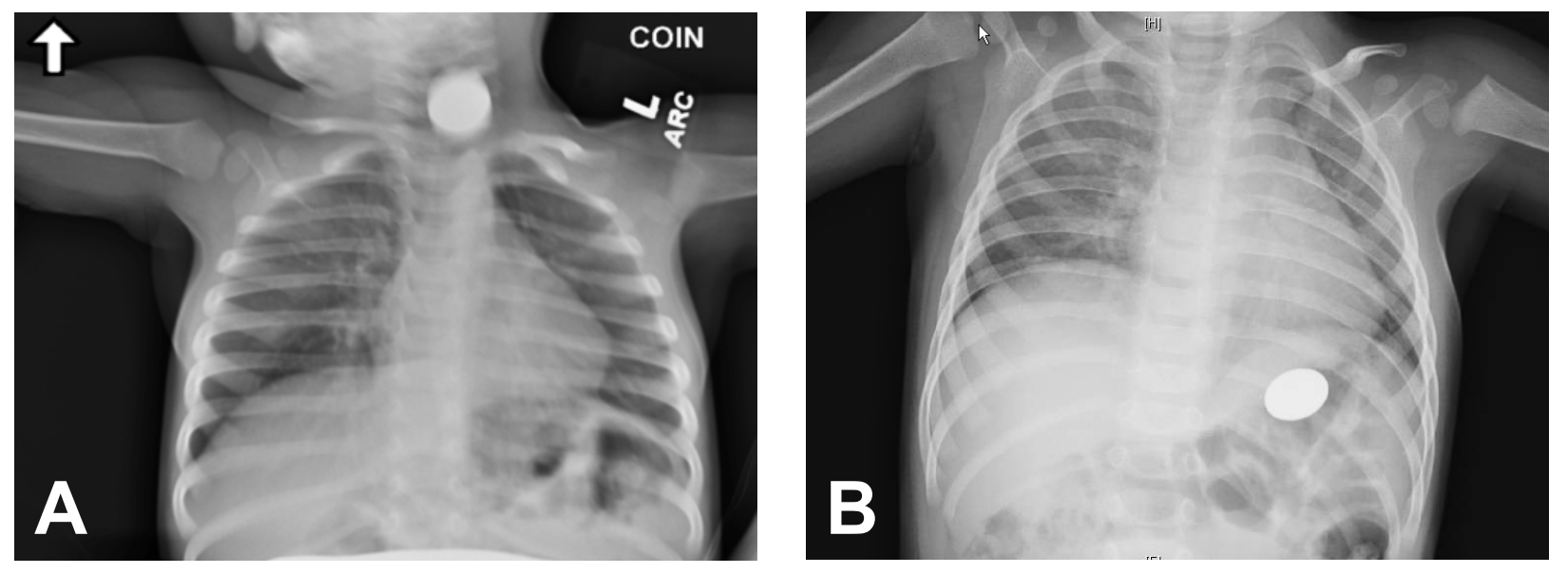

Figure 1: Anterior-posterior x-ray visualization of the ingested coin before and after treatment. A: The coin is visible near the thoracic inlet. B: Esophageal bougienage successfully advanced the coin into the stomach. 
"Science is simply the word we use to describe a method of organizing our curiosity."

- Tim Minchin 